Aus der Abteilung Neurologie

(Prof. Dr. med. M. Bähr)

im Zentrum Neurologische Medizin

der Medizinischen Fakultät der Universität Göttingen

\title{
Regulation der mRNA von Toll-Like-Rezeptoren bei experimentellen ZNS-Infektionen
}

Inaugural-Dissertation

zur Erlangung des Doktorgrades der Medizinischen Fakultät der Georg-August-Universität zu Göttingen

\footnotetext{
vorgelegt von

Zohre Dezhgahi

aus Abadan/Iran
}

Göttingen 2012 
Dekan: Prof. Dr. med. C. Frömmel

I. Berichterstatter: Prof. Dr. med. R. Nau

II. Berichterstatter/in:

III. Berichterstatter/in:

Tag der mündlichen Prüfung: 


\section{Inhaltsverzeichnis}

Inhaltsverzeichnis

Abkürzungsverzeichnis

1 Einleitung

1.1 Bakterielle und virale Infektionen des ZNS 1

1.1.1 Die bakterielle Meningitis 1

1.1.2 Herpes-simplex-Virus-Enzephalitis (HSV) 4

1.2 Toll-Like-Rezeptoren (TLR) 5

1.2.1 TLR und angeborene Immunität 5

$\begin{array}{ll}\text { 1.2.2 Subgruppen der TLR und ihre Liganden } & 7\end{array}$

$\begin{array}{ll}\text { 1.2.3 Expression der TLR } & 12\end{array}$

$\begin{array}{lll}1.2 .4 & \text { Regulation der TLR } & 13\end{array}$

$\begin{array}{lll}1.2 .5 & \text { TLR-Signalkaskade im Säugetier } & 14\end{array}$

$\begin{array}{lll}1.3 & \text { Ziele der Arbeit } & 16\end{array}$

2 Material und Methoden $\quad 18$

$\begin{array}{llr}2.1 & \text { Materialien } & 18\end{array}$

$\begin{array}{lll}2.2 \text { Mäuse } & 21\end{array}$

$\begin{array}{lll}2.3 & \text { Organotypische Hippokampuskulturen } & 22\end{array}$

$\begin{array}{lll}2.4 & \text { Infektionen } & 22\end{array}$

2.4.1 Infektion mit S. pneumoniae 22

2.4.2 Behandlung der organotypischen Hippokampuskulturen (OTC) mit Hitze-inaktivierten Pneumokokken R6 (hiR6) 23

$\begin{array}{lll}2.4 .3 & \text { Infektion mit } E \text {. coli } & 23\end{array}$ 
2.4.4 Infektion mit Herpes-simplex-Virus

2.5 RNA

2.5.1 RNA-Extraktion

2.5.2 Qualitative Kontrolle der RNA mittels Gel-Elektrophorese

2.5.3 Konzentrationsbestimmung der RNA-Lösung

2.6 Reverse Transkription

2.7 PCR, Reverse-Transkriptase-PCR und Real-Time-PCR

2.7.1 Mechanismus der PCR und Reverse-Transkriptase-PCR

2.7.2 Primer

2.7.3 Standardherstellung und Isolierung aus Gel

2.7.4 PCR-Mix und Protokolle für Standardherstellung

2.7.5 Real-Time-PCR

2.8 Statistische Auswertung

3.1 Regulation der TLR-mRNA in Gehirn und Milz von C57BL6-Mäusen nach intrazerebraler Infektion mit Streptococcus pneumoniae Typ 3

3.2 Behandlung organotypischer Hippokampuskulturen mit Streptococcus-R6 44

3.3 Regulation der TLR-mRNA in Gehirn und Milz von C57BL6-Mäusen nach intrazerebraler Infektion mit Escherichia coli

3.4 Regulation der TLR-mRNA in Gehirn und Milz von SJL-NBOM-Mäusen nach intranasaler Infektion mit Herpes-simplex-Virus

3.5 Regulation der TLR-mRNA in Gehirn und Milz von TLR9-defizienten Mäusen nach intrazerebraler Infektion mit Streptococcus pneumoniae Typ 3 
3.6 Regulation der TLR-mRNA in Gehirn und Milz von TLR4-defizienten Mäusen nach intrazerebraler Infektion mit $E$. coli

3.7 Regulation der TLR-mRNA in Gehirn und Milz von TLR2-defizienten Mäusen nach intrazerebraler Infektion mit $E$. coli

4 Diskussion

4.1 Regulierung der TLR in der Wildtyp-Maus

4.2 Regulierung der TLR in mutanten Mäusen

4.3 Schlussfolgerung

5 Zusammenfassung

6 Abbildungsverzeichnis

7 Literaturverzeichnis 


\section{Abkürzungsverzeichnis}

\begin{tabular}{|c|c|}
\hline Abb. & Abbildung \\
\hline Cat. No. & Katalognummer \\
\hline CD14 & Clusters of Differentiation 14 \\
\hline cDNA & Komplementäre DNA \\
\hline C-Ende & Carboxy-Ende \\
\hline CFU & Colony Forming Units \\
\hline $\mathrm{CHO}$-Zellen & Chinese hamster ovary cells \\
\hline cHSP60 & Chlamydia pneumoniae Heat Shock Protein 60 \\
\hline CpG-DNA & Cytidin-Guanosin-DNA \\
\hline CSF & Colony-stimulating Factor \\
\hline DC & Dendritische Zellen \\
\hline DEPC- $\mathrm{H}_{2} \mathrm{O}$ & Diethylpyrocarbonatwasser \\
\hline DNA & Desoxyribonukleinsäure \\
\hline E. coli & Escherichia coli \\
\hline $\mathrm{fg}$ & Femtogramm \\
\hline $\mathrm{h}$ & Stunde \\
\hline H. influenzae & Haemophilus influenzae \\
\hline $\mathrm{H}_{2} \mathrm{O}$ & Wasser \\
\hline hiR6 & Hitze-inaktivierte Pneumokokken R6 \\
\hline
\end{tabular}




\begin{tabular}{|c|c|}
\hline HSP 60 & Heat Shock Protein 60 \\
\hline HSV & Herpes-simplex-Virus \\
\hline ICAM & Intercellular Adhesion Molecule \\
\hline IFN & Interferon \\
\hline IKK & Inhibitory $\mathrm{kB}$ kinase \\
\hline IMD & Immune Deficiency Gene \\
\hline iNOS & Induzierbare Stickstoffmonoxid-Synthase \\
\hline IRAK & Interleukin-1-Receptor Associated Kinase \\
\hline IRF-3 & Interferon Regulatory Factor 3 \\
\hline JNK & c-Junction N-terminal kinase \\
\hline $\log$ & Logarithmus \\
\hline LPS & Lipopolysaccharid \\
\hline LPS-BP & Lipopolysaccharid-binding Protein \\
\hline LRR & Leucinreiches Fragment \\
\hline LTA & Lipoteichonsäure \\
\hline MALP-2 & Makrophagen-Aktivierendes Lipopeptid 2 \\
\hline \multirow[t]{2}{*}{ MD-2 } & Ein extrazelluläres Protein, das die Aktivierung von TLR4 durch \\
\hline & LPS bewirkt. \\
\hline MDC & Myeloide Dendritische Zellen \\
\hline $\mathrm{mg}$ & Milligramm \\
\hline
\end{tabular}




\begin{tabular}{|c|c|}
\hline MIF & Makrophagen-Migrations-Inhibitions-Faktor \\
\hline $\min$ & Minute \\
\hline$\mu g$ & Mikrogramm \\
\hline$\mu l$ & Mikroliter \\
\hline $\mathrm{ml}$ & Milliliter \\
\hline MMTV & Mouse Mammary Tumor Virus \\
\hline MyD88 & Myeloid Differentiation Primary Response Gene \\
\hline $\mathrm{n}$ & Anzahl \\
\hline $\mathrm{NaCl}$ & Natriumchlorid \\
\hline NF & Nuclear Factor \\
\hline $\mathrm{ng}$ & Nanogramm \\
\hline NO & Stickstoffmonoxid \\
\hline NOD2 & nukleotide-binding oligomerization domain 2 \\
\hline ОтС & Organotypische Hippokampuskulturen \\
\hline $\mathrm{p}$ & $\mathrm{p}$-Wert \\
\hline PAMP & Pathogen-associated Molecular Patterns \\
\hline PCR & Polymerase Chain Reaction (Polymerasekettenreaktion) \\
\hline PDC & Plasmozytoide Dendritische Zellen \\
\hline $\mathrm{pg}$ & Pikogramm \\
\hline$P C$ & Peptidoglykan \\
\hline
\end{tabular}


PGRP

PGRP-LC

PGRP-SA

Poly (I:C)

RNA

RS-Virus

RT-PCR

S. aureus

S. pneumoniae

TA

TBE-Puffer

TF

TIR

TIRAP/Mal

TLR

TNF $\alpha$

TRAF

VCAM

z. B.
Peptidoglycan Recognition Protein

Peptidoglycan Recognition Protein - long (ein PGRP-Gen mit langen Domänen in Drosophila)

Peptidoglycan Recognition Protein - short (ein PGRP-Gen mit kurzen Domänen in Drosophila)

Polyinosinic Polycytidylic Acid

Ribonukleinsäure(n)

Respiratory synzytial Virus

Reverse-Transkription-PCR

Staphylococcus aureus

Streptococcus pneumoniae

Teichonsäure

Tris-Borsäure-EDTA-Puffer

Tissue-Faktor

Toll-Interleukin-1-Rezeptor

TIR Domaincontaining Adaptor Protein/MyD88-Adaptor-Like

Toll-Like-Rezeptor(en)

Tumor-Nekrose-Faktor alpha

Tumor Necrosis Factor Receptor-associated Factor

Vascular Cell Adhesion Molecule

zum Beispiel 


\section{Einleitung}

\subsection{Bakterielle und virale Infektionen des ZNS}

\subsubsection{Die bakterielle Meningitis}

Bei der bakteriellen Meningitis handelt es sich um eine Entzündung der Hirnhäute, die häufig kombiniert als Meningoenzephalitis, Meningomyelitis und Enzephalomyelitis bzw. Abszessbildungen auftritt und meist durch bakterielle oder virale Infektionen verursacht wird (vgl. Masuhr und Neumann 1998).

Die Inzidenz der Meningitiden beträgt etwa 600.000 im Jahr weltweit. Die Letalität der bakteriellen Meningitis ist vom Erkrankungsalter und Erregertyp abhängig und liegt durchschnittlich bei 5-10\% bei Kindern und etwa bei $25 \%$ bei Erwachsenen. In den letzten 40 Jahren ist die Letalität trotz Verbesserung der diagnostischen Methoden, neuer Antibiotika, adjuvanter Therapien und trotz Verbesserung der Intensivtherapie unverändert geblieben (vgl. Nau und Brück 2002).

Eine eitrige Meningitis kann durch einer Reihe von Erregern verursacht werden. Mehr als $70 \%$ der Erkrankungen werden von Streptococcus pneumoniae, Neisseria meningitidis und Haemophilus influenzae Typ $b$ hervorgerufen. Im Neugeborenenalter werden allerdings ca. 2/3 aller Infektionen von $\beta$-hämolysierenden Streptokokken der Gruppe B und Escherichia coli hervorgerufen (Opferkuch und Tauchnitz 1991). Die Inzidenz der Meningitis durch $H$. influenzae bei Kindern ist infolge von Impfungen von 2,5 auf 0,4 pro 100.000 pro Jahr gesunken (Theodoridou et al. 2007).

Im Verlauf der Meningitis können zahlreiche Komplikationen auftreten. Als neurologische Komplikationen finden sich: subdurales Empyem, Hydrozephalus, Vaskulitis, Hirnödem und septische Sinusvenenthrombose. Als direkte oder indirekte Folgen des Neuronenschadens können Hörverlust, fokale neurologische Defizite und Beeinträchtigung des Lernens auftreten. In schweren Fällen muss mit einer Reihe internistischer Symptome wie Sepsis, Schock und Verbrauchskoagulopathie gerechnet werden. Zwei Drittel der Todesfälle bei Meningitis werden primär oder sekundär durch 
neurologische Komplikationen hervorgerufen (Van der Flier et al. 2003). Zwischen $5 \%$ und $40 \%$ der Überlebenden zeigen permanente neurologische Schäden. Die Häufigkeit ist von der Art des Keimes und dem Alter des Patienten abhängig (Arditi et al. 1998; Erickson und Wals 1998; Grimwood et al. 2000).

Als Folge der bakteriellen Meningitis treten häufig Hörschäden sowie Beeinträchtigungen des kognitiven Lernens und der intellektuellen Fähigkeiten auf, die von leichten Lernproblemen bis zu schwerer Beeinträchtigung der Intelligenz oder Verhaltensstörungen variieren können. Seltener kommt es zu epileptischen Anfällen, Spastizität und fokalen neurologischen Defiziten.

Die Erfahrungen zeigen, dass die antibiotische Therapie der Meningitis zur Auslösung einer starken Entzündungsreaktion vergleichbar mit der Jarisch-Herxheimer-Reaktion führen kann. Dies wird bei der Therapie mit Antibiotika beobachtet, die ihre Wirkung auf die Zellwand haben und damit zur Zelllyse führen. Es wird davon ausgegangen, dass die Lyse der Bakterien zur Freisetzung von Zellwandbestandteilen führt, die stark proinflammatorisch und daher schädigend auf den Wirtsorganismus wirken.

Bakterielle Komponenten und Toxine wie Lipopolysaccharid (LPS), Peptidoglykan (PG) und Lipoteichonsäure führen zur Freisetzung inflammatorischer Mediatoren wie Tumor-Nekrose-Faktor $\alpha(T N F \alpha)$ und Interleukine durch Mikroglia sowie ICAM (intercellular adhesion molecule) und VCAM (vascular cell adhesion molecule) durch Endothelzellen (Nau und Eiffert 2002). Die chemotaktischen Faktoren und die erhöhte Permeabilität der Endothelzellen verursachen die Migration von neutrophilen Granulozyten ins Gehirn. Die Anwesenheit der neutrophilen Granulozyten ist der wichtigste Faktor für die Entstehung der Vaskulitis und des Vasospasmus (Nau und Eiffert 2002; Nau und Brück 2002). Es kommt zur Verschlechterung des Blutflusses. Vasokonstriktive und vasodilatative Stoffe werden freigesetzt. Diese Stoffe verursachen den Verlust der Autoregulation der zerebralen Perfusion, was Hypoxie und Ischämie zur Folge haben kann (Nau und Brück 2002).

Erhöhte Permeabilität der Endothelzellen bedeutet andererseits eine Erhöhung der Durchlässigkeit der Blut-Hirn- und Blut-Liquor-Schranke. Dies führt zu vasogenem und interstitiellem Ödem. Hirnödem und Herniation ins Tentorium und ins Foramen 
magnum sind die wichtigsten Todesursachen (ein Drittel der Todesfälle) bei der Meningitis (Nau und Brück 2002).

Eine weitere Folge des Endothelschadens ist die Ausschüttung von Tissue-Faktor (TF), die zu Thrombose und Hämorrhagie führt. Bei der Autopsie werden häufig zerebrovaskuläre Thrombosen gefunden.

Der Neuronenschaden, der meist langzeitig oder permanent ist, ist u.a. bedingt durch die Wirkung von freien Radikalen. Sie können durch Hypoxie, Toxine oder Mediatoren des Wirtsorganismus entstehen. Es kommt zur direkten sowie Mikroglia-vermittelten Neurotoxizität, die Nekrose oder Apoptose in Gang setzt. Neuronenschaden tritt am häufigsten im Gyrus dentatus und in Pyramidenzellen der Hippokampusformation auf und wurde in 70 \% der humanen Autopsiefälle beobachtet (Nau und Brück 2002).

In dieser Arbeit werden bakterielle ZNS-Infektionen durch die zwei unten beschriebenen Erreger untersucht.

\section{a) Streptococcus pneumoniae (Pneumokokken)}

Pneumokokken sind Gram-positive, unbewegliche, sporenlose Bakterien, die meist in Diplokokkenform auftreten. Je ein Diplokokken-Pärchen ist von einer Kapsel umgeben. Die Einteilung in die mehr als 85 Serogruppen erfolgt anhand der unterschiedlichen Antigenität der Polysaccharidkapseln. Kapselbildung dient dem Schutz vor Phagozytose. Zu wichtigen Virulenzfaktoren der Pneumokokken zählen: Peptidoglykan und Lipoteichonsäure, Pneumolysin, Autolysin und Neuraminidase.

Die Pneumokokken werden häufig in der Normalflora des Nasen-Rachenraumes gefunden. Eine Infektion erfolgt als Tröpfcheninfektion oder als endogene Infektion durch die Normalflora. Prädisponierende Faktoren für eine Pneumokokkeninfektion stellen Lungenerkrankungen, Herz- und Niereninsuffizienz, Unterernährung, Tumorkachexie, Hyposplenismus und Splenektomie dar.

Pneumokokken sind die häufigsten Erreger von Meningitiden im Erwachsenenalter. Weiterhin können Pneumokokken Pneumonien, Bronchitiden, Sinusitis, Otitis media und Konjunktivitis verursachen. Komplikationen einer Pneumokokkeninfektion können 
die Abszedierung, das Pleuraempyem oder die Sepsis sein (vgl. Raetzer und Rensing 1999).

\section{b) Escherichia coli}

E. coli ist ein Gram-negatives, bewegliches, fakultativ anaerobes Stäbchenbakterium, das zur normalen Darmflora gehört. Wie alle Gram-negativen Stäbchen besteht es aus Zytoplasma mit Plasmamembran, einem periplasmatischen Spalt, einer dünnen Mureinschicht, einer Lipoproteinschicht und einer äußeren Zellmembran mit Lipopolysaccharid. Lipopolysaccharid, auch Endotoxin genannt, ist der hauptsächliche Virulenzfaktor bei opportunistischen Enterobakterien. Er bewirkt im Körper Fieber, Komplementaktivierung, Schock und Verbrauchskoagulopathie.

E. coli ist der häufigste Erreger von Sepsis und Meningitis bei Neugeborenen und Kleinkindern und wird bei Erwachsenen in $30 \%$ der Sepsisfälle nachgewiesen. Die größte klinische Bedeutung haben aber die darm- und uropathogenen Stämme.

Die Einteilung der Kolibakterien erfolgt anhand ihrer antigenen Eigenschaften. Die Kapselsubstanz wird als K-Antigen und die Geißeln als H-Antigen bezeichnet. Die Neugeborenen-Sepsis und -Meningitis wird durch Typ K1 verursacht (vgl. Raetzer und Rensing 1999).

\subsubsection{Herpes-simplex-Virus-Enzephalitis (HSV)}

HSV kommt in zwei Typen - Typ 1 und Typ 2 - vor, die sich durch ihre biologischen und pathogenetischen Eigenschaften unterscheiden. Das Typ-1-Herpes-Virus wird als „Oraltyp“ bezeichnet, weil die Primärinfektion vorwiegend über die Mundhöhle erfolgt. Bis zum 10. Lebensjahr werden praktisch alle Kinder mit dem HSV-Typ 1 infiziert. Die Infektion verläuft in etwa $90 \%$ der Fälle inapparent und bleibt das gesamte Leben über als latente Infektion bestehen. Aus der Latenz entwickeln sich wiederholt kurzdauernde Exazerbationen, meistens als bläschenförmige, harmlose Hauteruptionen.

Die Enzephalitis wird fast immer durch HSV-1 verursacht. Sie befällt die temporalen und orbitoparietalen Gebiete des ZNS und wird als nekrotisierende Enzephalitis 
manifest.

Als Ursache der Enzephalitis vermutet man einerseits die Ausbreitung von vom Trigeminus-Ganglion ausgehenden Viren ins ZNS, andererseits die Aktivierung von bereits im ZNS vorhandenen HSV-DNA (vgl. Falke 1991).

Die Herpes-Enzephalitis ist nach einer Studie im Jahr 2007 in Frankreich mit $22 \%$ der Hauptrepräsentant aller Enzephalitiserkrankungen (Mailles und Stahl 2009). In Deutschland kommen bei einer Durchseuchung von mehr als $95 \%$ etwa 100 Fälle von Herpes-Enzephalitis pro Jahr vor. Unbehandelt sterben etwa 70 \% der Erkrankten, die übrigen überleben mit neurologischen Abnormitäten (vgl. Falke 1991).

\subsection{Toll-Like-Rezeptoren (TLR)}

\subsubsection{TLR und angeborene Immunität}

Das Gen Toll wurde in Drosophila entdeckt. Es steuert die dorsoventrale Polarität der embryonalen Entwicklung (Anderson et al. 1985). Im Jahr 1988 wurde erstmals die Beteiligung des Gens Toll an der Steuerung der angeborenen Immunität beschrieben (Hashimoto et al. 1988).

In Drosophila ist Toll ein transmembranöser Rezeptor. Er besteht aus extrazellulären und zytoplasmatischen Domänen. Die extrazelluläre Domäne ist ein leucinreiches Repeat, und die intrazelluläre Domäne ähnelt dem Interleukin-1-Rezeptor (IL-IR) Typ 1, weshalb sie Toll/IL-IR (TIR) genannt wird (Akira 2000). Diese Ähnlichkeit war ein Hinweis, dass Toll wahrscheinlich an der Steuerung der Immunantwort beteiligt ist (Belvin und Anderson 1996).

Diese Theorie wurde durch eine Untersuchung bei Drosophila bestätigt. Fliegen, die eine Mutation in einem Bestandteil des Toll-Wegs besitzen, sind gegen Pilzinfektionen extrem anfällig (Lemaitre et al. 1996). Sie sind nicht in der Lage, das antimykotische Peptid Dorsomycin zu bilden.

Ein Jahr nach der Entdeckung der Beteiligung von Toll an der angeborenen Immunität 
gegen Pilze wurden Toll-Homologe in Säugetieren gefunden. Sie wurden Toll-like-Rezeptoren (TLR) genannt (Medzhitov et al. 1997).

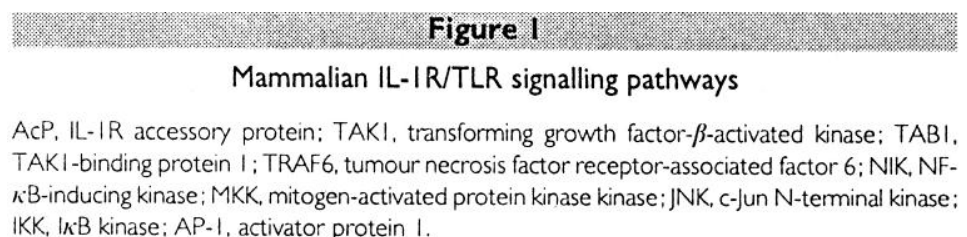
IKK, I $K$ B kinase: AP-I, activator protein I.

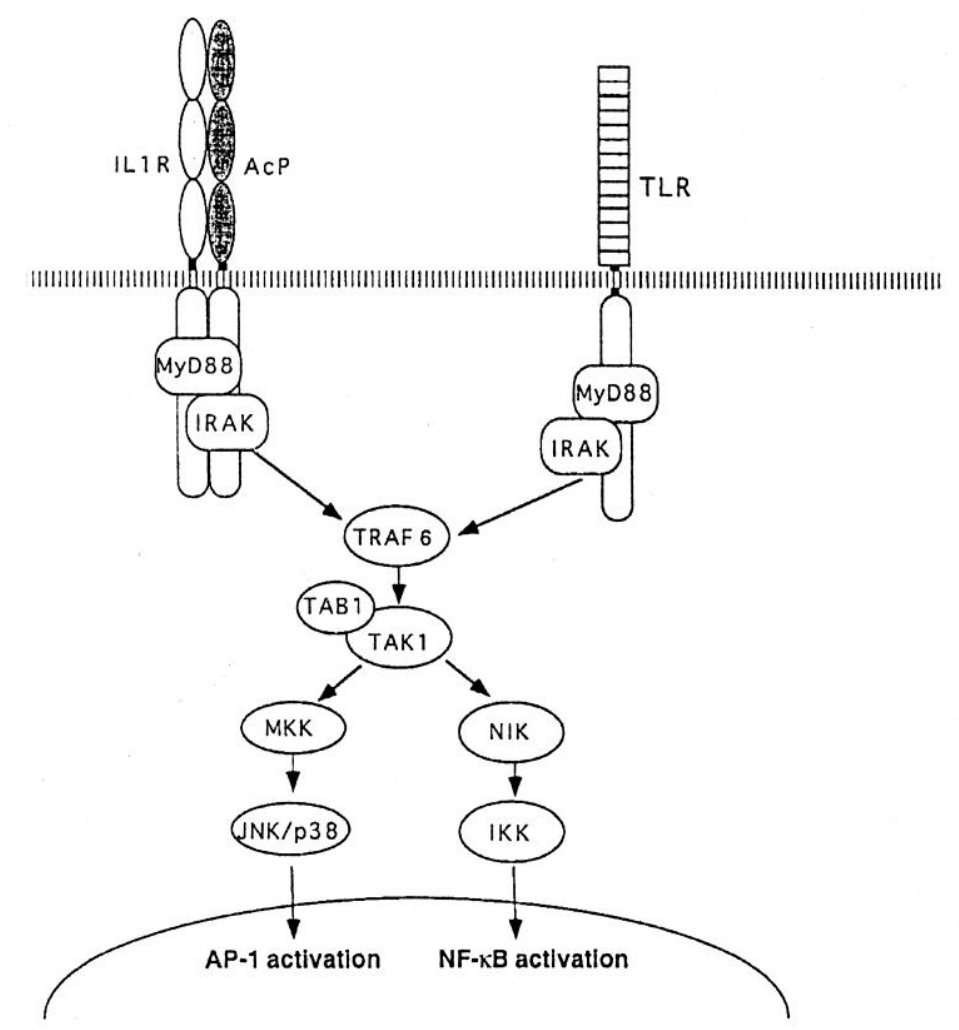

Abbildung 1: $\quad$ Toll-Like Rezeptoren im Säugetier: Die intrazellulären Domänen von Toll und IL-IR Typ 1 sind sehr ähnlich und haben die gleiche intrazelluläre Wirkung (Akira 2000, S. 552).

In den letzten Jahren wurden die TLR als Rezeptoren für bakterielle Komponenten pathogen associated molecular patterns (PAMPs) - beschrieben (Akira und Hemmi 2003). PAMPs sind Strukturen, die in vielen pathogenen Mikroorganismen gefunden werden und zum Teil die Pathogenität der Mikroorganismen bestimmen, z. B. LPS und PG. Jeder TLR erkennt bestimmte bakterielle und virale Komponenten.

Elf TLR (TLR1 - TLR11) wurden bisher entdeckt und charakterisiert. Strukturell zeigen alle TLR leucinreiche Ketten in der extrazellulären Domäne und TIR in der 
zytoplasmatischen Domäne (Takeda et al. 2003).

\subsubsection{Subgruppen der TLR und ihre Liganden}

Im Menschen werden die TLR in fünf Subgruppen unterteilt: die TLR2-Subgruppe besteht aus TLR1, TLR2, TLR6 und TLR10. TLR3, TLR4 und TLR5 bilden je eine Subgruppe. Die TLR9-Gruppe beinhaltet TLR7, TLR8 und TLR9 (Takeda et al. 2003). Die Unterteilung in Subgruppen basiert auf der genetischen Struktur. Die Lokalisationen der kodierenden Gene der elf TLR sind bereits bekannt.

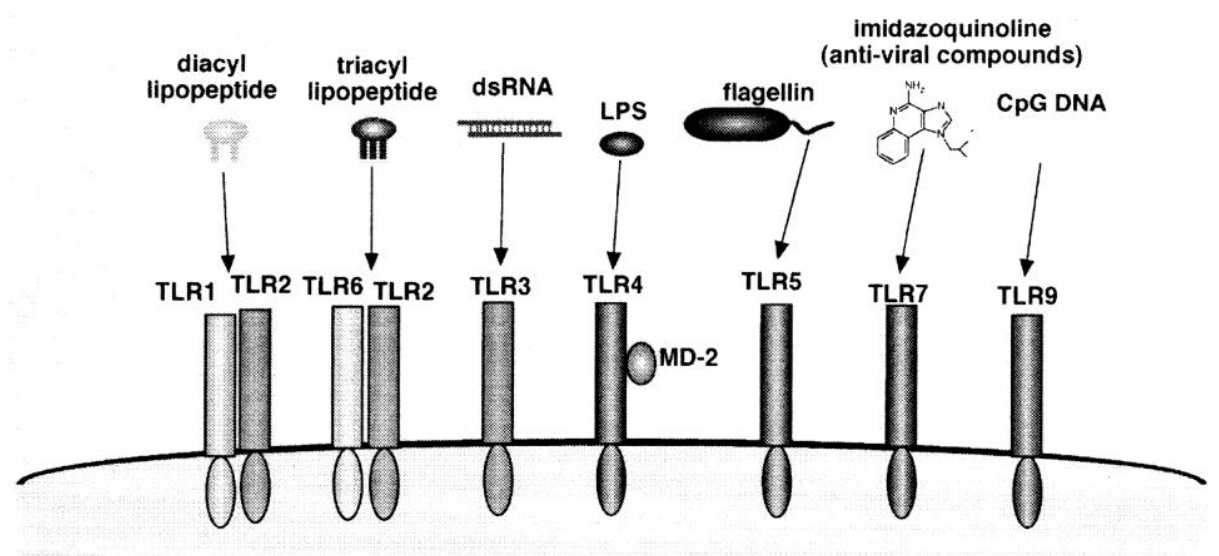

Abbildung 2: $\quad$ TLR und ihre Liganden (Takeda u. Akira 2003, S. 144). In dieser Abbildung sind die Begriffe diacyl lipopeptide und triacyl lipopeptide irrtümlich vertauscht.

\section{TLR2, TLR1 und TLR6}

TLR2 erkennt Lipoteichonsäure Gram-positiver Bakterien (Schwandner et al. 1999; Yoshimura et al. 1999) sowie Lipoprotein (Takeuchi et al. 1999 und 2000) und Lipopeptide vieler pathogener Bakterien (Takeda et al. 2003). Außerdem wirkt TLR2 mit NOD2 (nukleotide-binding oligomerization domain 2) bei Aktivierung der Mikrogliazellen durch Pedtidoglykan (PG) zusammen (Volz et al. 2010; Chen et al. 2008).

TLR2-defiziente Mäuse zeigen extreme Empfindlichkeit gegen Infektionen mit Staphylococcus aureus im Vergleich zu Wildtyp-Mäusen. TLR2 erkennt auch 
atypisches LPS von Leptospira interrogans und Porphyromonas gingivalis. Typisches LPS - LPS von Enterobakterien - wird von TLR4 erkannt. Die atypischen LPS unterscheiden sich von den typischen in der Zahl der Acylketten in Lipid A (Netea et al. 2002). In der Immunantwort gegen atypisches LPS müssen wahrscheinlich TLR1 und TLR6 mit TLR2 zusammen wirken (Takeda und Akira 2003). Makrophagen von TLR6-defizienten Mäusen zeigen keine Reaktionen gegen mykoplasmatische Diacyl-Lipopeptide, aber normale Reaktionen gegen Triacyl-Lipopeptide aus Gram-negativen Bakterien (Takeuchi et al. 2001). Makrophagen von TLR1-defizienten Mäusen zeigen dagegen eine normale Immunantwort auf mykoplasmatische Diacyllipopeptide und eine unvollständige Antwort gegen Triacyllipopeptide und -lipoproteine (Takeuchi et al. 2002).

In Experimenten mit Fibroblasten wurde gezeigt, dass TLR2 und TLR6 intakt sein müssen, um gegen mykoplasmatisches Makrophagen-Aktivierendes-Lipopeptid 2 (MALP-2) eine Immunantwort auszulösen. Makrophagen von TLR2-defizienten Mäusen zeigen aber keine Reaktion gegen jede Art von Lipopeptiden. Vermutlich führt eine physikalische Interaktion zwischen beiden Molekülen zu einer Aktivierung der Rezeptoren und zu zytoplasmatischen Signalen.

Die Beteiligung von TLR1 neben jener von TLR2 in der Erkennung der löslichen Faktoren von Neisseria meningitidis wurde experimentell in Hela-Zellen gezeigt (Takeda et al. 2003).

\section{TLR3}

Die Beteiligung von TLR3 an der Erkennung von doppelsträngiger RNA (dsRNA) wurde experimentell bestätigt. TLR3 scheint ein Rezeptor für dsRNA zu sein (Alexopoulou et al. 2001). dsRNA ist ein virales Produkt, das während der Replikation gebildet wird. Synthetische dsRNA [Poly (I:C) Polyinosinic Polycytidilic Acid] hat die gleiche Wirkung auf TLR3 wie dsRNA (Takeda et al. 2003). TLR3-defiziente Mäuse können gegen dsRNA und Poly (I:C) keine Immunantwort auslösen. dsRNA ist ein potenter Stoff, der die Interferon-Typ-1-Ausschüttung (IFN- $\alpha$ und- $\beta$ ) induziert. Interferon Typ 1 wird in der Maus und im Menschen hauptsächlich von plasmozytoiden 
dendritischen Zellen gebildet, der TLR3 hingegen wird in diesen Zellen nicht exprimiert. Es wird vermutet, dass andere Rezeptoren zusammen mit TLR3 an der Erkennung von viralen Infektionen und an der Interferonsynthese beteiligt sein müssen (Siegal et al. 1999; Asselin-Paturel et al. 2001; Nakano et al. 2001; Kadowaki et al. 2001; Takeda et al. 2003).

Eine Besonderheit des TLR3 ist, dass in seiner Struktur die Aminosäure Prolin fehlt, während diese in allen anderen TLR vorhanden ist und eine entscheidende Rolle in der Funktion der Rezeptoren spielt. Wenn diese Aminosäure in TLR4 fehlt, ist dieser funktionsunfähig (Takeda et al. 2003).

\section{TLR4}

TLR4 ist der hauptsächliche Rezeptor für LPS (Hoshino et al. 1999). Die mutanten Mäuse $\mathrm{C} 3 \mathrm{H} / \mathrm{HeJ}$ und $\mathrm{C} 57 \mathrm{BL} 10 / \mathrm{ScC}$ s sind seit langem für ihre schwache Immunantwort gegen LPS bekannt. Bei diesen mutanten Mäusen werden Mutationen in TLR4 gefunden. Die C57BL10/ScCr besitzt eine Nullmutation in TLR4. Bei C3H/HeJ besteht in der intrazellulären Domäne des TLR4 eine Punktmutation an der Stelle von Prolin, welches durch Histidin ersetzt ist.

Um LPS zu erkennen, müssen andere Moleküle wie LPS-BP (LPS-binding protein), CD14 (Cluster of Differentiation 14) und MD-2 (ein Protein, das die Aktivierung von TLR4 durch LPS bewirkt) mit TLR4 zusammenwirken. LPS-BP ist im Serum enthalten. Es bindet an LPS und der Komplex LPS/LPS-BP wird von CD14 erkannt. CD14 ist ein Glykosylphosphatidylinositol, das hautpsächlich von Monozyten/Makrophagen und neutrophilen Granulozyten exprimiert wird. Durch die Annäherung von CD14 und TLR4 wird ein intrazelluläres Signal gegeben (Takeda et al. 2003). MD-2 interagiert mit der extrazellulären Domäne des TLR4 in der Immunantwort gegen LPS (Akashi et al. 2000; Da Shilva Correia et al. 2001). Die MD-2-defiziente Maus ist gegen LPS-induzierten Endotoxinschock resistent, ebenso wie die TLR4-defiziente Maus (Nagai et al. 2002). Es wird vermutet, dass der funktionsfähige LPS-Rezeptor aus verschiedenen Molekülen zusammengesetzt ist (Takeda et al. 2003).

TLR4 und CD14 wirken auch als Rezeptor für Respiratory synzytial Virus (Kurt-Jones 
et al. 2000; Haynes et al. 2001). Die C3H/HeJ- und C57BL10/ScCr-Mäuse zeigen eine schwache Entzündungsreaktion und unvollständige Beseitigung des Virus. TLR4 scheint auch an der Erkennung von manchen anderen Viren beteiligt zu sein (Takeda et al. 2003).

TLR4 wird auch durch endogene Liganden wie beispielsweise HSP60 (heat shock protein 60) aktiviert (Ohashi et al. 2000; Vabulas et al. 2001). Die Beteiligung von HSP60 aus Chlamydia pneumoniae (cHSP60) an der Arteriosklerose ist bekannt. Makrophagen und cHSP60 werden in atheromatösen Läsionen nachgewiesen. cHSP60 scheint ein Faktor für die Arteriosklerose bei chronischen Chlamydia-Infektionen zu sein. Es aktiviert die glatte Muskulatur der Gefäße und die Makrophagen durch die Aktivierung von TLR4 (Sasu et al. 2001; Bulut et al. 2002). Ein anderer endogener TLR4-Ligand ist Hyaluronsäure. Hyaluronsäure ist als ein potenter Stoff bei der Aktivierung der dendritischen Zellen bekannt. Dieser Prozess findet durch die Aktivierung des TLR4 statt (Johnson et al. 2002).

Auch Fibrin wirkt als ein endogener Ligand bei der Aktivierung des TLR4. Die Zytokinfreisetzung aus Makrophagen durch Fibrin scheint durch die Aktivierung von TLR4 bedingt zu sein (Smiley et al. 2001).

Extrazelluläre Matrixkomponenten wie Fibronectin und Heparansulfat, die bei Gewebeschaden gebildet werden, sind wichtige Faktoren in der Geweberemodellierung und Wundheilung. Die Erkennung des Fibronectins wird mittels TLR4 verursacht. Fibronectin besitzt eine Domäne (Domäne A), die ähnliche immunstimulatorische Wirkung wie LPS hat (Okamura et al. 2001). Goos et al. beschreiben eine erhöhte Fibronectin-Konzentration im Liquor der an der Meningitis erkrankten Patienten. Es wird vermutet, dass Fibronectin die inflammatorische Reaktion gegen bakterielle Komponenten mittels TLR4 verstärken kann (Goos et al. 2007).

\section{TLR5}

CHO-Zellen (Chinese hamster ovary cells), die den menschlichen TLR5 exprimieren, 
zeigen Immunreaktionen gegen Listeria monocytogenes. Flagellin wurde in diesen Kulturen als aktivierender Faktor für TLR5 identifiziert (Hayashi et al. 2001). Flagellin ist das Protein, aus dem die Geißeln der Bakterien bestehen. Nur Bakterien, die Geißeln besitzen, aktivieren TLR5. Die Stimulierung der Epithelien des Darms mit Flagellin zeigt, dass nur die basolaterale Seite und nicht die apikale Seite in Kontakt mit Flagellin Entzündungsreaktionen auslöst (Takeda und Akira 2003). Das korreliert mit der Erkenntnis, dass nur die pathogenen Gram-negativen Bakterien, die in die Epithelien eindringen, eine Entzündungsreaktion auslösen.

\section{TLR7, TLR8 und TLR9}

TLR7 und TLR8 haben strukturelle Ähnlichkeit mit TLR9. Sie scheinen unter Mitwirkung von TLR9 an der Erkennung von Nukleinsäure-ähnlichen Strukturen von Mikroorganismen beteiligt zu sein. TLR7 ist an der Erkennung und am Auslösen der Immunreaktion gegen synthetische Stoffe beteiligt, die virale Infektionen imitieren (Hemmi et al. 2002). Imidazoquinoline wurden als antivirale Stoffe gegen Herpes-simplex-Infektionen experimentell angewandt. Heute werden sie klinisch gegen Infektionen mit humanen Papillomaviren eingesetzt. Sie lösen die Ausschüttung inflammatorischer Zytokine aus, insbesondere von IFN- $\alpha$. TLR7 wurde als Auslöser der Entzündungsreaktion gegen Imidazoquinoline beschrieben (Takeda und Akira 2003). TLR7-defiziente Mäuse zeigen keine Reaktion gegen Imidazoquinoline (Hemmi et al. 2002). Die Struktur von Imidazoquinoline ähnelt jener von viralen Nukleinsäuren. TLR7 scheint eine Abwehrreaktion gegen virale Infektionen durch die Erkennung viraler Nukleinsäure (Diebold et al. 2004) oder der vom Wirt gebildeten Stoffe bei der Infektion auszulösen (Takeda et al. 2003).

Die einzelsträngige, an Uracil und Guanosin reiche virale RNA wurde als physiologischer Ligand für TLR7 (Maus) und TLR8 (Mensch) identifiziert (Heil et al. 2004). Menschlicher TLR8 erkennt einzelsträngige virale RNA (Wagner 2004).

TLR7, 8 und 9 haben nicht nur große strukturelle Ähnlichkeiten, sondern auch funktionelle, da sie die ähnliche pathogene DNA- und RNA-Motive erkennen und die dendritischen Zellen in einem von MyD88-abhängigen (myeloid differentiation primary 
response gene) Weg aktivieren (Wagner 2004).

TLR9 ist der hauptsächliche Rezeptor für die Erkennung der bakteriellen DNA (Takeda et al. 2003). Das wurde durch Experimente mit TLR9-defizienten Mäusen bestätigt (Hemmi et al. 2000). Die Nukleinsäure von Prokaryonten besitzt einen hohen Anteil nichtmethyliertes CpG (Cytidin-Guanosin-Dinukleotide). In Wirbeltieren ist CpG an den Cytosinresten methyliert. Diesen Unterschied macht sich das Immunsystem der Vertebraten zu Nutze, um die fremde DNA zu erkennen. Synthetische Oligodinukleotide, die nichtmethyliertes $\mathrm{CpG}$ enthalten, aktivieren die Zellen des Immunsystems (Takeda et al. 2003). In der Zelllinie 293 wird keine Reaktion gegen CpG-DNA ausgelöst. Wenn die Kulturen mit einem TLR9-Agonisten stimuliert werden, wird eine optimale Reaktion gegen CpG-DNA ausgelöst (Bauer et al. 2001). Das zeigt, dass die CpG-DNA direkt von TLR9 erkannt wird (Takeda et al. 2003).

In einer Studie (lliev et al. 2004) wurde die Neurotoxizität von TLR9 (CpG-DNA) auf neuronale Kulturen in An- und Abwesenheit von Mikrogliazellen untersucht. Die Kulturen wurden entweder als reine Neuronenkulturen oder mit Mikrogliazellen mit CpG-DNA behandelt und mit nicht behandelten gleichwertigen Kulturen verglichen. Es wurde gezeigt, dass die Mikrogliazellen durch Stimulation mit nichtmethylierter CpG-DNA TNF- $\alpha$ und iNOS (induzierbare Stickstoffmonoxid-Synthase) ausschütten. TNF- $\alpha$ und iNOS haben toxische Wirkung auf Neurone und neuronale Fortsätze. Die schädlichen Effekte fehlen in reinen Neuronenkulturen ohne Mikrogliazellen und Zellkulturen, die nicht mit CpG-DNA behandelt wurden.

Während TLR1, TLR2 und TLR4 auf der Zellmembran exprimiert werden, wird TLR9 endosomal, vesikulär oder vakuolär gefunden (Ahmad-Nejad et al. 2002).

\subsubsection{Expression der TLR}

Muzio et al. (2000) berichten, dass Monozyten und Makrophagen mRNA aller TLR mit Ausnahme von TLR3 exprimieren. Sie konnten die TLR3-Expression nur bei reifen dendritischen Zellen (DC) beobachten.

Aus anderen Experimenten wurde beschrieben, dass im Gehirn die Mikrogliazellen im 
Mausmodell TLR1-9 exprimieren. Das geschieht in Anwesenheit von LPS unter Zusammenwirkung von TLR2 und CD14 (Olson und Miller 2004).

Bobcock berichtet, dass Mikrogliazellen bei axonalem Schaden im Hippokampus TLR2 exprimieren (Bobcock et al. 2006).

Bsibsi et al. (2002) haben die Expression von TLR im Gehirn untersucht, indem sie postmortal das Gehirn von an neurodegenerativen Erkrankungen leidenden Menschen mit Kontrollgewebe verglichen haben. Sie zeigten, dass Mikrogliazellen alle TLR exprimieren, TLR9 jedoch in sehr geringer Menge. In Astrozyten- und Oligodendrozytenkulturen konnte nur TLR2 und TLR3 detektiert werden. In manchen Kulturen wurde die Expression von TLR1 und TLR4 auch in diesen Zellen detektiert. Während TLR3 und TLR4 in Mikrogliazellen in zytoplasmatischen Vesikeln zu detektieren sind, sind diese in Oligodendrozyten auf der Zellmembran zu finden. In Astrozytenkulturen werden vergleichbare Mengen von TLR2 und TLR3 detektiert, in Mikrogliakulturen jedoch ist die detektierte Menge der verschiedenen Rezeptoren bei unterschiedlichen Krankheitsbildern sehr variabel.

Bei der Infektion mit HSV zeigen Mikrogliazellen der Wildtypmaus Apoptose, die von der Stimulation des TLR2 abhängig ist. In TLR2-/- Zellen wurden deutlich weniger apoptotische Zellen beobachtet (Aravalli et al. 2007).

Die meisten menschlichen Gewebe exprimieren mindestens einen TLR (Zarember und Godowski 2002).

\subsubsection{Regulation der TLR}

Die Regulation der TLR wird durch verschiedene Faktoren, z. B. Mikroorganismen und ihre Komponenten oder verschiedene Zytokine, beeinflusst (Takeda et al. 2003). Die Behandlung von Makrophagen mit Mycobacterium avium verursacht eine erhöhte Expression von TLR2 und eine reduzierte Expression von TLR4 (Wang et al. 2000). Mit E. coli infizierte Mäuse zeigten die Expression von TLR2 in $\gamma \delta T$-Zellen. Dies ist ein Indiz für eine frühe und unspezifische zelluläre Abwehr (Mokuno et al. 2000). In einer Studie (Miettinen et al. 2001) wurde die Expression der TLR1, 2, 3 und 7 von 
Makrophagen bei viralen Infektionen untersucht. Die Behandlung der Makrophagen mit IFN $\alpha / \beta$-Antikörper hemmte die Expression der oben genannten TLR. Das ist ein Hinweis dafür, dass IFN $\alpha / \beta$ die virusinduzierte Aktivierung der angeborenen Immunität durch die Modulation der TLR-Expression verstärkt. CSF-1 (colony-stimulating factor 1) hat eine supprimierende Wirkung auf die Expression von TLR9 in Makrophagen und hemmt die CpG-DNA-induzierte Freisetzung von Zytokinen (Sweet et al. 2002). MIF (macrophage migration inhibitory factor) wirkt als ein proinflammatorisches Zytokin beim Endotoxinschock (Bozza et al. 1999). MIF-defiziente Mäuse sind nicht in der Lage, gegen LPS eine Abwehrreaktion auszulösen. Die Behandlung normaler Zellen mit MIF-Antisense-mRNA reduziert die Aktivität des TLR4-Promotors und die Abwehrreaktion gegen LPS. So reguliert MIF die Expression des TLR4 (Roger et al. 2001).

\subsubsection{TLR-Signalkaskade im Säugetier}

Im Säugetier interagieren TLR mit MyD88 (myeloid differentiation primary response gene), das auch eine TIR-Domäne am C-Ende enthält. MyD88-defiziente Mäuse zeigen keinerlei Ausschüttung inflammatorischer Zytokine nach Behandlung mit LPS, Peptidoglykan, Lipoprotein, CpG-DNA, dsRNA, Flagellin oder Imidazoquinoline (Akira et al. 2001). MyD88 verursacht die Aktivierung von IRAK (interleukin-1 receptor associated kinase). Aktivierte IRAK interagiert mit TRAF6 (tumour necrosis factor receptor-associated factor 6). Sie setzen durch Aktivierung von NF-кB (nuclear factor kB) bzw. JNK (c-Jun N-terminal kinase) zwei verschiedene Abwehrwege in Gang (Muzio et al. 1997 und 1998; Wesche et al. 1997; Burns et al. 1998; Medzhitov et al. 1998).

Vier verschiedene IRAK-Moleküle sind bekannt: IRAK-1, IRAK-2, IRAK-M und IRAK-4 (Li et al. 2002). Während IRAK-1-defiziente Mäuse eine schwache Abwehrreaktion nach Behandlung mit LPS zeigen (Swantek et al. 2000), zeigen IRAK-4-defiziente Mäuse gar keine Reaktion nach Behandlung mit LPS, Peptidoglykan, dsRNA und CpG-DNA (Suzuki et al. 2002). Das ist ein Hinweis, dass IRAK-4 eine hauptsächliche Komponente bei der IL-1- und TLR-induzierten Abwehrreaktion ist (Takeda et al. 2003; Takeda und Akira 2003). Hingegen hat IRAK-M eine negative Wirkung auf die 
TLR-induzierte Abwehrreaktion. IRAK-M-defiziente Mäuse zeigen eine erhöhte Ausschüttung von inflammatorischen Zytokinen in Reaktion auf TLR-Liganden (Kobayashi et al. 2002).

Wie IRAK-4 und TRAF6 zur Aktivierung von NF-kB und JNK führen, ist noch nicht hinreichend geklärt. Eine Studie zeigt, dass TRAF6 zu IKK-Komplex-Bildung

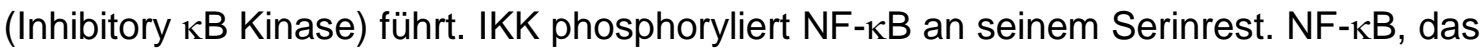
als Dimer an einen Inhibitor gebunden im Plasma vorliegt, setzt den Inhibitor frei und gelangt in den Zellkern, wo es als Transkriptionsfaktor für $\kappa$-Gene wirkt (Takeda et al. 2003; Van der Flier et al. 2003).

Die Existenz von MyD88 ist für die Ausschüttung der inflammatorischen Zytokine gegen bakterielle Komponenten notwendig. In MyD88-defizienten Makrophagen wurde bei Stimulation mit Peptidoglykan, Lipoprotein, CpG-DNA oder Imidazoquinolinen keine Aktivierung von NF-kB oder JNK beobachtet. Bei Stimulation mit LPS wurde dagegen eine verspätete Aktivierung von $\mathrm{NF}-\mathrm{kB}$ und JNK trotz Abwesenheit von inflammatorischen Zytokinen berichtet (Kawai et al. 1999). Das ist ein Indiz, dass die Freisetzung von inflammatorischen Zytokinen MyD88-abhängig ist. Es existiert aber ein MyD88-unabhängiger Weg bei der TLR4-Aktivierung. Bei Stimulation der TLR4-defizienten dendritischen Zellen mit LPS wird keine Reifung beobachtet, während die MyD88-defizienten Zellen unter gleichen Bedingungen ausreifen (Kaisho et al. 2001). In MyD88-defizienten Makrophagen wurde die Aktivierung von Interferon-induzierten Genen beobachtet (Kawai et al. 2001). Bei MyD88-defizienten Mäusen wurde die Aktivierung von NF-kB durch Stimulation mit dsRNA nachgewiesen (Alexopoulou et al. 2001).

Bei der Aktivierung von TLR3 und TLR4 wird ein Transkriptionsfaktor, genannt IRF-3 (Interferon Regulatory Factor 3), in seiner aktiven Form (phosphoryliert) gefunden (Kawai et al. 2001; Doyle et al. 2002). Phosphorylierter IRF-3 wird bei der Immunantwort gegen virale Infektionen gefunden und führt zur IFN- $\alpha / \beta$-Bildung (Weaver et al. 1998; Yoneyama et al. 1998). Die Phosphorylierung von IRF-3 ist unabhängig von MyD88 (Kawai et al. 2001). So wird vermutet, dass IRF-3 ein wichtiger Faktor bei der intrazellulären Signalinduktion von TLR3- und TLR4-Aktivierung in 
Abwesenheit von MyD88 ist (Takeda und Akira 2003).

Eine andere Komponente, die auch unabhängig von MyD88 zur intrazellulären Signalinduktion im Toll-Weg führt, ist TIRAP/Mal (TIR domain containing adaptor protein/ MyD88-adaptor-like) (Fitzgerald et al. 2001; Horng et al. 2001). TIRAP/Mal hat wie MyD88 eine TIR-Domäne am C-Ende. Dieses Protein zeigt besonders bei TLR4-Aktivierung durch LPS in Abwesenheit von MyD88 seine Funktion (Horng et al. 2002; Yamamoto et al. 2002).

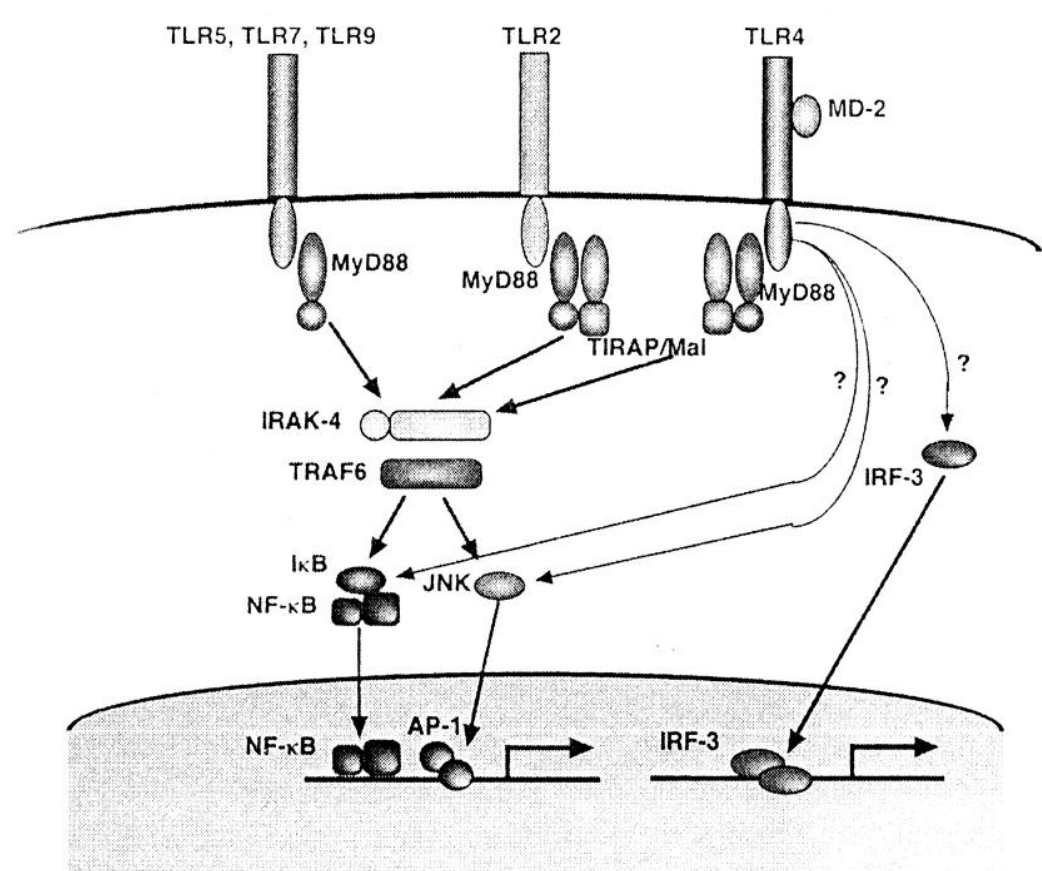

Abbildung 3: $\quad$ TLR-Signalkaskaden (Takeda u. Akira 2003, S. 149)

\subsection{Ziele der Arbeit}

Untersuchungen in der Pathophysiologie der Meningitis zeigen, dass die Komplikationen und permanenten Schäden hauptsächlich durch Immunreaktionen des Wirtsorganismus bedingt sind. Die antibiotische Therapie beseitigt die Keime, kann aber zur überschießenden Reaktion des Immunsystems und dadurch zur Schädigung des Wirts und einer Verschlechterung des Outcomes führen. 
Mit dem Ziel einer verbesserten Therapie von ZNS-Infektionen kann die Modulation der Immunreaktionskaskade der angeborenen Immunität in Betracht kommen. Die Voraussetzung hierfür ist das genauere Verstehen des Mechanismus. Hierfür untersuchen wir den wichtigen Bestandteil der angeborenen Immunität, nämlich TLR sowie deren Regulation und Expression bei häufigen ZNS-Infektionen im Mausmodell. Die Messungen werden von TLR2, 4 und 9 aufgrund ihrer entscheidenden Rolle bei bakteriellen und TLR3 und 7 wegen ihrer bekannten Rolle bei viralen Infektionen durchgeführt.

In der vorliegenden Arbeit wurden Mäuse mit Meningitis bzw. Enzephalitis verursachenden Keimen infiziert und die Expression der TLR untersucht. Eine Gruppe von Mäusen wurde mit Streptococcus pneumoniae infiziert, die zweite Gruppe mit Escherichia coli, und eine dritte mit Herpes-simplex-Virus. Die TLR2, TLR3, TLR4, TLR7 und TLR9 sollten quantitativ in der Test- und der Kontrollgruppe bestimmt werden. Die Ergebnisse von jeder Testgruppe wurden mit jenen der gesunden Kontrollgruppe verglichen.

In der zweiten Untersuchungsreihe wurden mutante Mäuse, in denen ein TLR nicht funktionsfähig ist, infiziert. Als Kontrollgruppen wurden Wildtyp-Mäuse unter gleichen Bedingungen und mit den gleichen Keimen infiziert. Die TLR2, TLR3, TLR4, TLR7 und TLR9 wurden in der Test- und in der Kontrollgruppe bestimmt und die Ergebnisse jeder Testgruppe mit ihrer Kontrollgruppen verglichen. 


\section{Material und Methoden}

In dieser Arbeit wurden molekularbiologische und Zellkulturmethoden angewandt. Um Verunreinigungen zu verhindern, wurde mit Handschuhen gearbeitet. Es wurden sterile Einmalwaren bzw. sterilisierte Plastik- und Glaswaren verwendet. Die verwendeten Lösungen, wie DEPC- $\mathrm{H}_{2} \mathrm{O}$ und TBE-Puffer, wurden autoklaviert.

\subsection{Materialien}

\section{Materialien für die RNA-Extraktion:}

- DEPC- $\mathrm{H}_{2} \mathrm{O}$ :

$1 \mathrm{ml}$ DEPC (Diethylpyrocarbonat)

auf 1 Liter destilliertes Wasser

- 75 \%iger Äthylalkohol

- Trizol Reagent

(Invitrogen ${ }^{\mathrm{TM}}$ life technologies; Cat. No.: 15596-026)

- Chloroform (Merck)

- Isopropylalkohol (Merck)

\section{Materialien für Agarose-Gele:}

- Agarose (Invitrogen; Cat. No.: 15510-027)

- 10-fach TBE-Puffer (Invitrogen; Cat. No.: 15581-051)

$60,7 \mathrm{~g}$ Tris

$26 \mathrm{~g}$ Borsäure

3,72 g EDTA

auf 1 Liter destilliertes Wasser 
- Ethidiumbromid (Appli Chem; Produkt Nr.: A1151)

- Ladepuffer (Invitrogen; Cat. No.: 15620-050)

\section{Materialien für die Reverse Transkription:}

- DEPC- $\mathrm{H}_{2} \mathrm{O}$ (s.o.)

- Omniscript RT Kit (Qiagen; Cat. No.: 205113) bestehend aus:

- RT-Puffer 10-fach

- dNTP-Mix $500 \mathrm{mM} / 100 \mu \mathrm{l}$

- Reverse Transkriptase $4 \mathrm{U} / \mu \mathrm{l}$

- Random Primers (Promega; Catalog C 1181) (random hexadeoxynucleotides)

$0,5 \mu \mathrm{g} / \mu \mathrm{l}$

- RNasin Ribonuclease Inhibitor (=RNase-Inhibitor) (Promega; Catalog N 2115) $40 \mathrm{U} / \mu \mathrm{l}$

\section{Materialien für PCR zur Herstellung der Standards:}

- DEPC- $\mathrm{H}_{2} \mathrm{O}$ (s.o.)

- PCR-Puffer (Invitrogen; Cat. No.: 15581-051)

- $\mathrm{MgCl}_{2} 50$ mM (Invitrogen; Cat. No.:18038-026)

- $\quad$ dNTPs 50 mM (Invitrogen; Cat. No.: U1511)

- Taq-DNA Polymerase $5 \mathrm{U} / \mu \mathrm{l}$ (Invitrogen Cat. No.: 18038-026)

- Spezifische Primer für TLR2, TLR3, TLR4, TLR7, TLR9 und GAPDH, (Sequenzdarstellung: s. Kap. 2.7.2) $100 \mathrm{pMol} / \mu \mathrm{l}$ (MWG) 


\section{Materialien für die Gelextraktion:}

- QIAquick Gel Extraction Kit (Qiagen; Catalog No.: 28704) bestehend aus:

- QIAquick Spin Columns

- $\quad$ Buffer QG

- Buffer PE (konzentriert)

- Buffer EB

- Collection Tubes (2 ml)

\section{Materialien für die Real Time-PCR:}

- DEPC- $\mathrm{H}_{2} \mathrm{O}$ (s.o.)

- Spezifische Primer für TLR2, TLR3, TLR4, TLR7, TLR9 und GAPDH $100 \mathrm{pMol} / \mu \mathrm{l}$ (MWG) (s. Kap. 2.7.2)

- Qiagen Quantitect ${ }^{\mathrm{TM}}$ Master-Mix bestehend aus:

- HotStarTaq DNA Polymerase

- QuantiTect SYBR Green PCR Buffer

- $\quad$ dNTP mix (bestehend aus dATP, dCTP, dGTP und dTTP/dUTP)

- QuantiTect SYBR Green I

- ROX (passive reference dye)

- $5 \mathrm{mM} \mathrm{MgCl}_{2}$ (Endkonzentration 2,5 mM)

Materialien für die organotypischen Kulturen (OTC):

- Mcllwain tissue chopper

- Grey's balanced salt solution (GBSS) mit Zusätze von 36mM D-Glucose und 2mM $\mathrm{MgSO}_{4}$

- Tryptic soy broth (TSB) 
- Eagle's basal medium (BME) $50 \%$

- Hanks' balanced salt solution (HBSS) $25 \%$

- Hitze-inaktiviertes Pferdeserum mit Zusatz von 36mM D-Glucose und 1mM Glutamin

- Plasma

- Thrombin.

\subsection{Mäuse}

Die Tierversuche wurden mit Genehmigung der Bezirksregierung Braunschweig unter Einhaltung des Tierschutzgesetzes in der zentralen tierexperimentellen Einrichtung der Universität Göttingen durchgeführt.

Die Mäuse wurden in normalen Tierkäfigen in einem Raum unter konstanten Temperatur- und Feuchtigkeitsverhältnissen gehalten, hatten freien Zugang zu Futter und Wasser und unterlagen einem 12-Stunden-Licht- und 12-Stunden-Dunkel- Zyklus.

Die Experimente wurden an den Wildtyp-Mäusen C57BL6 für die Infektion mit S. pneumoniae und $E$. coli und SJL-NBOM-Mäuse für die Infektion mit HSV durchgeführt. Als mutante Mäuse wurden Mäuse mit Mutationen in den TLR2-, TLR4und TLR9-Genen verwendet.

Die TLR9-/-Maus ist eine Maus, in der das leucinreiche Fragment (LRR) des TLR9 durch ein Neomycin-Resistenz-Gen der Länge von 1,0 kb ersetzt wurde. Der TLR9 in mutanten Mäusen ist so groß wie bei Wildtypen. Im Northern Blot von mRNA aus der Milz der mutanten Mäuse wurden niedrigere Expressionen von TLR9 im Vergleich mit Wildtypen beobachtet. Das Vorhandensein von Neomycin-Resistenz-Gen wurde aber bewiesen.

In der TLR4-defizienten Maus (C3H/HEJ) ist eine Punktmutation auf Chromosom 4 an der Stelle des Gens Lps, welches das TLR4-Transkript codiert, vorhanden. Die Mutation bewirkt eine Substitution von Histidin an der Stelle von Prolin. 
Bei der TLR2-/-Mäusen fehlt das codierende Gen des TLR2.

\subsection{Organotypische Hippokampuskulturen}

Von 5 bis 7 Tage alten Mäusen wurde nach Dekapitation die Hippokampusformation aus dem Gehirn präpariert. Diese wurde mit einem Schneidegrät (Mcllwain tissue chopper) in $400 \mu \mathrm{m}$ dicke transversale Scheiben geschnitten und in GBSS (Grey's balanced salt solution) mit $36 \mathrm{mM} \mathrm{D-Glucose} \mathrm{und} 2 \mathrm{mM} \mathrm{MgSO}_{4}$ in $4^{\circ} \mathrm{C}$ für 30 Minuten gehalten. Die Scheiben wurden in Plasma auf Coverslips gebettet und durch Thrombinzugabe koaguliert. Die Coverslips wurden in Kulturröhrchen mit $1 \mathrm{ml}$ Medium transferiert. Das Medium beinhaltete 50 \% BME (Eagle's basal medium), $25 \%$ HBSS (Hanks' balanced salt solution), $25 \%$ Hitze-inaktiviertes Pferdeserum mit $1 \mathrm{mM}$ Glutamin und $36 \mathrm{mM}$ D-Glucose. Die Kulturröhrchen wurden für zwei Wochen bei $36^{\circ} \mathrm{C}$ mit leichter Rotationsbewegung in einem luftventilierten Inkubator inkubiert. Das Medium wurde zweimal in der Woche gewechselt.

\subsection{Infektionen}

\subsubsection{Infektion mit S. pneumoniae}

Die Mäuse wurden mit $100 \mathrm{mg} / \mathrm{kgKG} \mathrm{Ketamin}+10 \mathrm{mg} / \mathrm{kgKG}$ Xylazin intraperitoneal narkotisiert. $\quad 1 \times 10^{4} \mathrm{CFU} / \mathrm{ml} \quad$ (Kolonie-bildende Einheiten) von Streptococcus pneumoniae Typ 3 in 12,5 $\mu$ l steriler 0,9\%iger $\mathrm{NaCl}$-Lösung wurde in ihren rechten Frontalkortex injiziert. Den Mäusen der Kontrollgruppe wurden unter gleicher Anästhesie 12,5 $\mu$ steriler 0,9\%iger NaCl-Lösung injiziert. Die Testgruppe entwickelte innerhalb von 24 Stunden Krankheitssymptome. 36 Stunden nach der Injektion wurden die Mäuse getötet (Dekapitation). Gehirn und Milz wurden in flüssigem Stickstoff eingefroren und bei $-80^{\circ} \mathrm{C}$ für die RNA-Isolierung aufbewahrt. TLR9-defiziente Mäuse wurden mit 12,5 $\mu$ l einer Bakteriensuspension mit Konzentration $1 \times 10^{3} \mathrm{CFU} / \mathrm{ml}$ infiziert. 


\subsubsection{Behandlung der organotypischen Hippokampuskulturen (OTC) mit Hitze-inaktivierten Pneumokokken R6 (hiR6) ${ }^{1}$}

Hitze-inaktivierte Pneumokokken R6 (hiR6):

Apathogene Pneumokokken R6 wurden über Nacht bei $37^{\circ} \mathrm{C}$ in TSB (tryptic soy broth) bis zur mittellogarithmischen Phase kultiviert. Die Zellen wurden zentrifugiert, in steriler $0,9 \%$ iger $\mathrm{NaCl}$-Lösung gewaschen und im Wasserbad bei $80^{\circ} \mathrm{C}$ für 20 Minuten inaktiviert. Dabei werden die Bakterien getötet und das Autolysin inaktiviert. Die Hitze-inaktivierten Pneumokokken wurden in einer Konzentration von $1 \times 10^{8} \mathrm{CFU} / \mathrm{ml}$ für die Stimulation der Hippokampuskulturen verwendet.

Die zwei Wochen alten Kulturen [(Organotypische Hippokampuskulturen - (OTC)] wurden für 48 Stunden mit Hitze-inaktivierten Pneumokokken R6 (hiR6) bzw. mit dem sterilen Medium stimuliert. Danach wurde RNA mit Trizolreagenz aus den Kulturen isoliert, in cDNA umgeschrieben und die Konzentration von TLR 2, 3, 4, 7 und 9 wurde bestimmt.

\subsubsection{Infektion mit E. coli}

Für Meningitis mit Escherichia coli wurde unter der gleichen Anästhesiemethode $1 \times 10^{6} \mathrm{CFU}$ von E. coli ATCC29922 in $12,5 \mu$ l sterilem $0,9 \%$ igem $\mathrm{NaCl}$ in den rechten Frontalkortex der Mäuse injiziert. Die Kontrollgruppe wurde wie bereits beschrieben mit steriler 0,9\%iger $\mathrm{NaCl}$-Lösung behandelt. Innerhalb von 24 Stunden entwickelten die Mäuse in der Testgruppe Krankheitssymptome. Nach 30 Stunden wurden sie getötet. Die TLR2-defizienten Mäuse wurden mit 12,5 $\mu \mathrm{l}$ einer Bakteriensuspension mit Konzentration $1 \times 10^{7} \mathrm{CFU} / \mathrm{ml}$ infiziert. 


\subsubsection{Infektion mit Herpes-simplex-Virus}

Weibliche SJL-NBOM-Mäuse (Bomholdgard Breeding and Research Center, DK 8680 Ry, Denmark) wurden mit Äther narkotisiert. $20 \mu$ l Suspension von Herpes simplex Virus Typ 1 (entspricht $10^{5}$ plaque forming units) wurden bei der Testgruppe intranasal injiziert. Die Kontrollgruppe wurde unter gleichen Bedingungen mit steriler 0,9\%iger $\mathrm{NaCl}$-Lösung behandelt. 7 Tage nach Inokulation wurden die Mäuse getötet. Gehirn und Milz wurden mikrochirurgisch entnommen und eingefroren.

\subsection{RNA}

\subsubsection{RNA-Extraktion}

RNA-Isolierung aus eingefrorenem Gewebe mit Trizol-Reagenz: 50-100 mg Gewebe (Gehirn oder Milz) wurden in $1 \mathrm{ml}$ Trizol-Reagenz homogenisiert. Das Homogenat wurde für 5 min bei Raumtemperatur $\left(15-30^{\circ} \mathrm{C}\right)$ inkubiert.

0,2 $\mathrm{ml}$ Chloroform wurden dazugegeben und für 15 Sekunden manuell gemischt. Nach 2-3 min Inkubation bei Raumtemperatur wurden die Proben bei $2-8{ }^{\circ} \mathrm{C}$ mit $12.000 \mathrm{~g}$ für 15 min zentrifugiert. Nach der Zentrifugation waren drei Phasen zu unterscheiden: eine untere rötliche Phenol-Chloroform Phase, eine mittlere weißliche Phase mit den Proteinen und eine obere wässrige Phase mit der RNA.

Die obere wässrige Phase wurde vorsichtig abgenommen, mit $0,5 \mathrm{ml}$ Isopropylalkohol versetzt und für 10 min bei Raumtemperatur inkubiert. Anschließend wurden die Proben 10 min mit $12.000 \mathrm{~g}$ bei $2-8^{\circ} \mathrm{C}$ zentrifugiert.

Die RNA setzte sich als sichtbares weißes Pellet ab. Nach der Entfernung der oberen Phase wurde das Pellet mit $1 \mathrm{ml} 75$ \%igem Äthylalkohol gewaschen und erneut bei 2$8^{\circ} \mathrm{C}$ für 5 Minuten mit $12.000 \mathrm{~g}$ zentrifugiert.

Danach wurde die Äthylalkoholphase vorsichtig aber vollständig entfernt. Das RNAPellet wurde luftgetrocknet, in $100 \mu \mathrm{l}$ RNAse-freiem Wasser $\left(\mathrm{DEPC}-\mathrm{H}_{2} \mathrm{O}\right)$ gelöst und 
bei $-80^{\circ} \mathrm{C}$ gelagert.

RNA-Extraktion aus Organotypischen Hippokampuskulturen wurde ebenso mit Trizolreagenz durchgeführt.

In der Versuchsreihe HSV-Enzephalitis wurde RNA mit RNA Clean (AGS, Heidelberg, Germany) extrahiert und mit einen RNA Core Kit (Applied Biosystem, Weiterstadt, Germany) durch reverse Transkription (RT-PCR) in cDNA umgeschrieben.

\subsubsection{Qualitative Kontrolle der RNA mittels Gel-Elektrophorese}

0,6 $\mathrm{g}$ Agarose wurden in $50 \mathrm{ml} 1$ x TBE-Puffer durch Aufkochen in der Mikrowelle gelöst. $1 \mu \mathrm{l}$ Ethidiumbromid wurde dazugegeben und in eine Gelkammer mit eingesetztem Kamm gegossen (1,2\%iges Agarosegel).

$1 \mu$ extrahierte RNA-Lösung und $2 \mu$ l Ladepuffer wurden gemischt und auf das Gel aufgetragen. Die RNA wurde bei 80 Volt elektrophoretisch getrennt und anschließend unter UV-Strahlung qualitativ überprüft.

Der Gel-Elektrophorese liegt folgendes Perinzip zu Grunde: Die in neutralem Milieu negativ geladenen Nukleinsäuren wandern bei Anlegung eines elektrischen Feldes zur Anode, wobei die kleineren Fragmente schneller und die größeren langsamer wandern. So trennen sich die Fragmente nach ihren Größen und werden als verschiedene Banden auf dem Gel durch UV-Licht sichtbar.

\subsubsection{Konzentrationsbestimmung der RNA-Lösung}

Die Konzentration der RNA-Probe wurde photometrisch bestimmt (Bio-Photometer Eppendorf).

Das Photometer misst die Lichtabsorption der Proben in einem bestimmten Wellenlängenbereich. Die RNA absorbiert UV-Strahlung bei einem Absorptionsmaximum von $260 \mathrm{~nm}$. Die Extinktion bei $260 \mathrm{~nm}$ wird mit einem Faktor multipliziert. Dieser Faktor beträgt 40,0 für RNA. Die Konzentration wird in $\mu \mathrm{g} / \mathrm{ml}$ 
angegeben. Wenn die Probe verdünnt ist, muss der Verdünnungsfaktor berücksichtigt werden. Zur Bestimmung der Konzentration wurde $1 \mu \mathrm{l}$ RNA-Lösung mit $99 \mu \mathrm{l}$ RNasefreiem Wasser gemischt.

$$
\begin{aligned}
& \mathbf{c}=\mathbf{E} 260 \times \mathbf{F} \\
& \mathbf{c}=\text { Konzentration }(\mu \mathrm{g} / \mathrm{ml}) \\
& \text { E260 = Extinktion bei } 260 \mathrm{~nm} \\
& F=\text { Faktor }(40 \text { für RNA, } 50 \text { für dsDNA) }
\end{aligned}
$$

Zur Eichung (Leerwert) wird Wasser verwendet. Die Schichtdicke der Küvette beträgt $10 \mathrm{~mm}$.

Zusätzlich zum Konzentrationsergebnis und der Extinktion bei der Messwellenlänge $260 \mathrm{~nm}$ werden als Anhaltspunkte für die Reinheit der gemessenen Nukleinsäureprobe die Extinktionen bei 280 und 320 nm, sowie der Quotient E260/E280 angezeigt. Dieser Quotient sollte zwischen 1,8 und 2,2 liegen. Die Extinktion bei $320 \mathrm{~nm}$ sollte bei reinen Proben nahe Null liegen.

Berechnung:

Verdünnungsfaktor: 100

Umrechnungsfakor $\mu \mathrm{g} / \mathrm{ml}$ zu $\mu \mathrm{g} / \mu \mathrm{l}: \quad 1 / 1000$

Extinktion in $260 \mathrm{~nm} \times 100 \times 40 \times 1 / 1000=$ Konzentration $(\mu \mathrm{g} / \mu \mathrm{l})$ 


\subsection{Reverse Transkription}

Omniskript ${ }^{\mathrm{TM}} \mathrm{RT}$ Qiagen Kit

$2 \mu \mathrm{g}$ RNA (entspricht $\mathrm{X} \mu \mathrm{l}$ RNA-Lösung) wurden mit DEPC-Wasser verdünnt. Gewünschtes Volumen:12 $\mu \mathrm{l}$

RT-Mix pro Probe

Material

Konzentration

Menge

RT-Puffer
dNTP-Mix
Random Primers
RNasin
(RNase-inhibitor 40 U/ $/$ I)
wurde vor dem Versuch 1:4
mit DEPC-Wasser verdünnt

ReverseTranskriptase

$4 \mathrm{U} / \mu \mathrm{l}$

$1 \mu \mathrm{l}$ (entspricht $4 \mathrm{U})$

$$
\Sigma=8 \mu l
$$

$12 \mu \mathrm{l}$ RNA-Lösung und $8 \mu \mathrm{l}$ RT-Mix wurden gemischt, kurz zentrifugiert und 60 Minuten bei $37^{\circ} \mathrm{C}$ inkubiert. Danach wieder kurz zentrifugiert und 5 min bei $93^{\circ} \mathrm{C}$ inkubiert (Cycler Biometra, UNO-Thermoblock).

Die cDNA wurde mit $80 \mu \mathrm{l}$ Wasser verdünnt und bei $-20^{\circ} \mathrm{C}$ bis zur Weiterverarbeitung gelagert. 


\subsection{PCR, Reverse-Transkriptase-PCR und Real-Time-PCR}

\subsubsection{Mechanismus der PCR und Reverse-Transkriptase-PCR}

Bei der PCR (Polymerase Chain Reaction) werden die nachzuweisenden spezifischen Nukleinsäuresequenzen vor der abschließenden Detektion enzymatisch amplifiziert. Das Reaktionsprinzip besteht in der Wiederholung eines zyklischen Reaktionsablaufs, dessen Einzelschritte bei genau definierten Temperaturen durchgeführt werden.

Zuerst wird die zu untersuchende doppelsträngige DNA denaturiert. An die nun vorliegenden Einzelstränge lagern sich die für die gesuchte Nukleinsäuresequenz spezifischen Oligonukleotide (Primer) an (Annealing). Im nächsten Reaktionsschritt werden die Primer dann an ihrem 3'-Ende von einer thermostabilen Polymerase (z. B. Taq-Polymerase) komplementär zur Matrix verlängert (Elongation). Die Reaktionsschritte Denaturierung, Annealing und Elongation werden nun ca. 30mal wiederholt. Die gesuchte Nukleinsäuresequenz wird dadurch exponenziell vervielfacht, da jeder von der Polymerase neu synthetisierte Nukleinsäurestrang in der folgenden Reaktion als neue Matrix genutzt werden kann.

In Reverse-Transkriptase-PCR (RT-PCR) wird mit Hilfe der Reversen Transkriptase ein zu der RNA komplementärer DNA-Strang (cDNA) hergestellt (s. Kap. 2.6 Reverse Transkription).

Zum Mechanismus des Real-Time-PCR siehe Kap. 2.7.5.

\subsubsection{Primer}

TLR2 Vorwärts: 5 '-aaa atg tcg ttc aag gag-3'

Rückwärts: $\quad 5$ '-ttg ctg aag agg act gtt-3'

TLR3 Vorwärts: $\quad 5^{\prime}$-act tgc tat ctt gga tgc-3'

Rückwärts: $\quad$ ' '-agt tct tca ctt cgc aac-3' 


$\begin{array}{lll}\text { TLR4 } & \text { Vorwärts: } & 5^{\prime} \text {-cct gat gac att cct tct-3' } \\ & \text { Rückwärts: } & 5^{\prime} \text {-agc cac cag att ctc taa-3' } \\ \text { TLR7 } & \text { Vorwärts: } & 5^{\prime} \text {-tga ctc tct tct cct cca-3' } \\ & \text { Rückwärts: } & 5^{\prime} \text {-gct tcc agg tct aat ctg-3' } \\ & & \\ \text { TLR9 } & \text { Vorwärts: } & 5^{\prime} \text {-ggt gtg gaa cat cat tct-3' } \\ & \text { Rückwärts: } & 5^{\prime} \text {-ata cgg ttg gag atc aag-3' }\end{array}$

Primer für GAPDH Vorwärts: 5'-ggt cta cat gtt cca gta tg-3'

Rückwärts: 5 '-tgg aag atg gtg atg ggc tt-3'

Die Größe der Produkte:
trr2: $211 \mathrm{bp}$
trr3: $345 \mathrm{bp}$
trr4: $255 \mathrm{bp}$
tlr7: $421 \mathrm{bp}$
trr9: $294 \mathrm{bp}$

\subsubsection{Standardherstellung und Isolierung aus Gel}

Um in der Real-Time-PCR die Konzentration der CDNA zu bestimmen, brauchten wir verschiedene Standard-Konzentrationen jedes zu bestimmenden Templates. So mussten wir eine Standardprobe mit bekannter Konzentration der CDNA jedes TLR herstellen. Mit cDNA aus der Wildtyp-Maus führten wir PCRs mit spezifischen Primern für jeden TLR durch. Das amplifizierte Fragment wurde auf einem Agarosegel elektrophoretisch von anderen unerwünschten Fragmenten getrennt. Im Vergleich mit einem Größenstandard wurde die gewünschte Bande von dem Gel herausgeschnitten und gereinigt (s. Gelextraktion). Die Konzentration des hergestellten TLR-Standards wurde bestimmt.

$1 \mu \mathrm{l}$ cDNA von einer Maus (Wildtyp) wurde mit den spezifischen Primern den jeweiligen TLR in der PCR eingesetzt. 
Verdünnung von Primer (z. B. spezifischer Primer für TLR2)

Material

Menge

Vorwärtsprimer

$10 \mu \mathrm{l}$

Rückwärtsprimer

$10 \mu \mathrm{l}$

DEPC- $\mathrm{H}_{2} \mathrm{O}$

$80 \mu \mathrm{l}$

$\Sigma=100 \mu \mathrm{l}$

PCR-Ansatz

Material

Konzentration

Menge

cDNA

$1 \mu \mathrm{l}$

Puffer (Invitrogen)

10fach

$5 \mu \mathrm{l}$

$\mathrm{MgCl}_{2}$ (Invitrogen)

$50 \mathrm{mM}$

$2 \mu \mathrm{l}$

dNTPs (Invitrogen)

$5 \mathrm{mM}$

$0,4 \mu \mathrm{l}$

Taq DNA Polymerase

$5 \mathrm{U} / \mu \mathrm{l}$

$0,5 \mu \mathrm{l}$

$500 \mathrm{U}$ (Invitrogen)

spezifischer Primer für TLR

$2 \mu l$

von hergestellter Lösung

(entspricht Vorwärts- und

Rückwärtsprimer je

(s.o.)

20 pMol) 
Die Produkte der PCRs der TLR und GAPDH (cDNA) wurden auf 2,5\%ige Gele aufgetragen und elektrophoretisch getrennt. Die gewünschten Banden wurden aus dem Gel herausgeschnitten. Die Fragmente auf dem Stück Gel wurden isoliert und als Standard-Template in Real-Time-PCR verwedet.

\section{Vorbereitung des Gels}

1,8 $\mathrm{g}$ Agarose in $70 \mathrm{ml}$ TBE-Puffer wurde in der Mikrowelle aufgekocht, mit 2,5 $\mu \mathrm{l}$ Ethidiumbromid gemischt und in eine Gelkammer mit eingesetztem Kamm gegossen (2,5 \%iges Agarosegel).

\section{Gel-Extraktion (QIA quick):}

Das Gelstück wurde in 6fachem Volumen von Puffer QG (für $1 \mu \mathrm{g}$ Gel $6 \mu$ l Puffer QG) im Wasserbad (Termperatur $50^{\circ} \mathrm{C}$ ) bis zum vollständigen Lösen inkubiert, mit gleichem Volumen Isopropanol ( $1 \mu \mathrm{l}$ Isopropanol für $1 \mu \mathrm{g} \mathrm{Gel})$ versetzt, auf ein „QIA quick spin column $2 \mu$ l collection tube“ gegeben und eine Minute bei $20.000 \mathrm{~g}$ zentrifugiert (nur $800 \mu \mathrm{l}$ Lösung auf eine Säule; im Falle einer höheren Menge Lösung wird die Prozedur solange wiederholt, bis die gesamte Lösung auf die Säule aufgetragen ist). Danach wurden $500 \mu$ l Puffer QG auf die Säule gegeben und zentrifugiert.

Anschließend wurden $750 \mu$ PE-Puffer auf die Säule gegeben und nach einer Minute Inkubation bei Raumtemperatur zentrifugiert.

Im letzten Schritt wurden $50 \mu \mathrm{l}$ Wasser auf die Säule gegeben, 5-10 Minuten bei Raumtemperatur inkubiert und zentrifugiert. Die cDNA war nun im Wasser gelöst und vom Gel vollständig getrennt.

Die Konzentration der Standardlösung wurde wie bei der RNA-Lösung bestimmt und berechnet ( $1 \mu \mathrm{l}$ Standard-Lösung $+99 \mu \mathrm{l}$ Wasser). Nähere Ausführungen siehe Kap. 2.5.3 Konzentrationsbestimmung der RNA-Lösung. 
Berechnung:

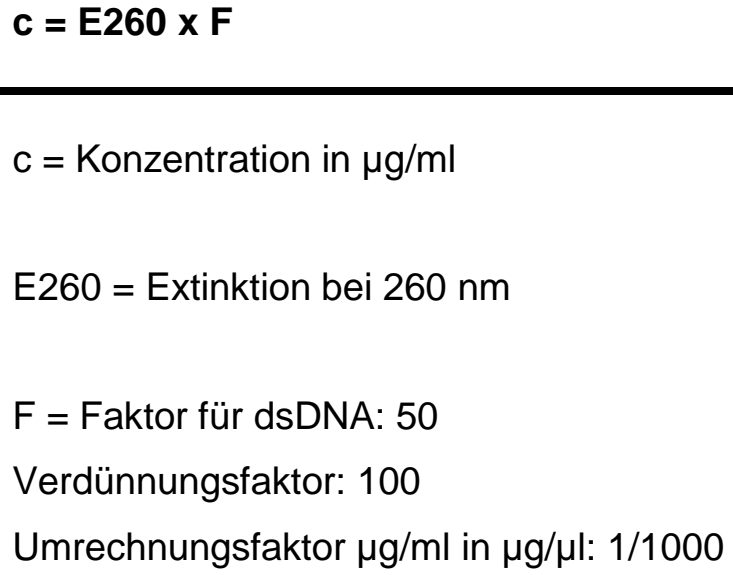

Von den Standardlösungen eines jeden TLR wurden Konzentrationen von $1 \mathrm{ng}$, $100 \mathrm{pg}, 10 \mathrm{pg}, 1 \mathrm{pg}, 100 \mathrm{fg}$ und $10 \mathrm{fg}$ pro $5 \mu \mathrm{l}$ Lösung hergestellt. In jeder Real-Time-PCR wurden $5 \mu \mathrm{l}$ Standardlösung eingesetzt.

Zur Größe der Produkte siehe Kap. 2.7.2 Primer.

\subsubsection{PCR-Mix und Protokolle für Standardherstellung}

PCR-Mix: (s. Kap. 2.7.3 PCR-Ansatz)

PCR-Programm für TLR2, TLR3, TLR4 und TLR9

1. Schritt: $2 \min \quad 94^{\circ} \mathrm{C}$

2. Schritt: $\quad 30 \mathrm{sec} \quad 94^{\circ} \mathrm{C}$

$30 \mathrm{sec} \quad 52^{\circ} \mathrm{C}$

$30 \mathrm{sec} \quad 72^{\circ} \mathrm{C} \quad$ (2. Schritt 35 Zyklen)

3. Schritt: $\quad 10 \mathrm{~min} \quad 72^{\circ} \mathrm{C}$ 


\section{PCR-Programm für TLR7}

1. Schritt: $2 \min \quad 94^{\circ} \mathrm{C}$

2. Schritt: $\quad 30 \mathrm{sec} \quad 94^{\circ} \mathrm{C}$

$30 \mathrm{sec} \quad 54^{\circ} \mathrm{C}$

$30 \mathrm{sec} \quad 72^{\circ} \mathrm{C} \quad$ (2. Schritt 35 Zyklen)

3. Schritt: $10 \mathrm{~min} \quad 72^{\circ} \mathrm{C}$

PCR-Programm für Housekeeping-Gen GAPDH

1. Schritt: $2 \min \quad 94^{\circ} \mathrm{C}$

2. Schritt: $\quad 30 \mathrm{sec} \quad 94^{\circ} \mathrm{C}$

$30 \mathrm{sec} \quad 60^{\circ} \mathrm{C}$

$30 \mathrm{sec} \quad 72^{\circ} \mathrm{C} \quad$ (2.Schritt 35 Zyklen)

3. Schritt: $10 \mathrm{~min} \quad 72^{\circ} \mathrm{C}$

\subsubsection{Real-Time-PCR}

Mechanismus der Real-Time-PCR:

Real-Time-PCR dient der quantitativen Bestimmung der cDNA in einer Probe. Dabei wird Fluoreszenz-emittierendes SYBR-Green verwendet. Bei der Elongation lagert sich SYBR-Green kontinuierlich in die Furchen der doppelsträngigen DNA ein, wodurch die Fluoreszenzintensität ansteigt. Die Intensität des Fluoreszenzsignals (y-Achse) wird in Relation zur Zahl der Zyklen (x-Achse) in einer Kurve gezeichnet. 


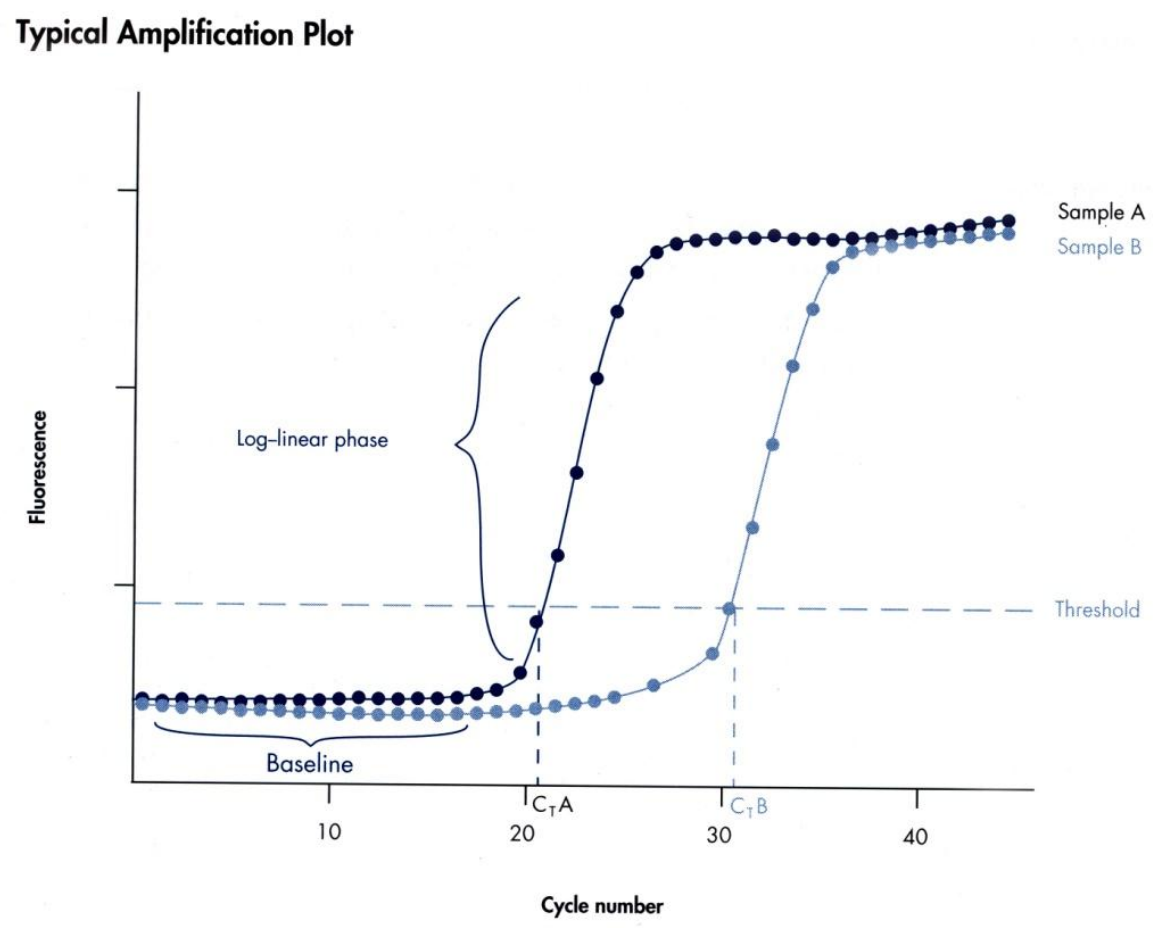

Abbildung 4: $\quad$ Fluoreszenzintensität in Abhängigkeit von der Zahl der Zyklen in der Real-Time-PCR (QuantiTect SYBR Green PCR Handbook 2003, S.31, Qiagen ${ }^{2}$ )

Das Fluoreszin dient der Eichung des Gerätes (iCycler, Bio-Rad) vor Beginn der PCR. Die flache Phase in der Anfangsphase der PCR (meistens zwischen dem 3. und 15. Zyklus) entspricht ungefähr der Fluoreszenzintensität vor Beginn der PCR (Elongation). In der Phase wird kein Anstieg des Fluoreszenzsignals detektiert (Baseline). Danach wird eine deutlich starke und schnelle Anhebung der Fluoreszenzintensität als eine lineare Phase der Kurve detektiert. In der Phase legt der Untersucher eine Schwelle fest, in der die lineare Phase anfängt (threshold). Die Intensität des Signals bei dem Schwellenwert für jede Probe (auf der y-Achse) ist der übernommene Wert für die Berechnung der Konzentration der Template in der Startzeit. Auf der x-Achse zeigt der Schwellenwert die Zahl der Zyklen, in der dieses Signal erreicht wurde $\left(\mathrm{C}_{\mathrm{T}}\right)$.

Zu verschiedenen Zeitpunkten erreichen die Proben dann die Plateauphase. Diese ist 
für die Konzentrationsbestimmung ungeeignet.

Standardgerade:

Um von der Signalintensität auf eine bestimmte Konzentration zu schließen, müssen Standards mit bekannten Konzentrationen unter gleichen Bedingungen in PCR eingesetzt werden. Wir haben jeweils eine Reihe der Standard-Templates mit bekannten Konzentrationen, nämlich: $1 \mathrm{ng}, 100 \mathrm{pg}, 10 \mathrm{pg}, 1 \mathrm{pg}, 100 \mathrm{fg}$ und $10 \mathrm{fg}$ eingesetzt. Das Standard- und das zu bestimmende Test-Template waren jeweils identisch, zum Beispiel wurden zur Bestimmung der TLR2-cDNA Standard-cDNA von TLR2 eingesetzt (s. Standardherstellung).

Jede Standardkonzentration erreicht in bestimmten Zykluszahlen den Schwellenwert (CT). Die CT-Werte aus verschiedenen Konzentrationen haben eine lineare Beziehung zur Konzentration der cDNA im Startzeitpunkt. Anhand dieser Auswertung wurde eine Standardgerade erstellt. Die Konzentration der cDNA im Zeitpunkt 0 für jede Testprobe wurde anhand dieser Standardgeraden bestimmt.

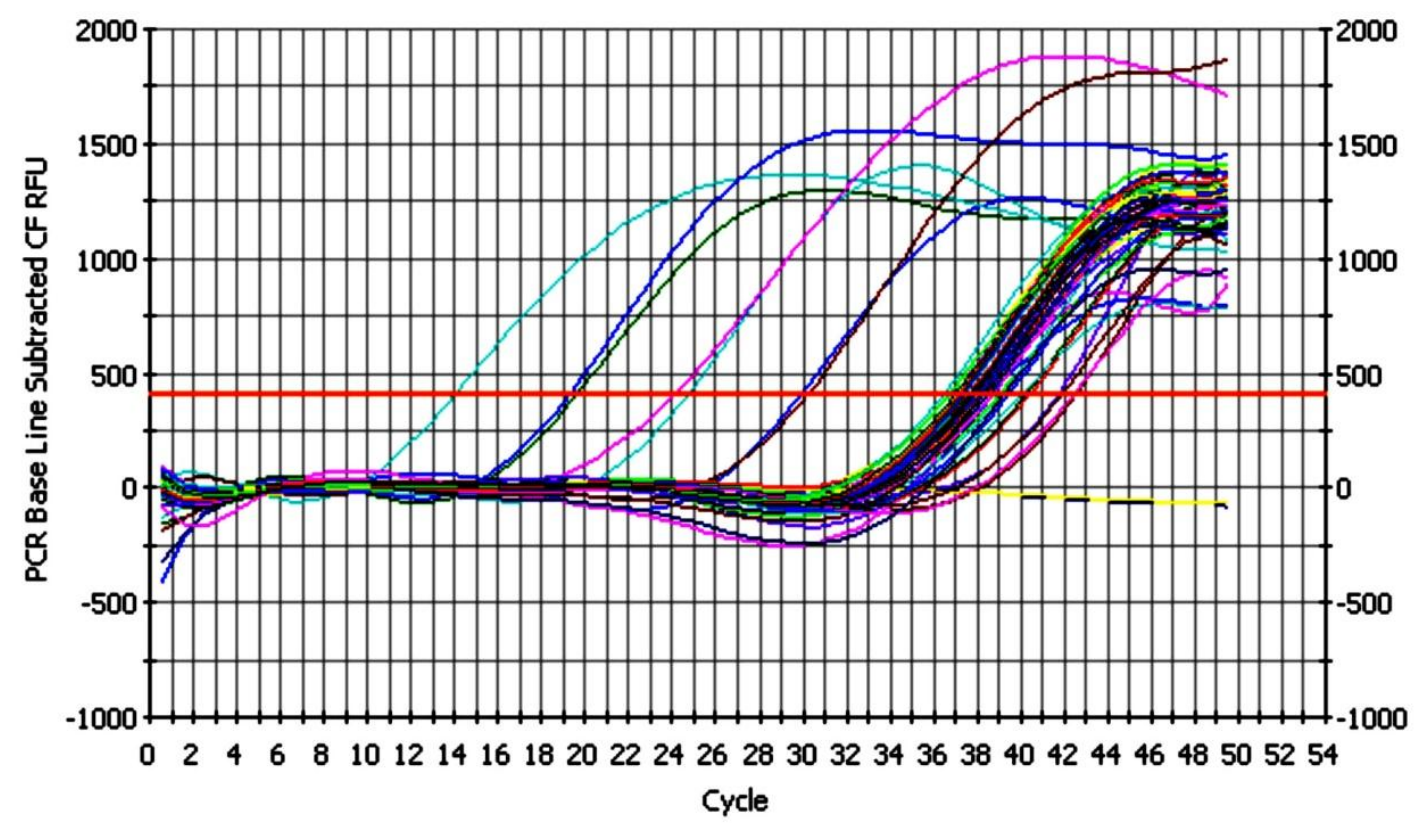

Abbildung 5: Befundbeispiel der Standardreihe und Testproben in Real-Time-PCR (selbsterstellte Graphik auf der Grundlage selbsterhobener Daten) 
Schmelzkurve:

Mit Hilfe der Schmelzkurve wird kontrolliert, ob nur die gewünschte cDNA oder auch weitere DNA-Fragmente amplifiziert wurden. Am Ende eines PCR-Laufes (4. Schritt) wird die Temperatur in 10 Sekundenschritten je $0,5^{\circ} \mathrm{C}$ erhöht (von $55^{\circ} \mathrm{C}$ bis $95^{\circ} \mathrm{C}$ ). Die Denaturierung der Produkte verursacht eine Senkung der detektierten Fluoreszenzintensität. In der Schmelzkurve wird nach einer Steigung der Fluoreszenzemission ein schneller Abfall der Signale detektiert. Der Abfall der Detektion ist durch die Denaturierung der Produkte bedingt. Die Schmelzkurve hat den Peak bei einer Temperatur, die für jedes Produkt spezifisch ist. So wird jedes andere versehentlich amplifizierte Produkt auf der Kurve sichtbar und erkannt. 


\section{Melting Curve Analysis}

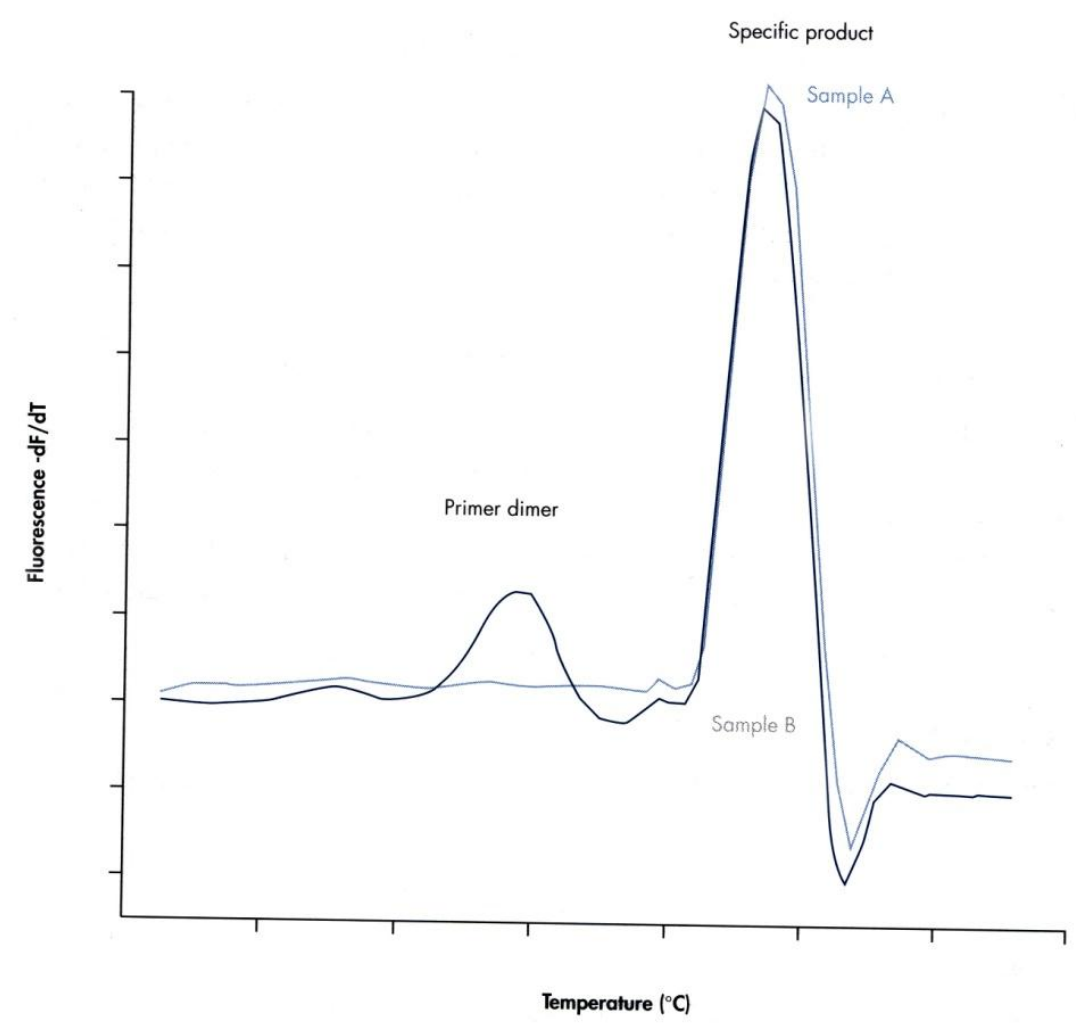

Abbildung 6: Schmelzkurve (Quantitect SYBR Green PCR Handbook 2003, S. 33, Qiagen ${ }^{3}$ )

Housekeeping Gen:

In allen eukaryontischen Zellen wird das Gen GAPDH (Glycerin-Aldehyd-PhosphatDehydrogenase) etwa gleich stark synthetisiert. Aus jeder cDNA-Probe setzten wir eine PCR mit GAPDH-Primer der Maus an.

Um die Ergebnisse aus verschiedenen Proben miteinander vergleichen zu können, dividierten wir die berechnete TLR-Konzentration in jeder Probe durch die GAPDH-Konzentration in der gleichen Probe: TLRx/GAPDH

3 Qiagen, Qiagen Strasse 1, 40724 Hilden, Germany. 
Durchführung der Real-Time-PCR

Real-Time-PCR wurde im Bio-Rad iCycler System durchgeführt.

PCR-Mix:

Material

Konzentration

Menge

Qiagen Quantitect Master

$12,5 \mu \mathrm{l}$

Mix

$\begin{array}{ll}\text { FITC (Fluorescin calibration } & 1: 10.000 \text { verdünnt mit } \\ \text { Dye1 mM in DMSO, Bio } & \text { RNasefreiem Wasser } \\ \text { Rad) } & \end{array}$

RNasefreies Wasser $\quad 5,3 \mu \mathrm{l}$

Primer (spezifisch für jede

$0,2 \mu \mathrm{l}=2 \mathrm{pMol}$

TLR vorbereitete Lösung)

Primervorbereitung:

$10 \mu l$ Vorwärtsprimer

$10 \mu$ l Rückwärtsprimer

$80 \mu \mathrm{LEPC}-\mathrm{H}_{2} \mathrm{O}$

Gesamt: $100 \mu \mathrm{l}$

Template

$5 \mu \mathrm{l}$

(Test- oder

Standard-cDNA)

$$
\Sigma=25 \mu l
$$

Von jeder Template-cDNA wurden zwei Ansätze hergestellt. In der Auswertung wurde der Mittelwert von zwei Ansätzen genommen. 


\section{PCR-Protokoll für TLR2:}

1. Schritt: $15 \min 94^{\circ} \mathrm{C}$

2. Schritt: $\quad 30 \sec 94^{\circ} \mathrm{C}$

$30 \sec 52^{\circ} \mathrm{C}$

$30 \sec 72^{\circ} \mathrm{C}$

$20 \sec 79,5^{\circ} \mathrm{C}$

(2. Schritt 50 Zyklen)

3. Schritt: $\quad 30 \sec 94^{\circ} \mathrm{C}$

4. Schritt: $\quad 10 \mathrm{sec} 55^{\circ} \mathrm{C}$ (Nach 10 Sekunden wird die Temperatur um $0,5^{\circ} \mathrm{C}$ erhöht und wieder 10 Sekunden in der Temperatur gehalten. Die Prozedur wird $80 \mathrm{Mal}$ bis $95^{\circ} \mathrm{C}$ wiederholt. In diesem Schritt wird die Schmelzkurve erstellt.)

\section{PCR-Protokoll für TLR3:}

1. Schritt: $15 \min 94^{\circ} \mathrm{C}$

2. Schritt: $\quad 30 \sec 94^{\circ} \mathrm{C}$

$30 \sec 52^{\circ} \mathrm{C}$

$30 \sec 72^{\circ} \mathrm{C}$

$20 \mathrm{sec} 77^{\circ} \mathrm{C} \quad$ (2. Schritt 60 Zyklen)

3. Schritt: $\quad 30 \sec 94^{\circ} \mathrm{C}$

4. Schritt: $\quad 10 \mathrm{sec} 55^{\circ} \mathrm{C}$ (nach 10 Sekunden wird die Temperatur um $0,5^{\circ} \mathrm{C}$ erhöht und wieder 10 Sekunden in der Temperatur gehalten. Die Prozedur wird $80 \mathrm{Mal}$ bis $95^{\circ} \mathrm{C}$ wiederholt. In diesem Schritt wird die Schmelzkurve erstellt.)

\section{PCR-Protokoll für TLR4:}

1. Schritt: $\quad 15 \min 94^{\circ} \mathrm{C}$ 
2. Schritt: $\quad 30 \sec 94^{\circ} \mathrm{C}$

$30 \sec 52^{\circ} \mathrm{C}$

$30 \sec 72^{\circ} \mathrm{C}$

$20 \sec 77^{\circ} \mathrm{C} \quad$ (2. Schritt 60 Zyklen)

3. Schritt: $\quad 30 \sec 94^{\circ} \mathrm{C}$

4. Schritt: $\quad 10 \mathrm{sec} 55^{\circ} \mathrm{C}$ (Nach 10 Sekunden wird die Temperatur um $0,5^{\circ} \mathrm{C}$ erhöht und wieder 10 Sekunden in der Temperatur gehalten. Die Prozedur wird $80 \mathrm{Mal}$ bis $95^{\circ} \mathrm{C}$ wiederholt. In diesem Schritt wird die Schmelzkurve erstellt.)

\section{PCR-Protokoll für TLR7:}

1. Schritt: $\quad 15 \min 94^{\circ} \mathrm{C}$

2. Schritt: $\quad 30 \sec 94^{\circ} \mathrm{C}$

$30 \sec 54^{\circ} \mathrm{C}$

$30 \sec 72^{\circ} \mathrm{C}$

$20 \sec 78^{\circ} \mathrm{C}$

(2. Schritt 50 Zyklen)

3. Schritt: $\quad 30 \sec 94^{\circ} \mathrm{C}$

4. Schritt: $\quad 10 \mathrm{sec} 55^{\circ} \mathrm{C}$ (Nach 10 Sekunden wird die Temperatur um $0,5^{\circ} \mathrm{C}$ erhöht und wieder 10 Sekunden in der Temperatur gehalten. Die Prozedur wird $80 \mathrm{Mal}$ bis $95^{\circ} \mathrm{C}$ wiederholt. In diesem Schritt wird die Schmelzkurve erstellt.)

\section{PCR-Protokoll für TLR9:}

1. Schritt: $\quad 15 \min 94^{\circ} \mathrm{C}$

2. Schritt: $\quad 30 \sec 94^{\circ} \mathrm{C}$

$30 \sec 52^{\circ} \mathrm{C}$

$30 \sec 72^{\circ} \mathrm{C}$

(2. Schritt 60 Zyklen) 
3. Schritt: $\quad 30 \sec 94^{\circ} \mathrm{C}$

4. Schritt: $\quad 10 \mathrm{sec} 55^{\circ} \mathrm{C}$ (Nach 10 Sekunden wird die Temperatur um $0,5^{\circ} \mathrm{C}$ erhöht und wieder 10 Sekunden in der Temperatur gehalten. Die Prozedur wird $80 \mathrm{Mal}$ bis $95^{\circ} \mathrm{C}$ wiederholt. In diesem Schritt wird die Schmelzkurve erstellt.)

\section{PCR-Protokoll für Housekeeping-Gen GAPDH:}

1. Schritt: $15 \min 94^{\circ} \mathrm{C}$

2. Schritt: $\quad 30 \sec 94^{\circ} \mathrm{C}$

$30 \sec 60^{\circ} \mathrm{C}$

$45 \sec 72^{\circ} \mathrm{C}$

$20 \mathrm{sec} 80^{\circ} \mathrm{C} \quad$ (2. Schritt 60 Zyklen)

3. Schritt: $\quad 30 \sec 94^{\circ} \mathrm{C}$

4. Schritt: $\quad 10 \sec 55^{\circ} \mathrm{C}$ (Nach 10 Sekunden wird die Temperatur um $0,5^{\circ} \mathrm{C}$ erhöht und wieder 10 Sekunden in der Temperatur gehalten. Die Prozedur wird $80 \mathrm{Mal}$ bis $95^{\circ} \mathrm{C}$ wiederholt. In diesem Schritt wird die Schmelzkurve erstellt.)

\subsection{Statistische Auswertung}

Die ausgewerteten Daten der Real-Time-PCR geben uns die Menge der jeweils untersuchten TLR-cDNA zum Startzeitpunkt der angesetzten Probe. Aus jeder Probe wurden zwei PCR-Röhrchen eingesetzt. Wir haben den Mittelwert der beiden Proben durch den Mittelwert aus den GAPDH-Proben der jeweiligen cDNA dividiert. Die Mediane (25./75. Perzentile) der ausgewerteten Daten wurde im Mann-Whitney U-Test den in gleicherweise ausgewerteten Daten aus den jeweiligen Kontrollgruppen in Säulengraphiken gegenübergestellt. $p<0,05$ wurde als signifikant definiert und mit * bzw. $p<0,01$ mit ${ }^{* *}$ und $p<0,001$ mit ${ }^{* * *}$ gekenzeichnet. 


\section{Ergebnisse}

\subsection{Regulation der TLR-mRNA in Gehirn und Milz von C57BL6-Mäusen nach intrazerebraler Infektion mit Streptococcus pneumoniae Typ $3^{4}$}

Um den Einfluss Gram-positiver bakterieller ZNS-Infektionen auf die Regulation der mRNA verschiedener TLR in Gehirn und Milz zu untersuchen, wurden die mRNA-Spiegel von TLR2, TLR3, TLR4, TLR7 und TLR9 in Gehirn und Milz von C57BL6-Mäusen nach intrazerebraler Infektion mit $S$. pneumoniae $(n=8)$ und von nicht infizierten Kontrollmäusen ( $n=8)$ miteinander verglichen.

Die S. pneumoniae-Meningitis/Sepsis führte zu einem Anstieg der mRNA-Expression von TLR2 (6-fach, $p=0,002$ ), TLR4 (2,2-fach, $p=0,003$ ) und TLR9 (4,6-fach, $p=0,002$ ) im Gehirn. Die Spiegel der mRNA von TLR3 und TLR7 im Gehirn von infizierten Mäusen und Kontrollmäusen unterschieden sich nicht signifikant (Abb.7: a u. b).

\footnotetext{
${ }^{4}$ Die Daten von TLR-Expression bei Meningitis-Enzephalitis in Wildtyp-Mäusen wurden in Aktuelle Neurologie 2003, 30, Supplement 1, Seite 63 als Poster (P326) veröffentlicht.

Teil der Daten des Kapitels 3.1. (die Daten der Bilder 7, 9, 10 und 12) wurden von anderen Autoren veröffentlicht (Böttcher et al. 2003).
} 


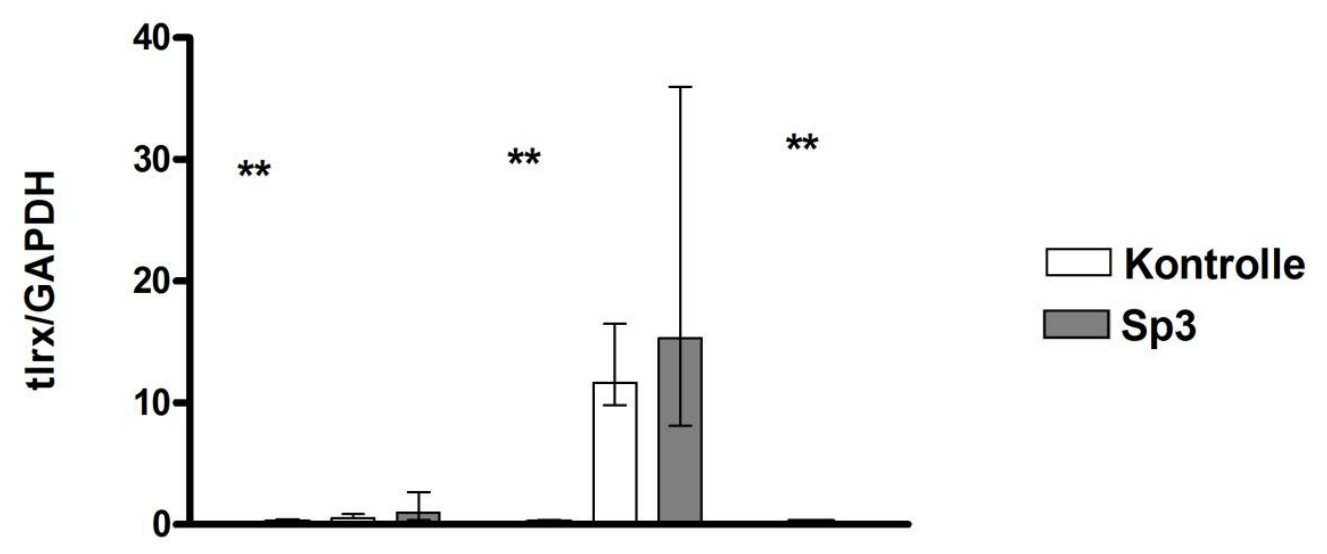

$\begin{array}{lllll}\operatorname{tIr} 2 & \operatorname{tIr} 3 & \operatorname{tIr} 4 & \operatorname{tlr} 7 & \operatorname{tIr} 9\end{array}$

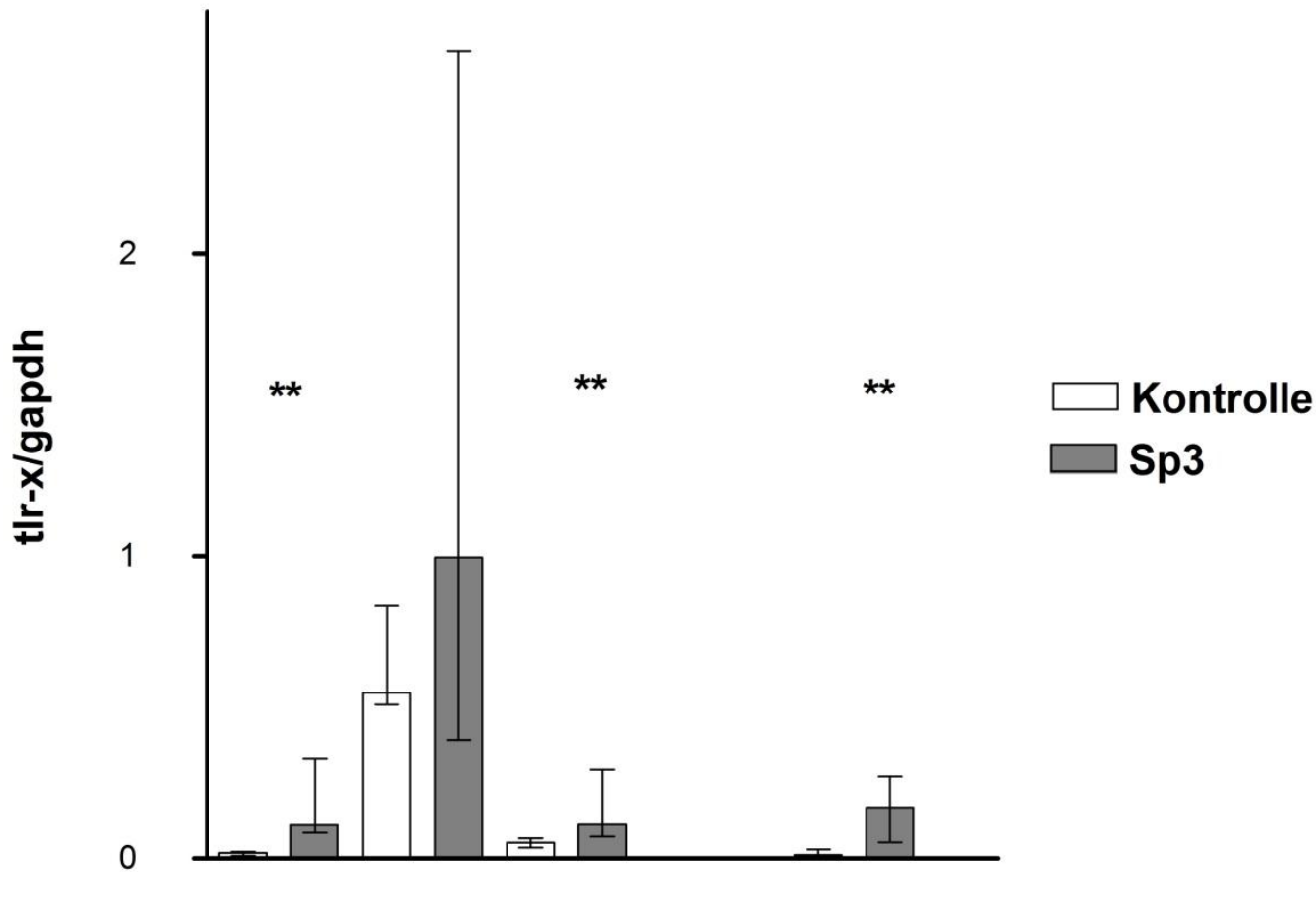

tIr $2 \quad \operatorname{tlr} 3 \quad \operatorname{tir} 4 \quad \operatorname{tir} 9$

Abbildung 7 (a und b): mRNA-Expression von TLR 2, 3, 4, 7 und 9 (normalisiert auf die GAPDHExpression) im Gehirn von C57BL6-Mäusen nach intrazerebraler Infektion mit S. pneumoniae ( $\mathrm{n}=8$; schwarze Säulen) und von nicht infizierten Kontrollmäusen ( $n=8$; weiße Säulen) nach 36 Stunden. Die Daten sind dargestellt als Mediane (25./75. Perzentile). ${ }^{*} p<0,05,{ }^{* \star} p<0,01,{ }^{\star \star *} p<0,001$

In der Milz bewirkte die $S$. pneumoniae-Meningitis/Sepsis einen Anstieg der mRNA-Expression von TLR2 (1,6-fach, $p=0,002)$, TLR3 (1,8-fach, $p=0,02)$, TLR4 (1,8-fach, $p=0,009)$ und TLR7 (1,5-fach, $p=0,02)$. Die mRNA-Spiegel von TLR9 in der 
Milz von infizierten Mäusen und Kontrollmäusen unterschieden sich nicht signifikant (Abb. 8).

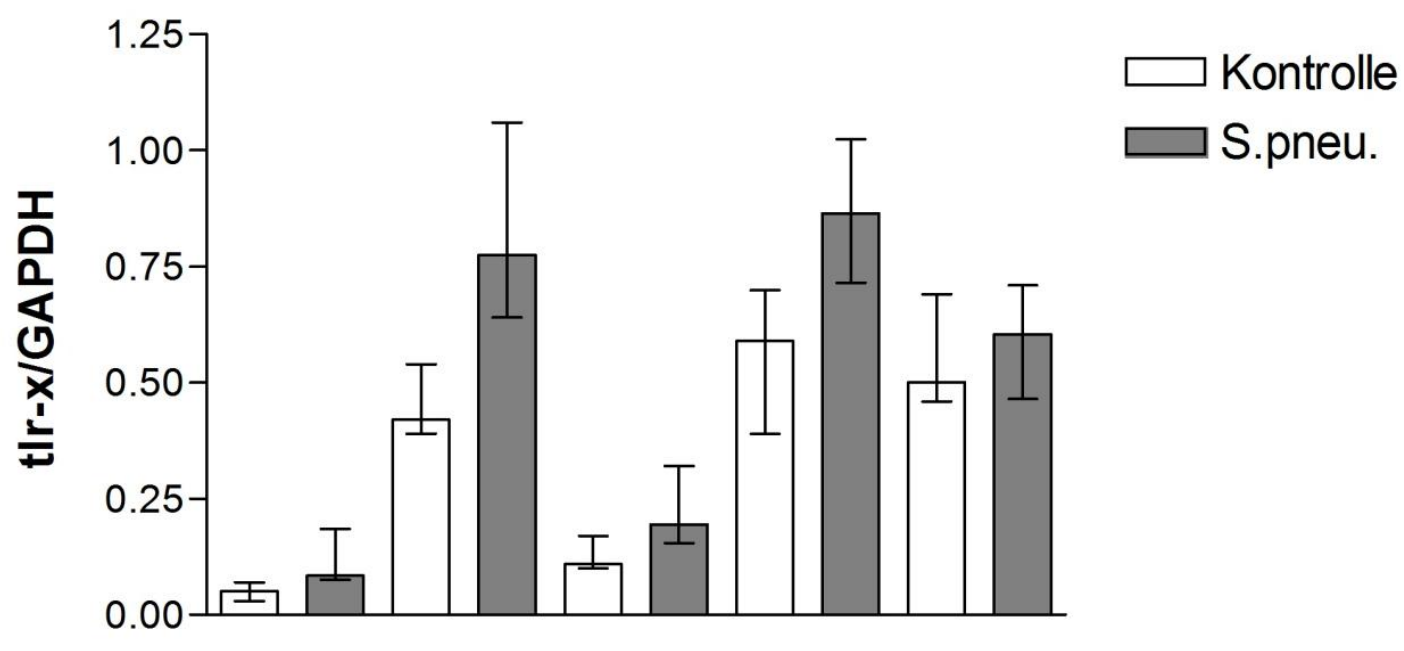

\section{tIr $2 \quad$ tIr $3 \quad$ tIr $4 \quad$ tIr $7 \quad$ tIr 9}

Abbildung 8: mRNA-Expression von TLR2, 3, 4, 7 und 9 (normalisiert auf die GAPDH-Expression) in der Milz von C57BL6-Mäusen nach intrazerebraler Infektion mit S. pneumoniae $(n=8$; schwarze Säulen) und von nicht infizierten Kontrollmäusen ( $n=8$; weiße Säulen) nach 36 Stunden. Die Daten sind dargestellt als Mediane (25./75. Perzentile). ${ }^{*} p<0,05$, ${ }^{* *} p<0,01,{ }^{* * *} p<0,001$

\subsection{Behandlung organotypischer Hippokampuskulturen mit Streptococcus pneumoniae R6}

Organotypische Hippokampuskulturen von Mäusen wurden mit Hitze-inaktivierten Pneumokokken R6 (hiR6) behandelt $(n=180)$. Die Kontrollkulturen wurden nur mit Medium behandelt $(n=180)$. Die Kulturen der mit hiR6-behandelten Testgruppen zeigten nach 48 Stunden eine erhöhte Expression der mRNA von TLR2 (11,9-fach, $p=0,0002)$ und TLR3 (5,6-fach, $p=0,001)$ im Vergleich mit der nur mit Medium behandelten Kontrollgruppe. Die Spiegel der mRNA von TLR4, TLR5 und TLR9 von mit hiR6 behandelten Kulturen und Kontrollkulturen unterschieden sich nicht signifikant (Abb. 9). 


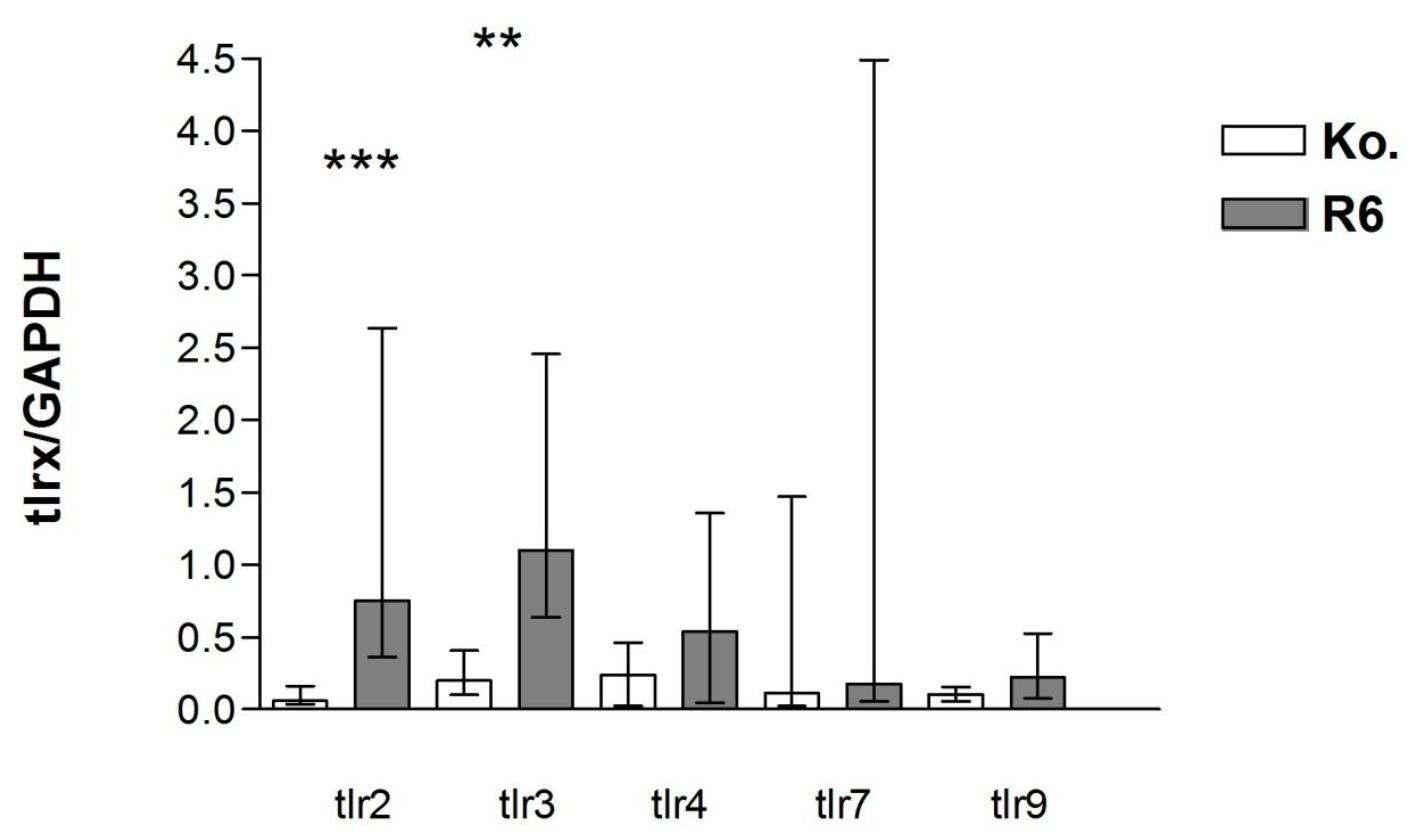

Abbildung 9: $\quad$ mRNA-Expression von TLR2, 3, 4, 7, und 9 (normalisiert auf GAPDH-Expression) in mit Hitze-inaktivierten $\quad S$. pneumoniae R6 behandelten organotypischen Hippokampuskulturen ( $n=180$; schwarze Säulen) und unbehandelten Kontrollkulturen ( $n=180$ : weiße Säulen) nach 48 Stunden. Die Daten sind dargestellt als Mediane (25./75. Perzentile). ${ }^{*} p<0,05,{ }^{* *} p<0,01,{ }^{* * *} p<0,001$

\subsection{Regulation der TLR-mRNA in Gehirn und Milz von C57BL6-Mäusen nach intrazerebraler Infektion mit Escherichia coli}

Um den Einfluss Gram-negativer bakterieller ZNS-Infektionen auf die Regulation der mRNA verschiedener TLR in Gehirn und Milz zu untersuchen, wurden die mRNA-Spiegel von TLR2, TLR3, TLR4, TL7 und TLR9 in Gehirn und Milz von C57BL6-Mäusen nach intrazerebraler Infektion mit E. coli $(n=8)$ und von nicht infizierten Kontrollmäusen $(n=8)$ miteinander verglichen.

Die E. coli-Meningitis/Sepsis führte zu einem Anstieg der mRNA-Expression von TLR2 (26-fach, $p=0,0002)$, TLR3 (3,5-fach, $p=0,0499)$, TLR4 (5,9-fach, $p=0,001)$ und TLR7 (1,9-fach, $p=0,007)$ Im Gehirn. Die Spiegel der mRNA von TLR9 im Gehirn von 
infizierten Mäusen und Kontrollmäusen unterschieden sich nicht signifikant (Abb. 10).

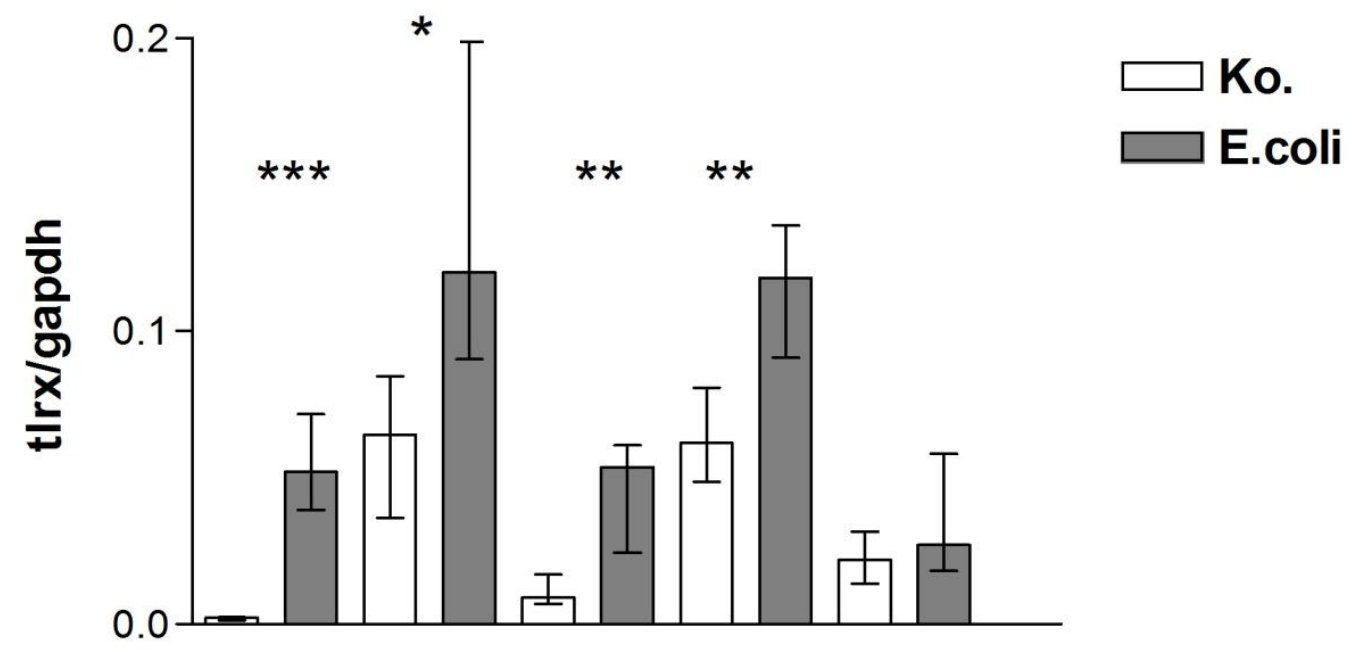

$\operatorname{tlr} 2 \quad \operatorname{tlr} 3 \quad \operatorname{tlr} 4 \quad \operatorname{tlr} 7 \quad \operatorname{tir} 9$

Abbildung 10: mRNA-Expression von TLR2, 3, 4, 7 und 9 (normalisiert auf die GAPDH-Expression) im Gehirn von C57BL6-Mäusen nach intrazerebraler Infektion mit $E$. coli $(n=8$; schwarze Säulen) und von nicht infizierten Kontrollmäusen ( $n=8$; weiße Säulen) nach 30 Stunden. Die Daten sind dargestellt als Mediane (25./75. Perzentile). ${ }^{*} p<0,05,{ }^{* *} p<0,01$, *** $p<0,001$

In der Milz bewirkte die E. coli-Meningitis/Sepsis einen Anstieg der mRNA-Expression von TLR2 (3,4-fach, $p=0,004)$, TLR7 (2,9-fach, $p=0,0002)$ und TLR9 (3,1-fach, $p=0,0047)$. Die mRNA-Spiegel von TLR3 und TLR4 in der Milz von infizierten Mäusen und Kontrollmäusen unterschieden sich nicht signifikant (Abb. 11). 


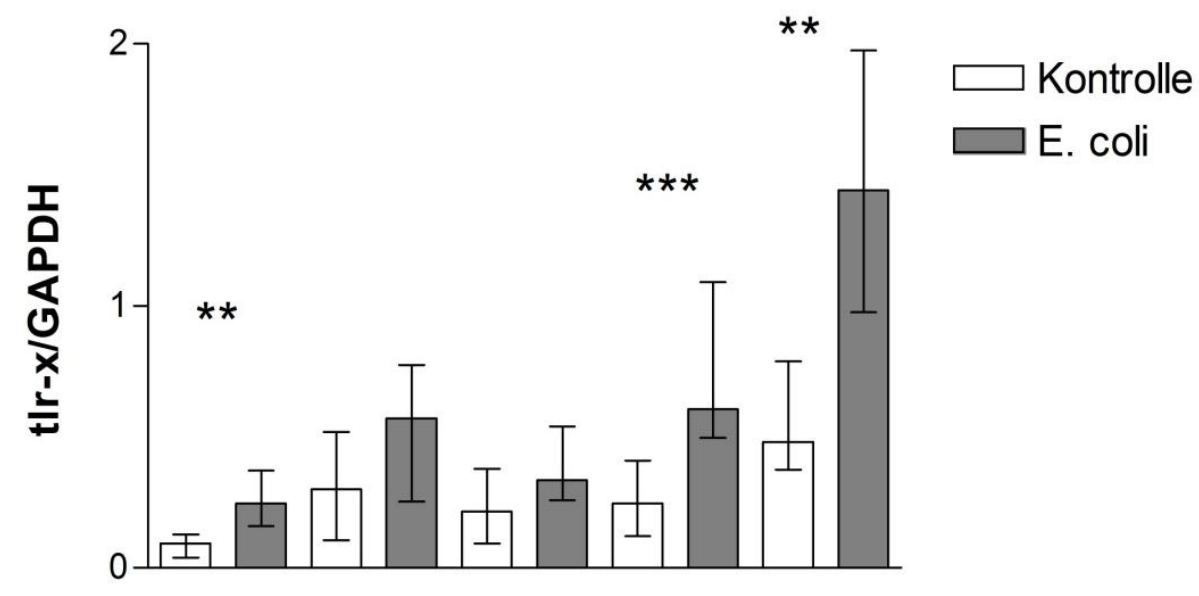

$\begin{array}{lllll}\text { tIr } 2 & \text { tIr } 3 & \text { tIr } 4 & \operatorname{tir} 7 & \text { tIr } 9\end{array}$

Abbildung 11: mRNA-Expression von TLR2, 3, 4, 7 und 9 (normalisiert auf die GAPDH-Expression) in der Milz von C57BL6-Mäusen nach intrazerebraler Infektion mit $E$. coli $(n=8$; schwarze Säulen) und von nicht infizierten Kontrollmäusen ( $n=8$; weiße Säulen) nach 30 Stunden. Die Daten sind dargestellt als Mediane (25./75. Perzentile). ${ }^{*} p<0,05,{ }^{* *} p<0,01$, *** $p<0,001$

\subsection{Regulation der TLR-mRNA in Gehirn und Milz von SJL-NBOM-Mäusen nach intranasaler Infektion mit Herpes-simplex-Virus}

Um den Einfluss der Herpes-simplex-Virus-Enzephalitis auf die Regulation der mRNA verschiedener TLR in Gehirn und Milz zu untersuchen, wurden die mRNA-Spiegel von TLR2, TLR3, TLR4, TLR7 und TLR9 in Gehirn und Milz von SJL-NBOM-Mäusen nach intrazerebraler Infektion mit HSV $(n=4)$ und nicht infizierten Kontrollmäusen $(n=4)$ miteinander verglichen.

Die HSV-Enzephalitis führte zu einem Anstieg der mRNA-Expression von TLR4 (2,4-fach, $p=0,0286)$ im Gehirn. Die Spiegel der mRNA von TLR2, TLR3, TLR7 und TLR9 im Gehirn von infizierten Mäusen und Kontrollmäusen unterschieden sich nicht signifikant (Abb. 12). 


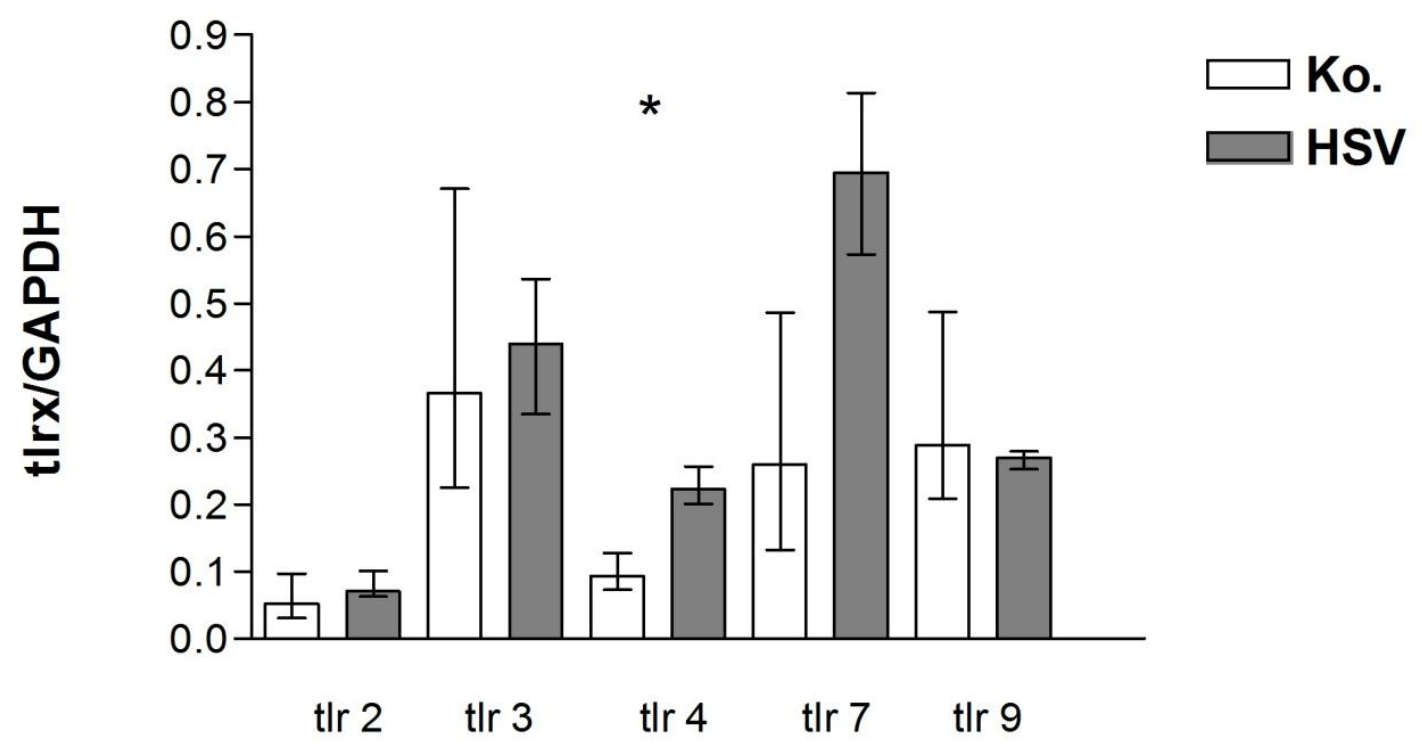

Abbildung 12: mRNA-Expression von TLR 2, 3, 4, 7 und 9 (normalisiert auf die GAPDH-Expression) im Gehirn von SJL-NBOM-Mäusen nach intrazerebraler Infektion mit HSV ( $n=4$; schwarze Säulen) und von nicht infizierten Kontrollmäusen ( $n=4$; weiße Säulen) nach 7 Tagen. Die Daten sind dargestellt als Mediane (25./75. Perzentile). ${ }^{\star} p<0,05,{ }^{* *} p<0,01$ 
Die Spiegel der mRNA von TLR2, TLR3, TLR4, TLR7 und TLR9 in der Milz von infizierten Mäusen und Kontrollmäusen unterschieden sich nicht signifikant (Abb. 13).

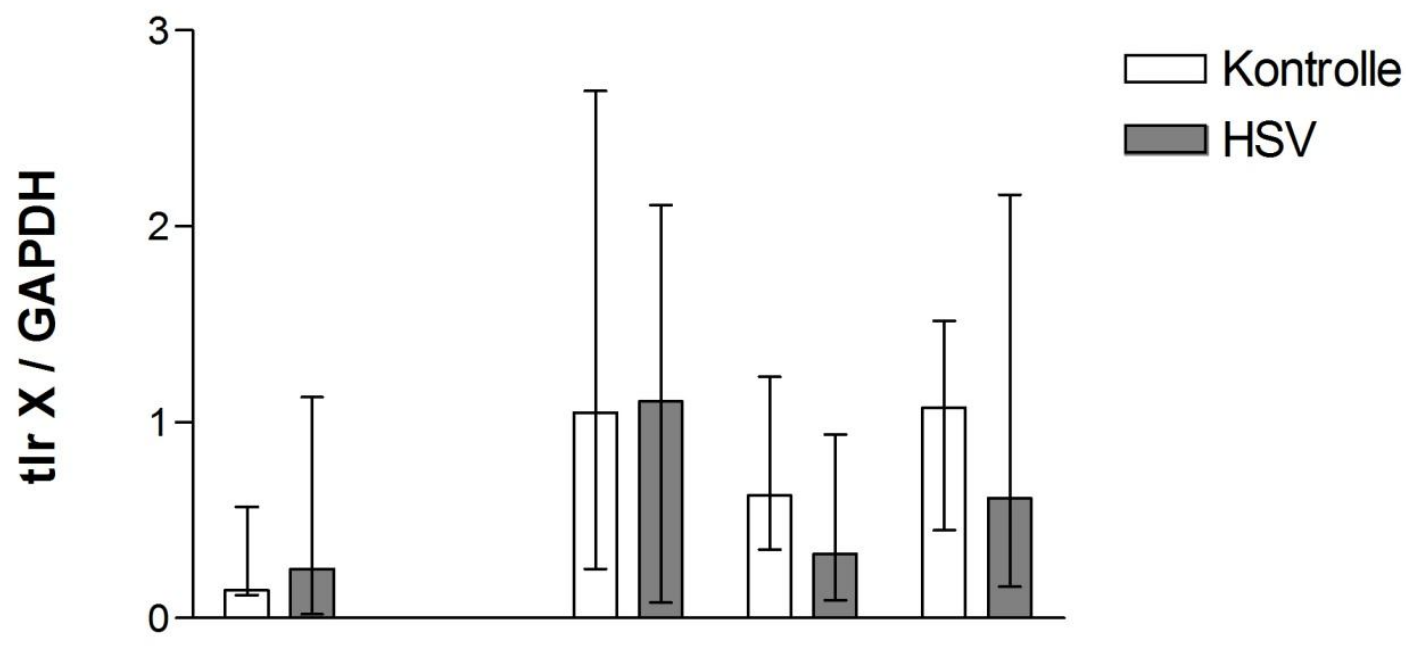

tlr $2 \quad \operatorname{tlr} 3 \quad \operatorname{tlr} 4 \quad \operatorname{tlr} 7 \quad \operatorname{tlr} 9$

Abbildung 13: mRNA-Expression von TLR 2, 3, 4, 7 und 9 (normalisiert auf die GAPDH-Expression) in der Milz von SJL-NBOM-Mäusen nach intrazerebraler Infektion mit HSV ( $n=4$; schwarze Säulen) und von nicht infizierten Kontrollmäusen ( $n=4$; weiße Säulen) nach 7 Tagen. Die Daten sind dargestellt als Mediane (25./75. Perzentile). ${ }^{*} p<0,05,{ }^{* *} p<0,01$

\subsection{Regulation der TLR-mRNA in Gehirn und Milz von TLR9-defizienten Mäusen nach intrazerebraler Infektion mit Streptococcus pneumoniae Typ 3}

Um die Auswirkungen einer TLR9-Defizienz auf die Regulation der TLR-Expression bei Gram-positiven bakteriellen ZNS-Infektionen zu untersuchen, wurden die mRNA-Spiegel von TLR2, TLR3, TLR4, TLR7 und TLR9 in Gehirn und Milz von TLR9-defizienten Mäusen ( $n=15)$ und B6-Mäusen $(n=15)$ nach intrazerebraler Infektion mit S. pneumoniae Typ3 miteinander verglichen.

Nach Infektion mit S. pneumoniae Typ3 zeigten TLR9-defiziente Mäuse im Vergleich zu Kontrollmäusen im Gehirn eine tendenziell, aber nicht signifikant erhöhte Expression der mRNA von TLR2, TLR3 und TLR7, die Expression von TLR4 war in 
beiden Gruppen ungefähr gleich (Abb.14).

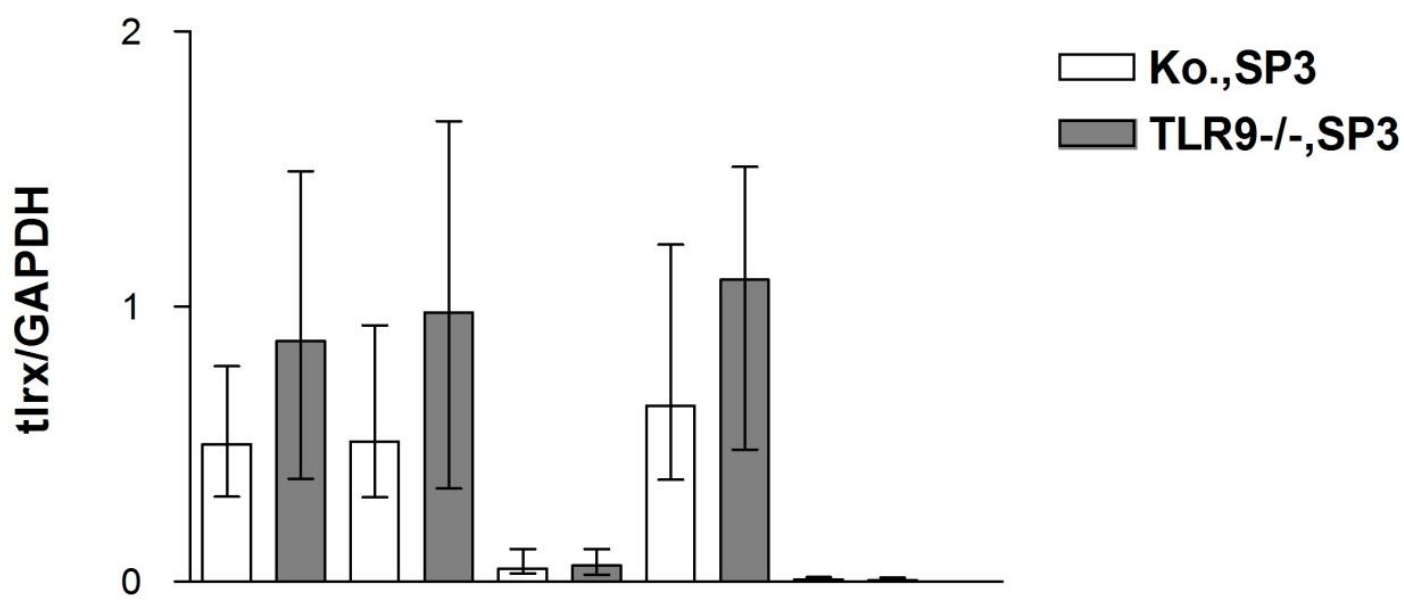

tIr $2 \quad \operatorname{tlr} 3 \quad \operatorname{tlr} 4 \quad \operatorname{tlr} 7 \quad \operatorname{tir} 9$

Abbildung 14: mRNA-Expression von TLR 2, 3, 4, 7 und 9 (normalisiert auf die GAPDH-Expression) im Gehirn von TLR9-defizienten Mäusen ( $n=15$; schwarze Säulen) und Kontrollmäusen $(n=15 ;$ weiße Säulen) nach 30 Stunden nach intrazerebraler Infektion mit S. pneumoniae. Die Daten sind dargestellt als Mediane (25./75. Perzentile). ${ }^{*} p<0,05$, ${ }^{* *} p<0,01,{ }^{* * *} p<0,001$

In der Milz der TLR9-defizienten Mäuse bewirkte die S. pneumoniae-Meningitis/Sepsis einen signifikanten Anstieg der mRNA von TLR2 (2,7-fach, $p=0.0411)$. Es zeigten sich keine signifikanten Unterschiede zwischen TLR9-defizienten Mäusen und Kontrollmäusen nach Infektion mit $S$.pneumoniae Typ3 bezüglich der mRNA-Expression von TLR3, TLR4, TLR7 und TLR9 in der Milz (Abb. 15 a und b). 

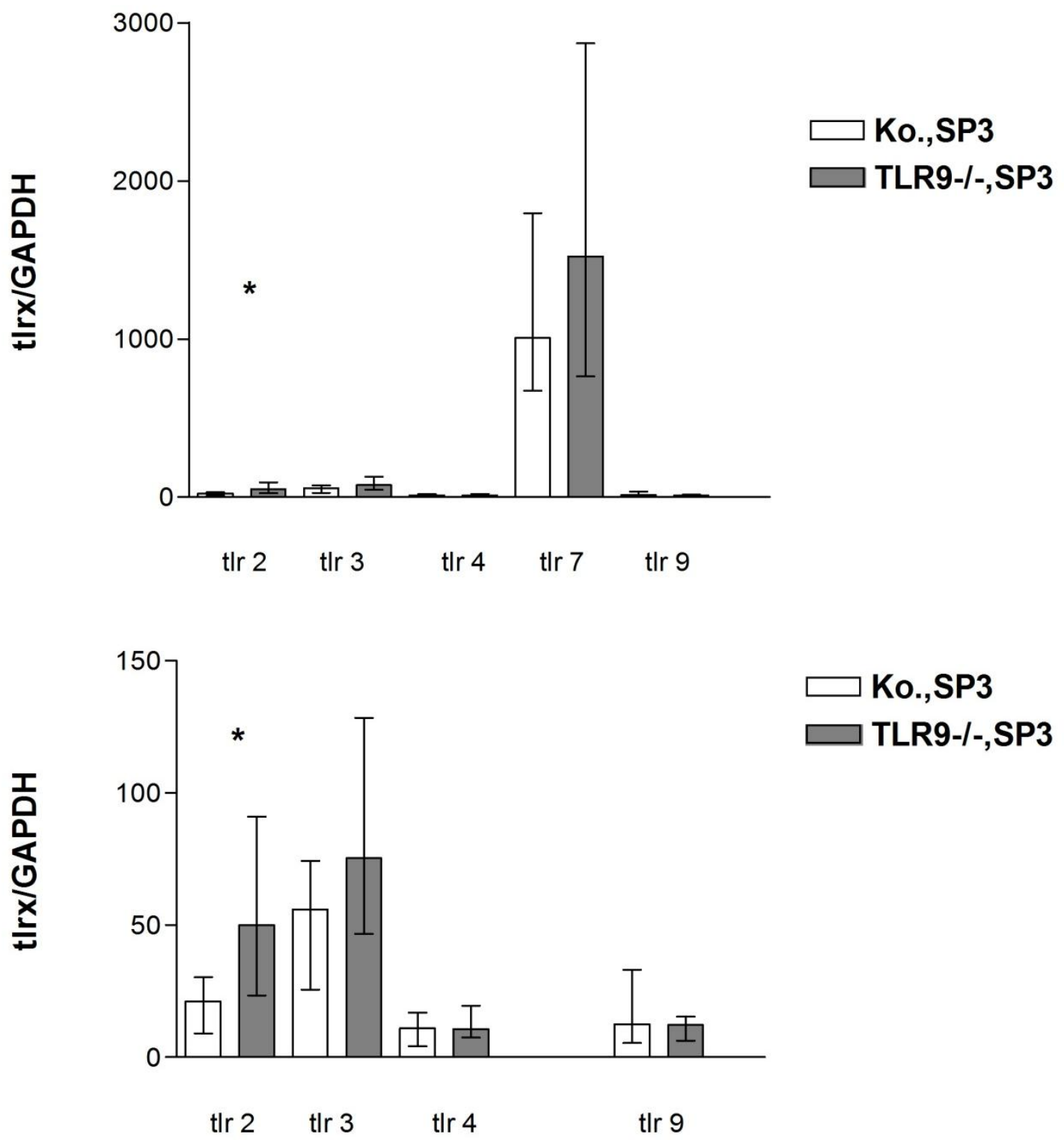

Abbildung 15 a und b: mRNA-Expression von TLR 2, 3, 4, 7 und 9 (normalisiert auf die GAPDHExpression) in der Milz von TLR9-defizienten Mäusen ( $n=6$; schwarze Säulen) und Kontrollmäusen ( $n=6$; weiße Säulen) 30 Stunden nach intrazerebraler Infektion mit S. pneumoniae. Die Daten sind dargestellt als Mediane (25./75. Perzentile). ${ }^{*} p<0,05$, ${ }^{* *} p<0,01,{ }^{* * *} p<0,001$ 


\subsection{Regulation der TLR-mRNA in Gehirn und Milz von TLR4-defizienten Mäusen nach intrazerebraler Infektion mit E. coli}

Um den Einfluss einer TLR4-Defizienz auf die Regulation der TLR-Expression bei Gram-negativen bakteriellen ZNS-Infektionen zu untersuchen, wurden die mRNA-Spiegel von TLR2, TLR3, TLR4, TLR7 und TLR9 in Gehirn und Milz von TLR4-defizienten Mäusen C3H/HEJ $(n=10)$ und C3H/HEN-Mäusen (Kontrollgruppe, $\mathrm{n}=10$ ) nach intrazerebraler Infektion mit $E$. coli miteinander verglichen.

Die TLR4-Defizienz führte in E. coli-Meningitis/Sepsis zu einer signifikanten Abnahme der mRNA-Expression von TLR2 (0,42-fach, $p=0,014)$ und TLR7 (0,76-fach, $p=0,019)$ im Gehirn. Der Spiegel der mRNA von TLR3 war näherungsweise gleich. Die mRNA-Expressionen von TLR9 im Gehirn der mutanten und Kontrollmäuse unterschieden sich nicht signifikant (Abb.16).

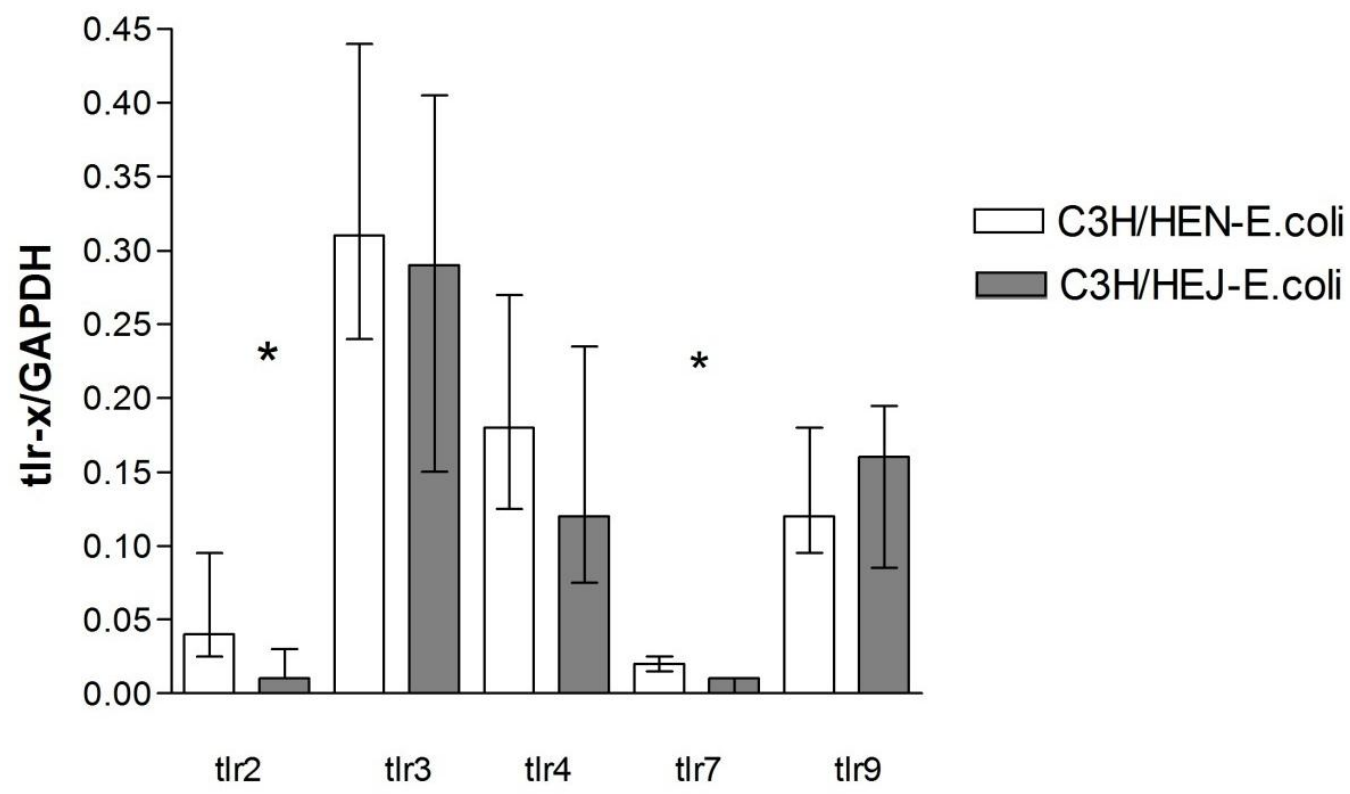

Abbildung 16: mRNA-Expression von TLR 2, 3, 4, 7 und 9 (normalisiert auf die GAPDH-Expression) im Gehirn von TLR4-defizienten ( $n=10$; schwarze Säulen) und Kontrollmäusen $(n=10$; weiße Säulen) 24 Stunden nach intrazerebraler Infektion mit E. coli. Die Daten sind dargestellt als Mediane (25./75. Perzentile). ${ }^{*} p<0,05,{ }^{* *} p<0,01,{ }^{* * *} p<0,001$ 
In der Milz bewirkte die TLR4-Defizienz in E. coli-Meningitis/Sepsis eine signifikante Abnahme der mRNA-Expression von TLR7 (0,45-fach, $p=0,0054)$ und TLR9 (0,5-fach, $p=0,0058)$. Die Spiegel der mRNA von TLR2 und TLR3 waren annähernd gleich (Abb.17).

Die Spiegel der mRNA von TLR4 waren sowohl im Gehirn als auch in der Milz bei infizierten $\mathrm{C} 3 \mathrm{H} / \mathrm{HEJ}$ - und $\mathrm{C} 3 \mathrm{H} / \mathrm{HEN}$-Mäusen annähernd gleich. Dies beruht auf der genetischen Struktur des mutierten TLR4-Gens. Die defiziente TLR4-mRNA wird in gleicher Länge wie das intakte Gen (255bp) expirimiert, es unterscheidet sich vom intakten Gen lediglich in einer Aminosäure (s. Kap. 2.2).

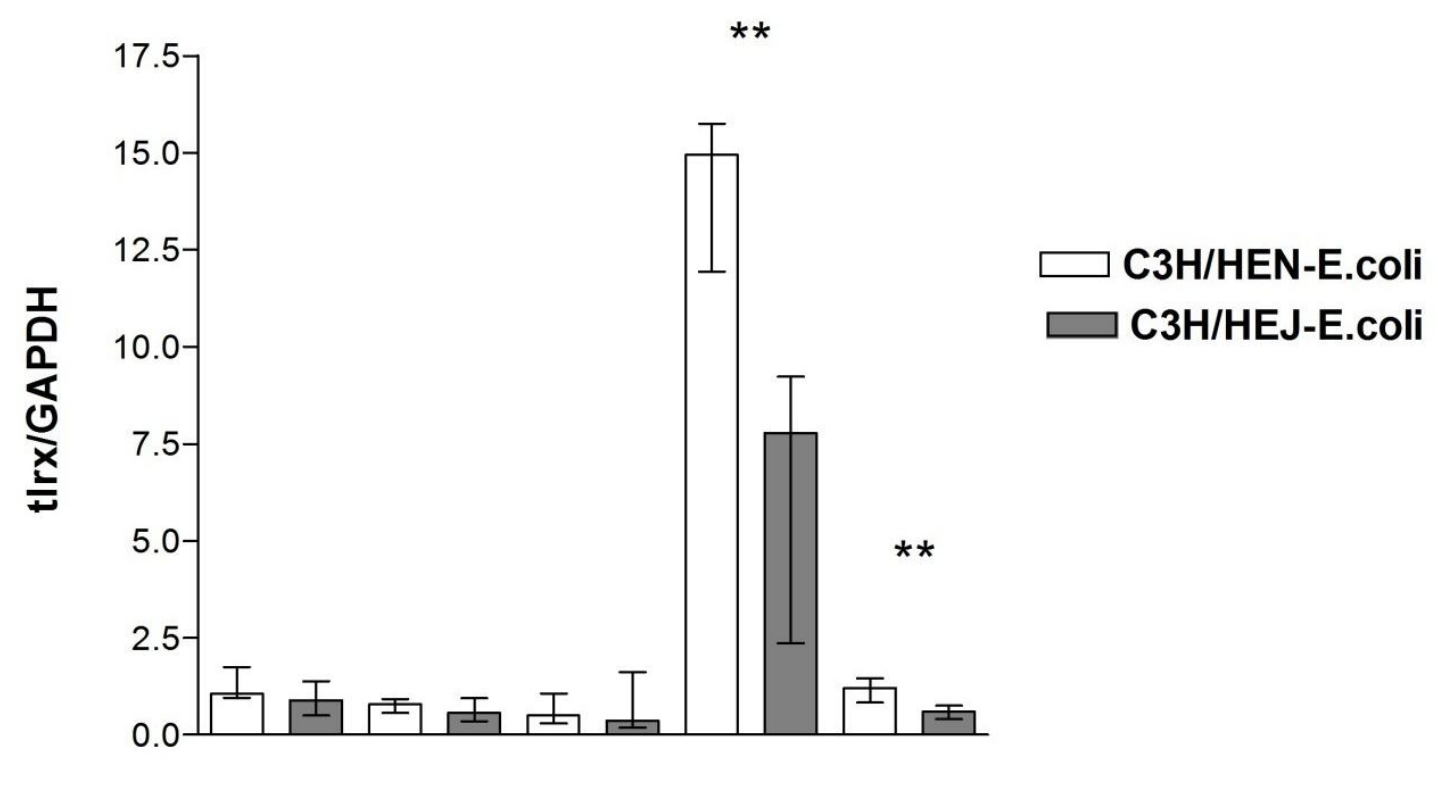

tIr $2 \quad \operatorname{tir} 3 \quad \operatorname{tir} 4 \quad \operatorname{tir} 7 \quad$ tIr9

Abbildung 17: mRNA-Expression von TLR 2, 3, 4, 7 und 9 (normalisiert auf die GAPDH-Expression) in der Milz von TLR4-defizienten ( $n=10$; schwarze Säulen) und Kontrollmäusen $(n=10$; weiße Säulen) 24 Stunden nach intrazerebraler Infektion mit E. coli. Die Daten sind dargestellt als Mediane (25./75. Perzentile). ${ }^{*} p<0,05,{ }^{* *} p<0,01,{ }^{* * *} p<0,001$ 


\subsection{Regulation der TLR-mRNA in Gehirn und Milz von TLR2-defizienten Mäusen nach intrazerebraler Infektion mit $E$. coli}

Um den Einfluss des TLR2 bei Gram-negativer bakterieller ZNS-Infektion in Gehirn und Milz zu untersuchen, wurden die mRNA-Spiegel von TLR2, TLR3, TLR4, TLR7 und TLR9 in Gehirn und Milz von TLR2-defizienten Mäusen ( $n=5)$ bzw. 129/B6-Mäusen $(\mathrm{n}=6)$ als Kontrollgruppe nach intrazerebraler Infektion mit E. coli miteinander verglichen. Die Mäuse starben innerhalb von 12 Stunden. Die mRNA-Expressionen von TLR2, TLR3, TLR4, TLR7 und TLR9 in Gehirn und Milz von TLR2-defizienten Mäusen $(n=5)$ und Kontrollmäusen $(n=6)$ wurde 12 Stunden nach Infektion miteinander verglichen.

Die E. coli-Meningitis/Sepsis führte innerhalb der ersten 12 Stunden zu keinem signifikanten Unterschied der mRNA-Spiegel von TLR2, TLR3, TLR4, TLR7 und TLR9 im Gehirn von infizierten TLR2-defizienten und Kontrollmäusen. Die mRNA-Expression von TLR2 war im Gehirn der TLR2-defizienten Mäuse niedriger als in dem der Kontrollmäuse. Die mRNA-Spiegel von TLR3, TLR4, TLR7 und TLR9 im Gehirn von infizierten Test- und Kontrollmäusen unterschieden sich nicht (Abb. 18).

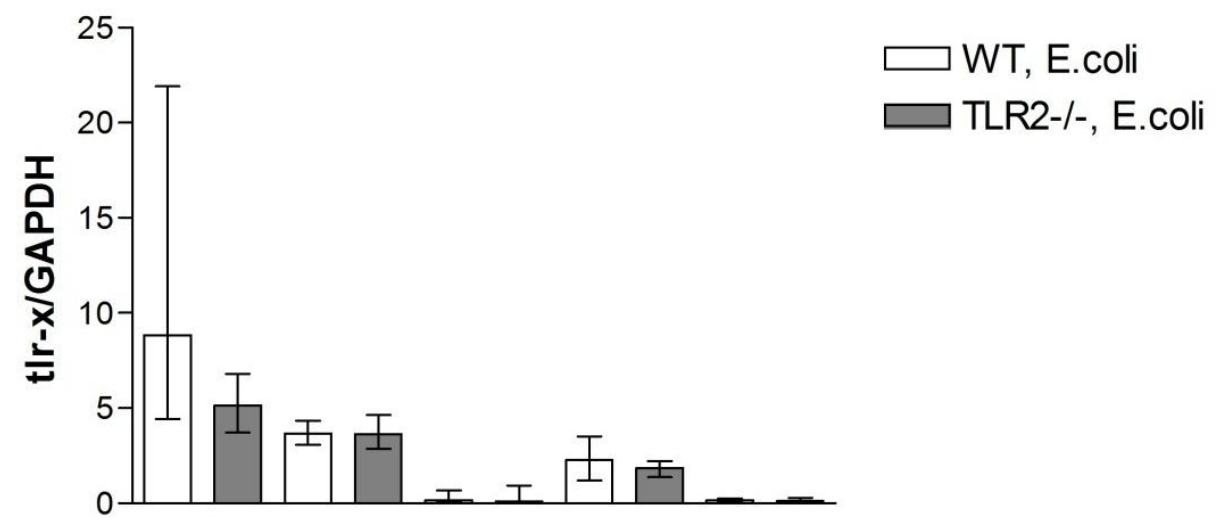

\section{tIr $2 \quad$ tIr $3 \quad \operatorname{tir} 4 \quad \operatorname{tir} 7 \quad \operatorname{tir} 9$}

Abbildung 18: mRNA-Expression von TLR 2, 3, 4, 7 und 9 (normalisiert auf die GAPDH-Expression) im Gehirn von TLR2-defizienten ( $n=5$; schwarze Säulen) und Kontrollmäusen $(n=6$; weiße Säulen) 12 Stunden nach intrazerebraler Infektion mit E. coli. Die Daten sind dargestellt als Mediane (25./75. Perzentile). ${ }^{*} p<0,05,{ }^{* *} p<0,01,{ }^{* * *} p<0,001$ 
In der Milz bewirkte die E. coli-Meningitis/Sepsis innerhalb der ersten 12 Stunden einen Anstieg der mRNA-Expression des TLR7 von TLR2-defizienten Mäusen im Vergleich mit Kontrollmäusen. Die mRNA-Spiegel von TLR2, TLR3, TLR4 und TLR9 in der Milz von infizierten Test- und Kontrollmäusen unterschieden sich nicht signifikant (Abb. 19).

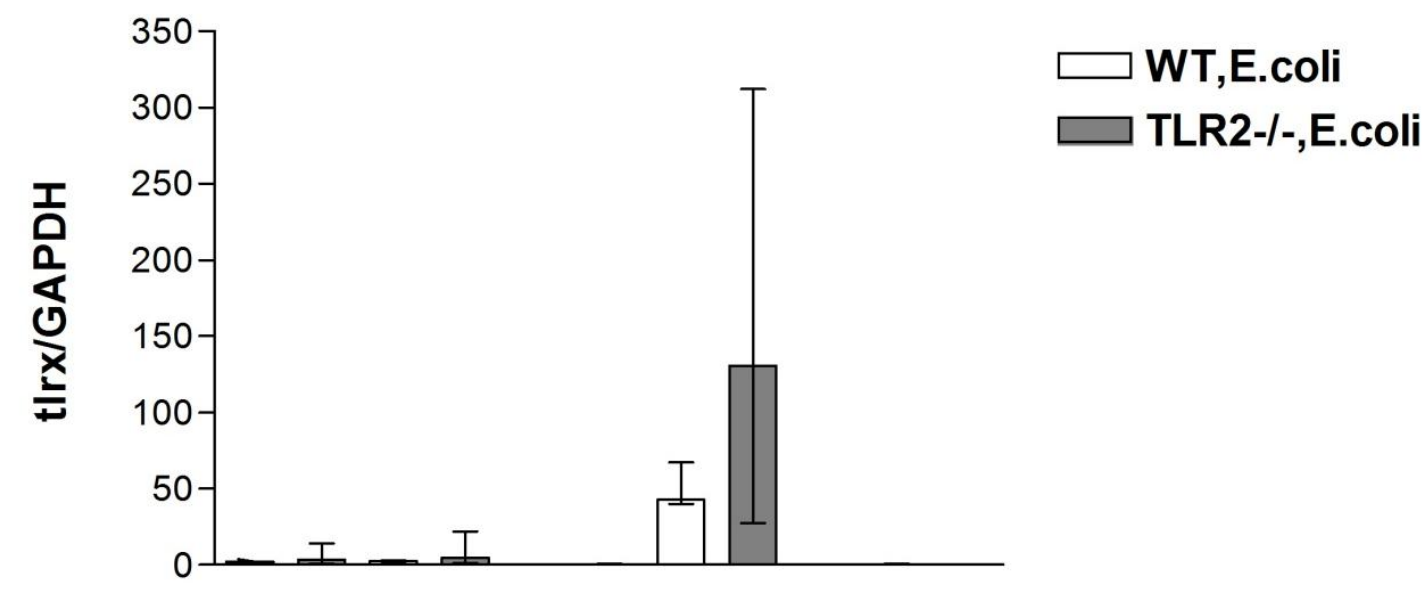

$\begin{array}{lllll}\operatorname{tir} 2 & \operatorname{tlr} 3 & \operatorname{ttr} 4 & \operatorname{tir} 7 & \operatorname{tr} 9\end{array}$

Abbildung 19: mRNA-Expression von TLR 2, 3, 4, 7 und 9 (normalisiert auf die GAPDH-Expression) in der Milz von TLR2-defizienten ( $n=5$; schwarze Säulen) und Kontrollmäusen ( $n=6$; weiße Säulen) 12 Stunden nach intrazerebraler Infektion mit E. coli. Die Daten sind dargestellt als Mediane (25./75. Perzentile). ${ }^{*} p<0,05,{ }^{* *} p<0,01,{ }^{* * *} p<0,001$ 


\section{Diskussion}

\subsection{Regulierung der TLR in der Wildtyp-Maus}

Bei der ZNS-Infektion der Wildtyp-Maus mit Streptococcus pneumoniae wurde eine signifikant höhere Expression der TLR2, TLR4 und TLR9 beobachtet. Die höhere Expression von TLR2 kann durch Erkennung von Lipoteichonsäure von S. pneumoniae bedingt sein. Die erhöhte Expression von TLR9 kann auf der Erkennung der bakteriellen DNA beruhen. Die Aktivierung des TLR4 durch Stimulierung mit Pneumolysin wurde berichtet (Ebert et al. 2005). Im Versuch mit OTC-Kulturen war die TLR4-mRNA-Expression nicht signifikant erhöht. Dies ist möglicherweise darauf zurückzuführen, dass bei Hitze-inaktivierten Streptokokken Pneumolysin denaturiert wurde.

Die ZNS-Infektion durch E. coli führte zu einer signifikant höheren Expression von TLR2, TLR4 und TLR7. E. coli als Gram-negatives Bakterium besitzt LPS, welches als ein wichtiger Ligand für TLR4 beschrieben wurde. Von der erhöhten TLR2-Expression bei Infektionen mit Gram-negativen Bakterien wurde bereits berichtet (Laflamme et al. 2001). Die signifikant höhere Expression von TLR7 konnte nicht erklärt werden. Diese wurde sowohl im Gehirn $(p=0.007)$ als auch in der Milz $(p=0.0002)$ detektiert. Wir haben keine signifikante Erhöhung der Expression von TLR9 beobachtet. Dieses Ergebnis konnte auch nicht erklärt werden.

In organotypischen Hippokampuskulturen wurde nach Behandlung mit hiR6 eine signifikant höhere Expression der TLR2 und TLR3 beobachtet. Die Kulturen beinhalten vor allem die Neuronen, Astrozyten, Oligodendrozyten und die lokalen Mikrogliazellen. An den erhöhten Expressionen von TLR2 und TLR3 sind vermutlich hauptsächlich die Mikrogliazellen beteiligt.

Bei der HSV-Enzephalitis wurde nur TLR4 signifikant höher exprimiert. Als virale Liganden für TLR4 wurden RS-Virus (Haynes et al. 2001) und MMTV (Mouse Mammary Tumor Virus) genannt (Takeda et al. 2003). Außerdem können einige 
endogene Liganden wie Fibronectin und Polysaccharidfragmente von Heparansulfat als Liganden für TLR4 wirken. Die Expression von TLR7 in der Testgruppe war im Vergleich zur Kontrollgruppe erhöht, die Differenz war jedoch nicht signifikant.

In der Milz infizierter Mäuse mit Streptococcus pneumoniae wurden die TLR2, TLR3, TLR4 und TLR7 signifikant höher exprimiert. Während die höheren Expressionen von TLR2 und TLR4 mit unseren Ergebnissen der Messung von Rezeptoren aus dem Gehirn der gleichen Mäuse übereinstimmten, beobachteten wir keine erhöhte Expression von TLR9. Außerdem waren nur in der Milz TLR3 und TLR7 signifikant erhöht und nicht im Gehirn. Für TLR3 und TLR7 sind meines Wissens noch keine bakteriellen Liganden bekannt. Es wird vermutet, dass TLR7 virale Nukleinsäure (Diebold et al. 2004) oder vom Wirt ausgeschüttete Stoffe bei viralen Infektionen erkennt (Takeda et al. 2003).

In der Milz von mit E. coli infizierten Mäusen wurde eine erhöhte Expression der TLR2, TLR7 und TLR9 beobachtet. Während die erhöhte Expression von TLR2 und TLR7 mit unseren Ergebnissen aus dem Gehirn der gleichen Mäuse übereinstimmte, wurde eine erhöhte TLR4-Expression nur im Gehirn und nicht in der Milz beobachtet. Die höhere Expression von TLR9 wurde hingegen nur in der Milz und nicht im Gehirn beobachtet.

In der Milz der mit HSV infizierten Mäuse wurde kein signifikanter Unterschied gegenüber den gesunden Mäusen beobachtet. Die erhöhte Expression des TLR4 im Gehirn wurde nicht in der Milz beobachtet.

Zusammengefasst ist in allen Vesuchen mit Wildtyp-Mäusen im Gehirn die TLR4-Expression statistisch signifkant erhöht. Vergleichbar ist in der Milz die ehöhte TLR7 bei Infektionen mit S. pneumoniae und E. coli. in Wildtypmäusen signifikant. Man kann davon ausgehen, dass der Regulation der anderen Rezeptoren im Gehirn bzw. in der Milz unterschiedliche Mechanismen zugrunde liegen. 


\subsection{Regulierung der TLR in mutanten Mäusen}

Die Regulation der TLR im Gehirn der infizierten TLR9-defizienten Mäuse mit S. pneumoniae zeigte keinen signifikanten Unterschied im Vergleich mit infizierten Wildtyp-Mäusen. Im Gehirn infizierter TLR9-defizienter Mäuse waren die TLR2, TLR3 und TLR7 höher exprimiert als bei den Wildtypen. Der Unterschied war aber nicht signifikant. Hierbei stellt sich die Frage, auf welchen Mechanismus die erhöhte Expression der TLR2, 3 und 7 bei funktionsunfähigem TLR9 zurückzuführen ist. Eine kompensatorische Wirkung von TLR6 bei Defizienz des TLR1 oder von anderen TLR wird vermutet (Takeda et al. 2003).

TLR4 wurde in der Kontroll- und in der Test-Gruppe in ungefähr gleicher Menge detektiert. Man kann davon ausgehen, dass der funktionsuntüchtige TLR9 die Expression von TLR4 nicht beeinflusst. Im Gehirn der beiden Gruppen wurde TLR9 sehr niedrig exprimiert. In wiederholten Versuchen wurde das gleiche Ergebnis beobachtet. Wir können die niedrige Expression von TLR9 in beiden Gruppen nicht begründen. Bsibsi berichtete über ähnliche Beobachtungen bei der Untersuchung des TLR9 im menschlichen Gehirn (Bsibsi et al. 2002). Eine supprimierende Wirkung von CSF-1 (Colony-stimulating Factor) auf die TLR9-Expression wurde berichtet (Sweet et al. 2002).

In der Milz der TLR9-defizienten Mäuse wurden TLR3, TLR4 und TLR9 ungefähr gleich exprimiert wie in der Kontrollgruppe. Wir gehen davon aus, dass die Defizienz des TLR9 keinen bedeutenden Einfluss auf die Regulation der TLR3 und TLR4 in der Milz hatte. Die Spiegel der mRNA von TLR2 war bei TLR9-defizienten Mäusen signifikant höher als in der Milz von Wildtyp-Mäusen $(p=0.04)$. Die mRNA von TLR7 wurde bei TLR9-defizienten Mäusen geringgradig höher exprimiert als bei den Wildtyp-Mäusen. Der Unterschied war jedoch nicht statistisch signifikant. Möglicherweise führte die Funktionsuntüchtigkeit des TLR9 im Falle der Meningitis/Sepsis mit S. pneumoniae zur erhöhten Expression von TLR2 in der Milz.

Im Gehirn der infizierten TLR4-defizienten Mäuse mit E. coli wurden TLR2 und TLR7 signifikant niedriger exprimiert als in der Kontrollgruppe. In der Milz der mutanten 
Mäuse wurden die TLR7 und TLR9 signifikant niedriger exprimiert als in Wildtyp-Mäusen. Die Expression des TLR2 in der Milz war in TLR4-defizienten Mäusen niedriger als in Wildtyp-Mäusen. TLR4-mRNA wurde in mutanten und Wildtyp-Mäusen sowohl im Gehirn als auch in der Milz in ungefähr gleicher Menge detektiert. Hierbei stellt sich die Frage, ob zumindest bei Meningitis mit E. coli die Funktionstüchtigkeit des TLR4 die Voraussetzung für die höhere Expression der TLR2 und TLR7 im Gehirn und TLR7 und TLR9 in der Milz ist. Diese Beobachtung kann auf die schwächere Immunreaktion bei mutanten Mäusen im Verglich zu Wildtyp-Mäusen hindeuten. TLR4 könnte eine Schlüsselrolle bei der Regulation der anderen TLR spielen. Diese könnte auch im Krankheitsverlauf Konsequenzen haben.

Vergleichbare Beobachtungen wurden von Lehnardt et al. (2003) beschrieben. Sie zeigten in einer In-vitro-Untersuchung, dass die Aktivierung des TLR4 in Anwesenheit von Mikrogliazellen zur Neuronenschädigung (Neurodegeneration) führt. In den Vergleichskulturen von Wildtyp- und TLR4-defizienten Mäusen beobachteten sie keinen direkten Neuronenschaden bei TLR4-defizienten Mäusekulturen. Im Mausmodell führte die Stimulierung der TLR4-defizienten Mäuse mit LPS ebenso zur keinen neuronalen Schäden im Vergleich mit den Wildtypmäusen.

Im Gehirn der infizierten TLR2-defizienten Mäuse mit E. coli zeigte die Expression der TLR keinen nennenswerten Unterschied im Vergleich mit Wildtyp-Mäusen. TLR2 wurde in defizienten Mäusen weniger exprimiert. In der Milz der gleichen Versuchsreihe wurde bei mutanten Mäusen eine höhere Expression des TLR7 detektiert. Diese Ergebnisse stammen aus einer sehr frühen Krankheitsphase, nämlich den ersten 12 Stunden nach der Infektion. 


\subsection{Schlussfolgerung}

In den Experimenten an Wildtyp-Mäusen zeigte sich, dass die TLR bei Meningitis mit Gram-positiven bzw. Gram-negativen Bakterien sowie bei der HSV-Enzephalitis unspezifisch reguliert werden. Bei allen Meningitis- und Enzephalitisversuchen war eine signifikant erhöhte TLR4-Expression im Gehirn zu beobachten. Es wurde jedoch kein spezifisches Bild bei Meningitis und Enzephalitis beobachtet.

Die Ergebnisse der Untersuchung mit defizienten Mäusen zeigten keinen signifikanten Unterschied in der Regulation der TLR zwischen Wildtyp-Mäusen und TLR9-defizienten Mäusen im Gehirn bei Infektion mit $S$. pneumoniae. TLR2 wurde bei TLR9-defizienten Mäusen höher exprimiert als bei den Wildtyp-Mäusen. Der Unterschied erreichte jedoch die Signifikanzgrenze nicht. In der Milz der TLR9-defizienten Mäuse wurde TLR2 signifikant höher exprimiert als bei den Wildtyp-Mäusen. Daraus können wir schließen, dass die Funktionsfähigkeit des TLR9 einen Einfluss auf die Expression von TLR2 hat. TLR2 könnte eine kompensatorische Wirkung in Abwesenheit von TLR9 zeigen, oder TLR9 könnte einen hemmenden Effekt auf die Expression von TLR2 bewirken, insbesondere in der Milz.

Durch den Vergleich der TLR4-defizienten Mäuse mit Wildtyp-Mäusen bei Infektion mit E. coli konnten wir eine signifikant niedrigere Expression der TLR2 und TLR7 im Gehirn sowie der TLR7 und TLR9 in der Milz beobachten. Im Experiment mit E. coli-infizierten Wildtyp-Mäusen haben wir eine signifikant höhere Expression von TLR2, TLR4 und TLR7 im Gehirn im Vergleich mit der Kontrollgruppe beobachtet. In TLR4-defizienten Mäusen waren TLR2 und TLR7 signifikant niedriger reguliert. Man könnte die These aufstellen, dass die Regulation der TLR2 und TLR7 in einer Beziehung steht mit der Funktion des TLR4 - zumindest im Falle der Meningitis mit $E$. coli. Die Funktionsfähigkeit von TLR4 scheint eine stimulierende Wirkung auf die Expression von TLR2 und TLR7 zu haben. Zur Bestätigung dieser These müssen weitere Experimente durchgeführt werden.

In der Milz der TLR4-defizienten Mäuse waren TLR7 und TLR9 signifikant niedriger exprimiert als in Wildtyp-Mäusen. In mit E. coli infizierten Wildtyp-Mäusen wurden die 
TLR2, TLR7 und TLR9 signifikant höher exprimiert als in der gesunden Kontrollgruppe. Dies bedeutet, dass die niedrigere Expression von TLR7 und TLR9 wieder in Beziehung mit TLR4 und seinen Funktionen stehen könnte. Der TLR2 war in mutanten Mäusen auch niedriger exprimiert als in Wildtyp-Mäusen; der Unterschied war jedoch nicht signifikant.

Fazit 1: Bei Meningitis und Enzephalitis im Mausmodell war eine signifikant erhöhte Expression der TLR4-mRNA im Gehirn zu beobachten.

Wir konnten keine spezifische Regulation der TLR-mRNA bei ZNS-Infektionen beobachten. Um eine eventuelle Gesetzmäßigkeit der Regulation zu finden, benötigen wir weitere Untersuchungen mit anderen Gram-negativen und Gram-positiven Bakterien bzw. anderen viralen Enzephalitis-Erregern. Die spezifische Regulation könnte vom Erreger abhängig sein. Ein spezifisches Bild könnten die Infektionen mit verschiedenen Gram-positiven Bakterien bzw. mit verschiedenen Gram-negativen Bakterien ergeben. Ebenso könnte die erhöhte TLR-Expression ein spezifisches Bild für virale Enzephalitiden zeigen.

Fazit 2: In Meningitis mit E. coli bei TLR4-defizienten Mäusen wurden signifikant niedrigere Expressionen von TLR2 und TLR7 im Gehirn und TLR7 und TLR9 in der Milz detektiert.

Wir müssen das Problem auf verschiedenen Ebenen der Immunreaktionskaskaden betrachten. Es ist bekannt, dass TLR9, TLR2 und TLR4 auf einem MyD88-abhängigen Weg die gleiche Reaktionskaskade zur Aktivierung des NF-kB in Gang setzen (Takeda et al. 2003). Aus diesen Ergebnissen können wir schließen, dass bei der Erforschung der TLR-abhängigen Signalwege Interaktionen und kompensatorische Funktionen verschiedener Reaktionskaskaden berücksichtigt werden müssen.

Um über TLR4 und seine Funktionen für die Auslösung der Immunantwort eine Aussage zu machen, benötigen wir weitere Untersuchungen:

Weitere Experimente mit infizierten TLR4-defizienten Mäusen durch andere Erreger von Meningitis und Enzephalitis könnten die Frage beantworten, ob die niedrigeren 
Expressionen von TLR2 und TLR7 im Gehirn nur bei der Infektion mit E. coli auftreten oder auch bei der Infektion mit anderen Gram-negativen Bakterien oder bei allen bakteriellen Infektionen. Es kann der Frage nachgegangen werden, wie die TLR dieser Mäuse bei viraler Enzephalitis exprimiert werden. Wenn TLR4 eine Schlüsselfunktion in der Immunreaktion hat, sollte aufgeklärt werden, ob diese bei allen Infektionen des ZNS, bei bakteriellen Infektionen oder nur bei einer Infektion durch E.coli vorkommt. Die Versuche müssen auch in vivo geplant werden, weil die Immunreaktion komplex ist und verschiedene zelluläre, aber auch plasmatische Komponenten daran beteiligt sind.

Sollte die Schlüsselfunktion von TLR4 in der Immunreaktion bestätigt werden, könnte das Abschalten des TLR4 klinische Vorteile bringen. Damit kann die überschießende Immunreaktion bei ZNS-Infektionen moduliert werden. Dies spricht für Untersuchungen über den Einsatz von Rezeptor-Antagonisten zur Immunmodulation in Behandlung vielerlei infektiöser, entzündlicher oder rheumatischer Erkrankungen. Weitere Forschungen über das Abschalten des TLR4 in der Immunantwort könnten hilfreich sein. Es ist notwendig, den klinischen Verlauf der Meningitis bei TLR4-defizienten Mäusen mit kranken Wildtyp-Mäusen zu vergleichen. Im Vergleich der klinischen Krankheitsverläufe von Wildtyp- bzw. defizienten Mäusen muss die klinische Konsequenz der niedrigeren Expression der TLR herausgefunden werden. Nur wenn es klinische Unterschiede gibt, könnte die Regulation der TLR4 Vorteile bringen. Nur wenn bei defizienten Mäusen der Krankheitsverlauf signifikant besser ist als bei den Wildtyp-Mäusen, kann geschlussfolgert werden, dass die niedrigere Expression von Rezeptoren eine Verbesserung im klinischen Ablauf verursacht. Außerdem könnte man die pathologischen Schäden im Gehirn dieser Mäuse miteinander vergleichen. Aus dem Unterschied der pathologischen Schäden könnte man den Schluss ziehen, dass die Regulation von Immunrezeptoren der entscheidende Faktor für die Vermeidung pathologischer Schäden ist.

Weitere Forschungen über die Funktionen des TLR4 könnten hilfreich sein: Falls die Expression der Rezeptoren nicht zu regulieren ist, könnte man in weiteren Schritten bei der Ausschüttung der Mediatoren intervenieren, um diese zu neutralisieren. 


\section{Zusammenfassung}

Toll-Like-Rezeptoren sind Sensoren bzw. Regulatoren der angeborenen Immunität. In Anbetracht der schädlichen Wirkung der überschießenden Immunantwort bei Meningitis und Enzephalitis haben wir die Expression der TLR in o. g. Infektionen durch S. pneumoniae, E. coli und HSV in Mausmodellen untersucht.

Bei der intrazerebralen Infektion durch S. pneumoniae waren im Gehirn mRNA von TLR2, TLR4 und TLR9 im Vergleich mit der Kontrollgruppe erhöht. In der Milz wurden erhöhte mRNA von TLR2, TLR3, TLR4 und TLR7 detektiert.

In organotypischen Hippokampuskulturen wurden nach der Behandlung mit Hitze-inaktivierten Pneumokokken erhöhte mRNA von TLR2 und TLR3 beobachtet.

In mit E. coli intrazerebral infizierten Mäusen waren mRNA von TLR2, TLR3, TLR4 und TLR7 im Gehirn und TLR2, TLR7 und TLR9 in der Milz erhöht exprimiert.

Bei der HSV-Enzephalitis wurde im Gehirn höhere mRNA von TLR4 detektiert. In der Milz ergab sich kein signifikanter Unterschied im Vergleich mit der Kontrollgruppe.

In mit E. coli infizierten TLR4-defizienten Mäusen wurden niedrigere mRNA von TLR2 und TLR7 im Gehirn und TLR7 und TLR9 in der Milz im Vergleich zu infizierten Wildtyp-Mäusen beobachtet.

In mit S. pneumoniae infizierten TLR9-defizienten Mäusen ergab sich im Gehirn eine nicht signifikant erhöhte mRNA von TLR2, TLR3 und TLR7. In der Milz war eine signifikant erhöhte Expression des TLR2 im Vergleich zu infizierten Wildtyp-Mäusen zu beobachten.

In den mit E. coli infizierten TLR2-defizienten Mäusen gab es im Gehirn (nach 12 Stunden) keine Unterschiede der Expression der TLR im Vergleich zu mit E. coli infizierten Wildtyp-Mäusen. In der Milz der infizierten TLR2-defizienten Mäuse war die Expression des TLR7 auf mRNA-Ebene im Vergleich zu den infizierten Wildtyp-Mäusen erhöht. Der Unterschied war auf Grund der geringen Untersuchungszahl $(n=5)$ statistisch nicht signifikant. 
Bei den Untersuchungen ergab sich außer der erhöhten TLR4-mRNA im Gehirn kein spezifisches Bild der Expression der Rezeptoren bei Meningitis und Enzephalitis, jedoch wird ein Zusammenhang der Expression von TLR2, TLR7 und TLR9 mit intaktem TLR4 vermutet, weil bei TLR4-defizienten Mäusen signifikant niedrigere Expressionen von TLR2 und TLR7 im Gehirn und von TLR7 und TLR9 in der Milz beobachtet wurden. 


\section{Abbildungsverzeichnis}

Abbildung 1: $\quad$ Toll-Like-Rezeptoren im Säugetier 6

$\begin{array}{lll}\text { Abbildung 2: } & \text { TLR und ihre Liganden } & 7\end{array}$

$\begin{array}{lll}\text { Abbildung 3: } & \text { TLR-Signalkaskaden } & 16\end{array}$

Abbildung 4: Abhängigkeit der Fluoreszenzintensität und Zykluszahlen in der Real-Time-PCR

Abbildung 5: $\quad$ Befundbeispiel bei der Real-Time-PCR 35

$\begin{array}{lll}\text { Abbildung 6: } & \text { Schmelzkurve } & 37\end{array}$

Abbildung 7: $\quad$ Infektion der Wildtypmaus mit S. pneumoniae, Gehirn 43

Abbildung 8: $\quad$ Infektion der Wildtypmaus mit S. pneumoniae, Milz 44

Abbildung 9: $\quad$ Behandlung organotypischer Hippokampuskulturen mit R6 45

Abbildung 10: Infektion der Wildtypmaus mit E. coli, Gehirn 46

Abbildung 11: $\quad$ Infektion der Wildtypmaus mit E. coli, Milz 47

Abbildung 12: $\quad$ Infektion der Wildtypmaus mit HSV, Gehirn 48

Abbildung 13: Infektion der Wildtypmaus mit HSV, Milz 49

Abbildung 14: Infektion der TLR9-defizienten Maus mit S. pneumoniae, Gehirn 50

Abbildung 15: $\quad$ Infektion der TLR9-defizienten Maus mit S. pneumoniae, Milz 51

Abbildung 16: Infektion der TLR4-defizienten Maus mit E.coli, Gehirn 52

Abbildung 17: Infektion der TLR4-defizienten Maus mit E.coli, Milz 53

Abbildung 18: Infektion der TLR2-defizienten Maus mit E.coli, Gehirn 54

Abbildung 19: Infektion der TLR2-defizienten Maus mit E.coli, Milz 55 


\section{$7 \quad$ Literaturverzeichnis}

Ahmad-Nejad P, Hacker H, Rutz M, Bauer S, Vabulas RM, Wagner H (2002): Bacterial CpG- DNA and lipopolysaccharides activate Toll-like receptors at distinct cellular compartments. Eur J Immunol 32, 1958-1968

Akashi S, Shimazu R, Ogata H, Nagai Y, Takeda K, Kimoto M, Miyate K (2000):

Cutting Edge: cell surface expression and lipopolysaccharide signaling via the Toll-like receptor 4-MD-2 complex on mouse peritoneal macrophages. J Immunol 164, $3471-3475$

Akira S (2000): Toll-like receptors: lessons from knockout mice. Biochem Soc Trans 28, 551-556

Akira S, Hemmi H (2003): Recognition of pathogen-associated molecular patterns by TLR family. Immunol Lett $\underline{85}, 85-95$

Akira S, Takeda K, Kaisho T (2001): Toll-like receptors: critical proteins linking innate and acquired immunity. Nat Immunol 2, $675-680$

Alexopoulou L, Holt AC, Medzhitov R, Flavell RA (2001): Recognition of doublestranded RNA and activation of NF-kB by Toll-like receptor 3. Nature $\underline{413}, 732-738$

Anderson KV, Jürgens G, Nüsslein-Volhard C (1985): Establishment of dorsal-ventral polarity in the Drosophila embryo. Cell $\underline{42}, 779-789$

Aravalli RN, Hu Sh, Lokensgard JR (2007): Toll-like rceptor 2 signling is a madiator of apoptosis in herpes simplex virus-infected microglia. J Neuroinflamation $\underline{4}: 11,30$.Apr (Pub Med ID: 17470292)

Arditi M, Mason EO, Bradley JS, Tan TQ, Barson WJ, Schutze GE, Wald ER, Givner LB, Kim KS, Yogev R, Kaplan SL (1998): Three-year multicenter survillance of pneumococcal meningitis in children: clinical characteristics, and outcome related to penicillin susceptibility and dexamethasone use. Padiatrics 102, 1087-1097

Asselin-Paturel C, Boonstra A, Dalod M, Durand I, Yessaad N, Dezutter-Dambuyant C, Vicari A, O‘Garra A, Biron C, Brière F, Trinchieri G (2001): Mouse type I IFN-producing cells are immature APCs with plasmacytoid morphology. Nat Immunol $\underline{2}, 1144-1150$

Baraff L, Lee JS, Schriger DL (1993): Outcomes of bacterial meningitis in children: a meta-analysis. Padiatr Infect Dis J 12, 389-394

Bauer S, Kirschning CJ, Häcker H, Redecke V, Hausmann S, Akira S, Wagner H, Lipford GB (2001): Human TLR 9 confers responsiveness to bacterial DNA via speciesspecific CpG motif recognition. Proc Natl Acad Sci U S A 98, 9237-9242

Belvin MP, Anderson KV (1996): A conserved signaling pathway: the Drosophila toll- 
dorsal pathway. J Annu Rev Cell Dev Biol 12, 393-416

Bobcock AA, Wirenfeldt M, Holm T, Nielsen HH, Dissing-Olesen L, Toft-Hansen $\mathrm{H}$, Millward JM, Landmann R, Rivest S, Finsen B, Owens T (2006): Toll-like receptor 2 signaling in response to brain injury: an innate bridge to neuroinflammation. J Neurosci $\underline{26}, 12826-12837$

Böttcher T, Von Mering M, Ebert S, Meyding-Lamade' U, Kuhnt U, Gerber J, Nau R (2003): Differential regulation of Toll-like receptor mRNAs in experimental murine central nervous system infections. Neurosci Lett $\underline{344}, 17-20$

Bozza M, Satoskar AR, Lin G, Lu B, Humbles AA, Gerard C, David JR (1999): Targeted disruption of migration inhibitory factor gene reveals its critical role in sepsis. J Exp Med 189, 341-346

Bsibsi M, Ravid R, Gveric D, van Noort JM (2002): Broad expression of toll-like receptors in the human central nervous system. J Neuropathol Exp Neurol $\underline{61}, 1013-$ 1021

Bulut Y, Faure E, Thomas L, Karahashi H, Michelsen KS, Equils O, Morrison SG, Morrison RP, Arditi M (2002): Chlamydial heat shock protein 60 activates macrophages and endothelial cells through Toll-like receptor 4 and MD2 in a MyD88-dependent pathway. J Immunol 168, 1435-1440

Burns K, Marinon F, Esslinger C, Pahl H, Schneider P, Bodmer JL, Di Marco F, French L, Tschopp J (1998): MyD88, an adaptor protein involved in interleukin-1 signalling. J Biol Chem 273, 12203-12209

Chen K, Zhang L, Huang J, Gong W, Dunlop NM, Wang JM (2008): Cooperation between NOD2 and Toll-like receptor 2 ligands in the up-regulation of mouse mFPR2, a G-protein-coupled A $\beta 42$ peptide receptor, in microglial cells. J Leukoc Biol $\underline{83}, 1467-$ 1475

Da Shilva Correia J, Soldau K, Christen U, Tobias PS, Ulevitch J (2001):

Lipopolysaccharide is in close proximity to each of the protein in its membrane receptor complex. J Biol Chem 276, 21129-21135

Diebold SS, Kaisho T, Hemmi H, Akira S, Reis e Sousa C (2004): Innate antiviral responses by means of TLR7-mediated recognition of single-stranded RNA. Science $\underline{303}, 1529-1531$

Doyle S, Vaidya S, O'Connell R, Dadgostar H, Dempsey P, Wu T, Rao G, Sun R, Haberland M, Modlin R, Cheng G (2002): IRF 3 mediates a TLR3/TLR4-specific antiviral gene program. Immunity $\underline{17}, 251-263$

Ebert S, Gerber J, Bader S, Mühlhauser F, Brechtel K, Mitchell TJ, Nau R (2005):

Dose-dependent activation of microglial cells by Toll-like receptor agonists alone and in combination. J Neuroimmunol $\underline{159}$, 87-96 
Erickson L, Wals PD (1998): Complications and sequelae of meningococcal disease in Quebec, Canada, 1990 - 1994. Clin Infect Dis 26, 1159-1164

Falke D: Herpes-Gruppe; in: Medizinische Mikrobiologie; hrsg. Hahn h, Falke D, Klein P; Springer-Verlag, Berlin 1991, 791-814

Fitzgerald KA, Palsson-McDermott EM, Bowie AG, Jefferies CA, Mansell AS, Brady G, Brint E, Dunne A, Gray P, Harte MT, McMurray D, Smith DE, Sims JE, Bird TA, O'Neill LA (2001): Mal (MyD88-adaptor-like) is required for Toll-like receptor-4 signal transduction. Nature $\underline{413}, 78-83$

Goos M, Lang P, Hanish UK, Prinz M, Scheffel J, Bergmann R, Ebert S, Nau R (2007): Fibronectin is elevated in the cerebrospinal fluid suffering from bacterial meningitis and enhances inflammation caused by bacterial products in primary mouse microglial cell cultures. J Neurochem 102, 2049-2060

Grimwood K, Anderson P, Anderson V, Tan T, Nolan T (2000): Twelve year outcomes following bacterial meningitis: further evidence for persisting effects. Arch Dis Child $\underline{83}$, 111-116

Hashimoto C, Hudson KL, Anderson KV (1988): The Toll gene of Drosophila, required for dorsal-ventral embryonic polarity, appears to encode a transmembrane protein. Cell $\underline{52}, 267-279$

Hayashi F, Smith KD, Ozinsky A, Hawn TR, Yi EC, Goodlett DR, Eng JK, Akira S, Underhill DM, Aderem A (2001): The innate immune response to bacterial flagellin is mediated by Toll-like receptor 5 . Nature $\underline{410}, 1099-1103$

Haynes LM, Moore DD, Kurt-Jones EA, Finberg RW, Anderson LJ, Tripp RA (2001): Involvement of Toll-like receptor 4 in innate immunity to respiratory syncytial virus. J Virol $\underline{75}, 10730-10737$

Heil F, Hemmi H, Hochrein H, Ampenberger F, Kirschning C, Akira S, Lipford G, Wagner H, Bauer S (2004): Species-specific recognition of single-stranded RNA via toll-like receptor 7 and 8 . Science $\underline{303}, 1526-1529$

Hemmi H, Takeuchi O, Kawai T, Kaisho T, Sato S, Sanjo H, Matsumoto M, Hoshino K, Wagner H, Takeda K, Akira S (2000): A Toll-like receptor recognizes bacterial DNA. Nature $\underline{408}, 740-745$

Hemmi H, Kaisho T, Takeuchi O, Sato S, Sanjo H, Hoshino K, Horiuchi T, Tomizawa H, Takeda K, Akira S (2002): Small anti-viral compounds activate immune cells via TLR 7 MyD88-dependent signaling pathway. Nat Immunol $\underline{3}$, 196-200

Horng T, Barton GM, Medzhitov R (2001): TIRAP: an adaptor molecule in the Toll signaling pathway. Nat Immunol $\underline{2}, 835-841$

Horng T, Barton GM, Flavell RA, Medzhitov R (2002): The adaptor molecule TIRAP provides signaling specificity for Toll-like receptors. Nature $\underline{420}, 329-333$ 
Hoshino K, Takeuchi O, Kawai T, Sanjo H, Ogawa T, Takeda Y, Takeda K, Akira S (1999): Cutting Edge: Toll-like receptor 4 (TLR4)-deficient mice are hyporespensive to lipopolysaccharide: evidence for TLR4 as the Lps gene product. J Immunol 162, 3749-3752

Iliev AI, Stringaris AK, Nau R, Neumann H (2004): Neuronal injury mediated via stimulation of microglial toll-like receptor 9 (TLR 9). FASEB J $\underline{18}, 412-414$

Johnson GB, Brunn GJ, Kodaira Y, Platt JL (2002): Receptor-mediated monitoring of tissue well-being via detection of soluble heparan sulfate by Toll-like receptor 4 . $\mathrm{J}$ Immunol 168, 5233-5239

Kaisho T, Takeuchi O, Kawai T, Hoshino K, Akira S (2001): Endotoxin-induced maturation of MyD88-deficient dendritic cells. J Immunol 166, 5688-5694

Kawai T, Adachi O, Ogawa T, Takeda K, Akira S (1999): Unresponsiveness of MyD88deficient mice to endotoxin. Immunity $\underline{11}, 115-122$

Kawai T, Takeuchi O, Fujita T, Inoue J, Mühlradt PF, Sato S, Hoshino K, Akira S (2001): Lipopolysaccharide stimulates the MyD88-independent pathway and results in activation of IFN-regulatory factor 3 and the expression of a subset of lipopolysaccharide-inducible genes. J Immunol $\underline{167}$, 5887-5894

Kobayashi K, Hernandez LD, Galan JE, Janeway CA Jr., Medzhitov R, Flavell RA (2002): IRAK-M is a negative regulator of Toll-like receptor signaling. Cell $\underline{110}, 191-202$

Kurt-Jones EA, Popova L, Kwinn L, Haynes LM, Jones LP, Tripp RA, Walsh EE, Freeman MW, Golenbock DT, Anderson LJ, Finberg RW (2000): Pattern recognition receptors TLR4 and CD14 mediate response to respiratory syncytial virus. Nat Immunol $\underline{1}$, 398-401

Laflamme N, Soucy G, Rivest S (2001): Circulating cell wall components drived from gram-negative, not gram-positive, bacteria cause a profound induction of the gene-encoding Toll-like receptor 2 in the CNS. J Neurochem $\underline{79}, 648-657$

Lehnardt S, Massillon L, Follett P, Jensen FE, Ratan R, Rosenberg PA, Volpe JJ, Vartanian T (2003): Activation of innate immunity in the CNS triggers neurodegeneration through a Toll-like receptor 4-dependent pathway. Proc Natl Acad Sci U S A $\underline{100}, 8514-8519$

Lemaitre B, Nicolas E, Michaut L, Reichhart JM, Hoffmann JA (1996): The dorsoventral regulatory gene cassette spätzle/Toll/cactus controls the potent antifungal response in Drosophila adults. Cell $\underline{86}, 973-983$

Li S, Strelow A, Fontana EJ, Wesche H (2002): IRAK-4, a novel member of the IRAK family with the properties of an IRAK-kinase. Proc Natl Acad Sci U S A $\underline{99}$, 5567-5572

Mailles A, Stahl JP (2009): Infectious encephalitis in france in 2007: a national prospective study. Clin Infect Dis $\underline{49}, 1848-1850$ 
Masuhr KF, Neumann M: Neurologie. (Duale Reihe), 4. Auflage; Hippokrates Verlag, Stuttgart 1998

Medzhitov R, Preston-Hurlburt P, Janeway CA Jr (1997): A human homologue of the Drosophila Toll protein signals activation of adaptive immunity. Nature $\underline{388}, 394-397$

Medzhitov R, Preston-Hurlburt P, Kopp E, Stadlen A, Chen C, Ghosh S, Janeway CA Jr. (1998): MyD88 is an adaptor protein in the hToll/IL1 receptor family signaling pathways. Mol Cell 2 , 253-258

Miettinen M, Sareneva T, Julkunen I, Matikainen S (2001): IFNs activate toll-like receptor gene expression in viral infections. Genes Immun 2, 349-355

Mokuno Y, Matsuguchi T, Takano M, Nishimura H, Washizu J, Ogawa T, Takeuchi O, Akira S, Nimura Y, Yoshikai Y (2000): Expression of Toll-like receptor 2 on $\gamma \delta$ T cells bearing invariant $\mathrm{V} \gamma 6 / \mathrm{V} \delta 1$ induced by Escherichia coli infection in mice. J Immunol $\underline{165}$, 931-940

Muzio M, Ni J, Feng P, Dixit VM (1997): IRAK (Pelle) family member IRAK-2 and MyD88 as proximal mediators of IL-1 signaling. Science $\underline{278}, 1612-1615$

Muzio M, Natoli G, Saccani S, Levrero M, Mantovani A (1998): The human Toll signalling pathway: divergence of nuclear factor $\kappa B$ and JNK/SAPK activation upstream of tumor necrosis factor receptor-associated factor 6 (TRAF 6). J Exp Med 187, 2097-2101

Muzio M, Bosisio D, Polentarutti N, D'amico G, Stoppacciaro A, Mancinelli R, van't Veer C, Pentol-Rol G, Ruco LP, Allavena P, Mantovani A (2000): Differential expression and regulation of toll-like receptors (TLR) in human leukocytes: selective expression of TLR3 in dendritic cells. J Immunol 164, 5998-6004

Nagai Y, Akashi S, Nagafukou M, Ogata M, Iwakura Y, Akira S, Kitamura T, Kosugi A, Kimoto M, Miyake K (2002): Essential role of MD-2 in LPS responsiveness and TLR4 distribution. Nat Immunol $\underline{3}, 667-672$

Nakano H, Yanagita M, Gunn MD (2001): CD 11C+ B220+ Gr-1+ cells in mouse lymph nodes and spleen display characteristics of plasmacytoid dendritic cells. J Exp Med $\underline{194}, 1171-1178$

Nau R, Brück W (2002): Neuronal injury in bacterial meningitis: mechanisms and implications for therapy. Trends Neurosci $\underline{25}, 38-45$

Nau R, Eiffert H (2002): Modulation of release of proinflammatory bacterial compounds by antibacterials: Potential impact on Course of inflammation and outcome in sepsis and meningitis. Clin Microbiol Rev $\underline{15}$, 95-110

Netea MG, van Deuren M, Kullberg BJ, Cavaillon JM, van der Maer WM (2002): Does the shape of lipid A determine the interaction of LPS with Toll-like receptors? Trends Immunol 23, 135-139 
Ohashi K, Burkart V, Flohe S, Kolb H (2000): Cutting edge: heat shock protein 60 is a putative endogenous ligand of the toll-like receptor-4 complex. J Immunol 164, 558-561

Okamura Y, Watari M, Jerud ES, Young DW, Ishizaka ST, Rose J, Chow JC, Strauss JF $3^{\text {rd }}$. (2001): The extra domain A of fibronectin activates Toll-like receptor 4. J Biol Chem 276, 10229-10233

Olson JK and Miller SD (2004): Microglia initiate central nervous system innate and adaptive immune responses through multiple TLRs. J Immunol 173, 3916-3924

Opferkuch W, Tauchnitz C: Mikroiell bedingte Etzündunen des Zntralnervensytems; in: Medizinische Mikrobiologie; hrsg. Hahn H, Falke D, Klein P; Springer-Verlag, Berlin $1991,513-521$

Raetzer K, Rensing K: Medizinische Mikrobiologie; in: Das Erste; hrsg. Buchta M, Höper DW; Urban \& Fischer Verlag, München 1999, 325-448

Roger T, David J, Glauser MP, Calandra T (2001): MIF regulates innate immune responses through modulation of Toll-like receptor 4. Nature $\underline{414}, 920-924$

Sasu S, La Verde D, Qureshi N, Golenbock DT, Beasley D (2001): Chlamydia pneumoniae and chlamydial heat shock protein 60 stimulate proliferation of human vascular smooth muscle cells via toll-like receptor 4 and p44/p42 mitogen-activated protein kinase activation. Circ Res $\underline{89}, 244-250$

Schwandner R, Dziarski R, Wesche H, Rothe M, Kirsching CJ (1999): Peptidoglycanand lipoteichoic acid-induced cell activation is mediated by Toll-like receptor 2 . J Biol Chem 274, 17406-17409

Siegal FP, Kadowaki N, Shodell M, Fitzgerald-Bocarsly PA, Shah K, Ho S, Antonenko S, Liu YJ (1999): The nature of the principal type 1 interferon-producing cells in human blood. Science 284, 1835-1837

Smiley ST, King JA, Hancock WW (2001): Fibrinogen stimulates macrophage chemokine secretion through Toll-like receptor 4. J Immunol 167, 2887-2894

Suzuki N, Suzuki S, Duncan GS, Millar DG, Wada T, Mirtsos C, Takada H, Wakeham A, Itie A, Li S, Penninger JM, Wesche H, Ohashi PS, Mak TW, Yeh WC (2002): Severe impairment of interleukin-1 and Toll-like receptor signalling in mice lacking IRAK-4. Nature $\underline{416}, 750-756$

Swantek JL, Tsen MF, Cobb MM, Thomas JA (2000): IL-1 receptor-associated kinase modulates host responsiveness to endotoxin. J Immunol 164, 4301-4306

Sweet MJ, Campbell CC, Sester DP, Xu D, McDonald RC, Stacey KJ, Hume DA, Liew FY (2002): Colony-stimulating factor-1 suppresses responses to CpG DNA and expression of toll-like recepter 9 but enhances responses to lipopolysaccharide in murine macrophages. J Immunol $\underline{168}$, 392-399 
Takeda K, Akira S (2003): Micoreview: Toll receptors and pathogen resistance. Cell Microbiol $\underline{5}, 143-153$

Takeda K, Kaisho T, Akira S (2003): Toll-Like Receptors. Annu Rev Immunol 21, 335-376

Takeuchi O, Hoshino K, Kawai T, Sanjo H, Takada H, Ogawa T, Takeda K, Akira S (1999): Differential roles of TLR2 and TLR4 in recognition of gram-negative and grampositive cell wall components. Immunity $\underline{11}$, 443-451

Takeuchi O, Kaufmann A, Grote K, Kawai T, Hoshino K, Morr M, Mühlradt PF, Akira S (2000): Cutting edge: preferentially the R-stereoisomer of the mycoplasmal lipopeptide makrophage-activating lipopeptide-2 activates immune cells through a toll-like receptor 2- and MyD88-dependent signalling pathway. J Immunol 164, 554-557

Takeuchi O, Kawai T, Mühlradt PF, Radolf JD, Zychlinsky A, Takeda K, Akira S (2001): Discrimination of bacterial lipopeptides by Toll-like receptor 6 . Int Immunol $\underline{13}$, 933-940

Takeuchi O, Horiuchi T, Hoshino K, Takeda K, Dong Z, Modlin RL, Akira S (2002):

Role of TLR1 in mediating immune response to microbial lipoproteins. J Immunol $\underline{169}$, 10-14

Theodoridou MN, Vasilopoulou VA, Atsali EE, Pangalis AM, Mostrou GJ, Syriopoulou VP, Hadjichristodoulou CS (2007): Meningitis registry of hospitalized cases in children: epidemiological patterns of acute bacterial meningitis throughout a 32-year period.

BMC Infect Dis 7: 101 30.Aug (Pub Med ID: 17760993)

Vabulas RM, Ahmad-Nejad P, da Costa C, Miethke T, Kirschning CJ, Häcker H, Wagner H (2001): Endocytosed HSP60s use toll-like receptor 2 (TLR2) and TLR4 to activate the toll/interleukin-1 receptor signaling pathway in innate immune cells. J Biol Chem 276, 31332-31339

Van der Flier M, Geelen SPM, Kimpen JLL, Hoepelmann IM, Tuomanen EI (2003): Reprogramming the host response in bacterial meningitis: how best to improve outcome? Clin Microbiol Rev $\underline{16}$, 415-429

Volz T, Nega M, Buschmann J, Kaesler S, Guenova E, Peschel A, Röcken M, Götz F, Biedermann T (2010): Natural Staphylococcus aureus-drived peptidoglycan fragments activate NOD2 and act as potent costimulators of the innate immune system exclusively in the presence of TLR signals. FASEB J $\underline{24}, 4089-4102$

Wagner $\mathrm{H}$ (2004): The immunobiology of the TLR 9 subfamily. Trends Immunol $\underline{7}$, 381-386

Wang T, Laufuse WP, Zwilling BS (2000): Regulation of Toll-like receptor 2 expression by macrophages following Mycobacterium avium infection. J Immunol $\underline{165}$, 6308-6313

Weaver BK, Kumar KP, Reich NC (1998): Interferon regulatory factor 3 and CREBbinding protein/p300 are subunits of double-stranded RNA-activated transcription factor 
DRAF1. Mol Cell Biol 18, $1359-1368$

Wesche H, Henzel WJ, Shillinglaw W, Li S, Cao Z (1997): MyD88: an adaptor protein that recruits IRAK to the IL-1 receptor complex. Immunity $\underline{7}$, 837-847

Yamamoto M, Sato S, Hemmi H, Sanjo H, Uematsu S, Kaisho T, Hoshino K, Takeuchi O, Kobayashi M (2002): Essential role for TIRAP in activation of the signalling cascade shared by TLR2 and TLR4. Nature $\underline{420}, 324-329$

Yoneyama M, Suhara W, Fukuhara Y, Fukuda M, Nishida E, Fujita T (1998): Direct triggering of the type I interferon system by virus infection: activation of a transcription factor complex containing IRF-3 and CBP/p300. EMBO J 17, 1087-1095

Yoshimura A, Lien E, Ingalls RR, Tuomanen E, Dziarski R, Golenbock D (1999): Cutting edge: recognition of Gram-positive bacterial cell wall components by the innate immune system occurs via Toll-like receptors 2 . J Immunol $\underline{165}, 1-5$

Zarember KA, Godowski PJ (2002): Tissue expression of human Toll-like receptors and differential regulation of Toll-like receptor mRNAs in leukocytes in response to microbes, their products, and cytokines. J Immunol $\underline{168}, 554-561$ 